Aus der Klinik für Kardiologie und Pneumologie

(Prof. Dr. med. G. Hasenfuß)

im Zentrum Innere Medizin

der Medizinischen Fakultät der Universität Göttingen

\title{
Stellenwert von GDF-15 bei Patienten mit einer diastolischen Dysfunktion und Herzinsuffizienz mit erhaltener linksventrikulärer Ejektionsfraktion
}

\author{
INAUGURAL - DISSERTATION
}

zur Erlangung des Doktorgrades

der Medizinischen Fakultät der

Georg-August-Universität zu Göttingen

vorgelegt von

Fabian Gabriel

aus

Stuttgart

Göttingen 2013 
Dekan:
I. Berichterstatter:
II. Berichterstatter:
III. Berichterstatter:
PD Dr. med. F. Edelmann
Prof. Dr. mult. T. Meyer
Prof. Dr. med. M. Oppermann

Tag der mündlichen Prüfung:
Prof. Dr. rer. nat. H. K. Kroemer

03.06.2014 


\section{Inhaltsverzeichnis}

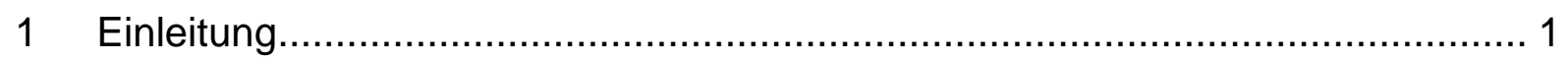

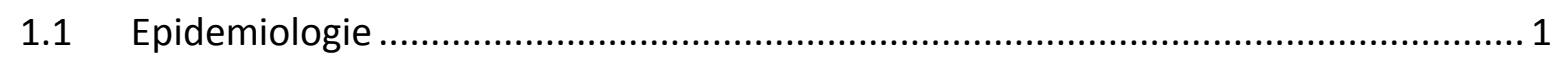

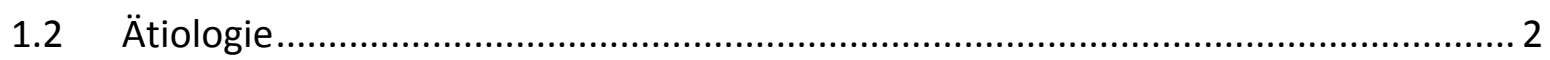

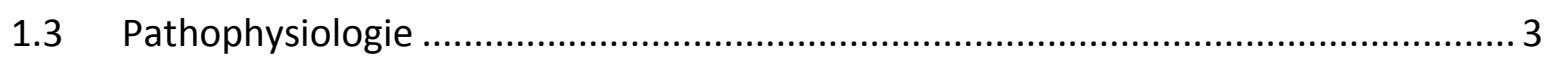

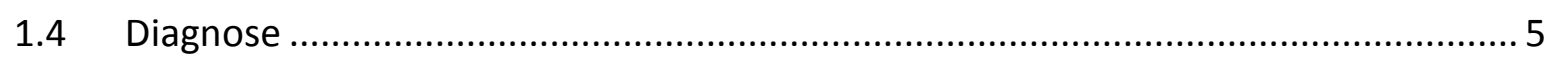

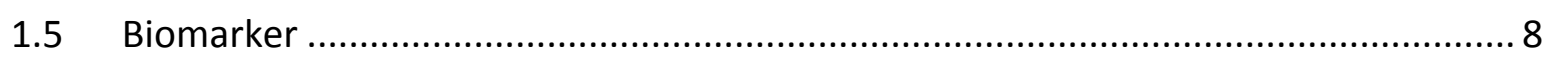

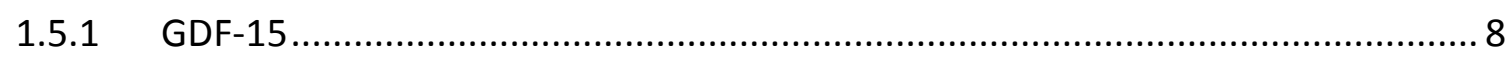

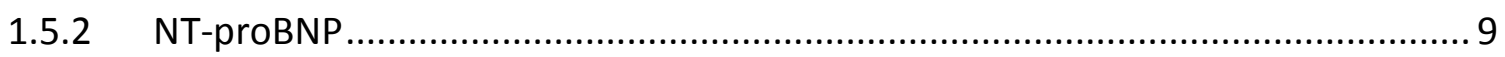

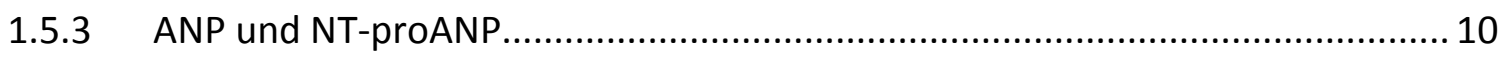

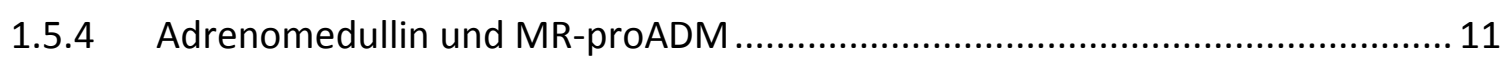

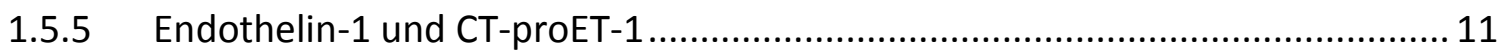

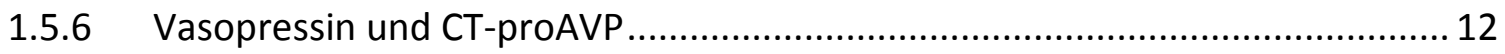

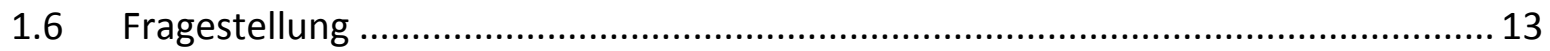

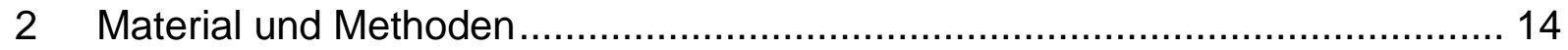

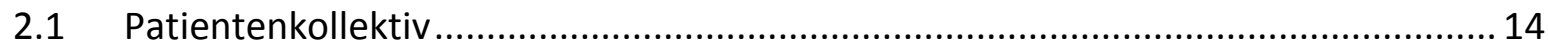

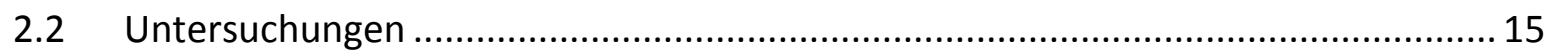

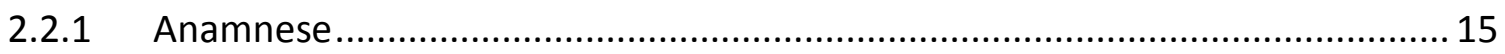

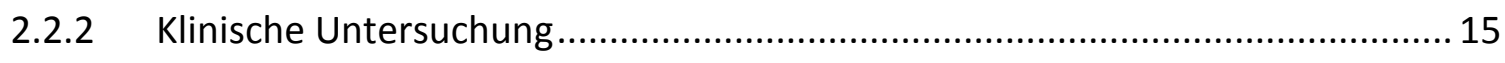

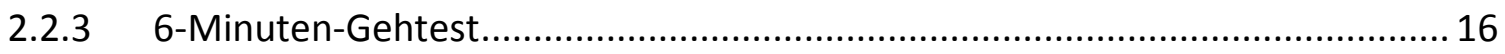

2.2.4 Short Form Health Survey (SF-36) ............................................................. 17

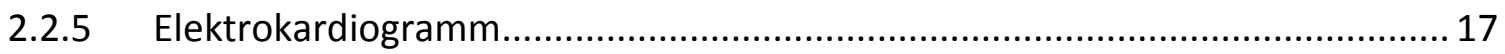

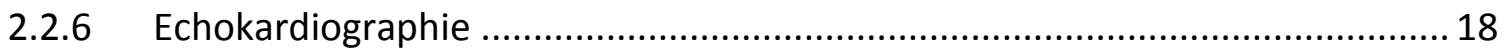

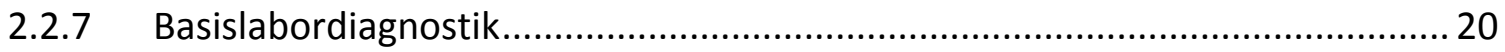

2.3 Spezielle Labordiagnostik ............................................................................. 20

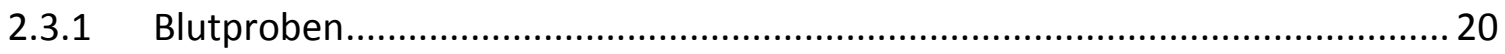

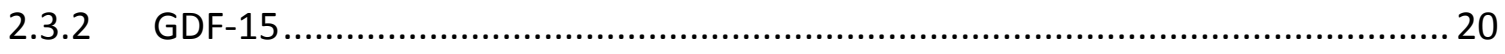

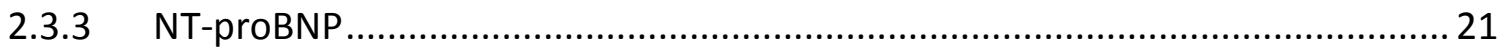

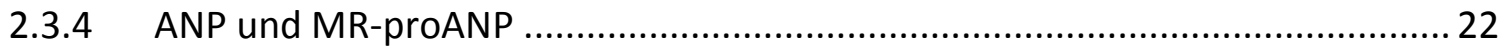

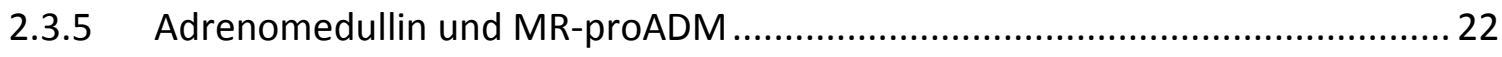

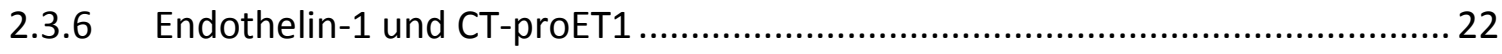

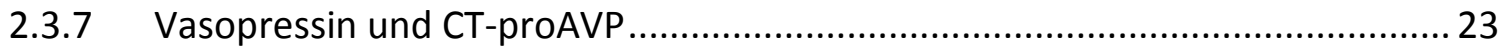

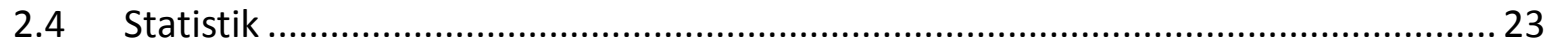

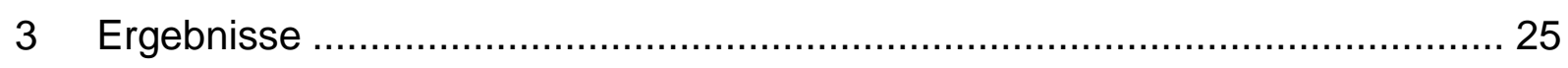

3.1 Deskriptive Statistik des Patientenkollektivs........................................................ 25 


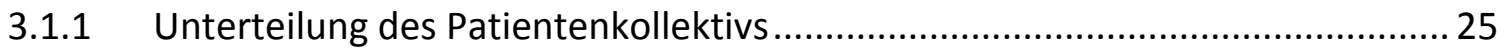

3.1.2 Allgemeine und klinische Daten des Patientenkollektivs ............................... 25

3.1.3 Körperliche Leistungsfähigkeit und detaillierte Lebensqualität im

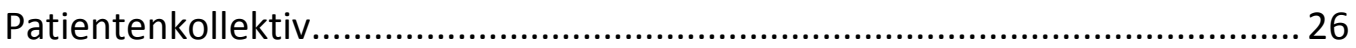

3.1.4 Kardiovaskuläre Risikofaktoren im Patientenkollektiv ................................. 27

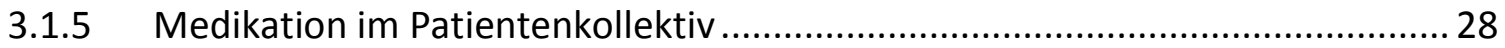

3.1.6 Echokardiographische Parameter im Patientenkollektiv................................29

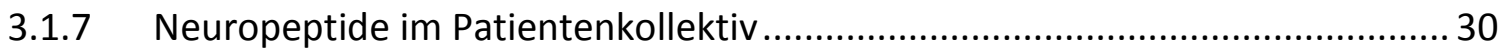

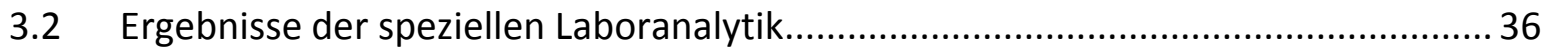

3.2.1 Bivariate Korrelation von GDF-15 und demografischen sowie klinischen

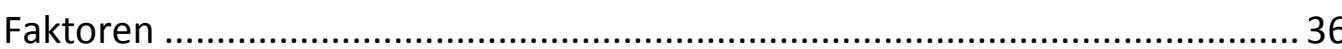

3.2.2 Bivariate Korrelation von GDF-15 und körperlicher Leistungsfähigkeit sowie

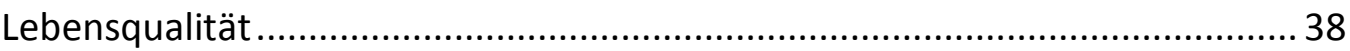

3.2.3 Bivariate Korrelation von GDF-15 und der linksventrikulären Morphologie sowie systolischer und diastolischer Funktion ................................................. 39

3.2.4 Bivariate Korrelation von GDF-15 und Neuropeptiden ................................. 40

3.3 Zusammenhang zwischen GDF-15 und dem Grad der diastolischen Funktion, echokardiographischen Parametern sowie der körperlichen Leistungsfähigkeit und Lebensqualität im Gesamtkollektiv....

3.4 Zusammenhang zwischen GDF-15 und dem Vorliegen einer DD bzw. einer HFPEF unter Berücksichtigung klinischer und demografischer Kovariablen

3.4.1 Zusammenhang von GDF-15 und DD unter Berücksichtigung klinischer und demografischer Kovariablen

3.4.2 Zusammenhang von GDF-15 und HFPEF unter Berücksichtigung klinischer und demografischer Kovariablen

3.5 Eignung von GDF-15 als prädiktiver Wert zur Diagnose einer DD oder einer HFPEF 55

3.5.1 Vorhersage des Vorhandenseins einer DD anhand des Laborparameters

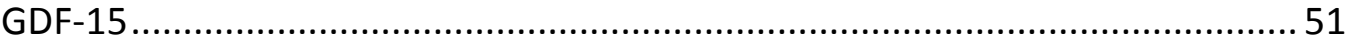

3.5.2 Vorhersage des Vorhandenseins einer HFPEF anhand des Laborparameters

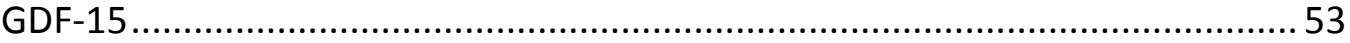

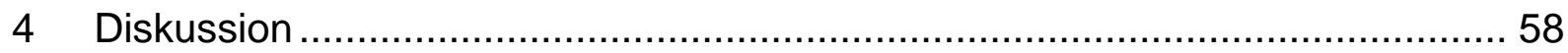

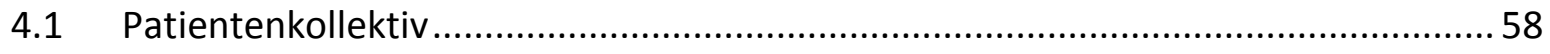

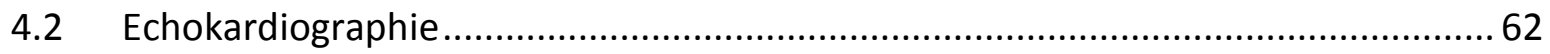

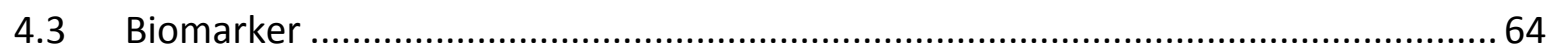

4.3.1 Erhöhung von GDF-15 bei Patienten mit DD und HFPEF ................................ 64

4.3.2 Zusammenhang von GD-15 mit der körperlichen Leistungsfähigkeit und der

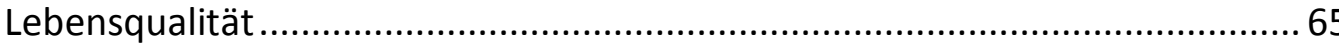

4.3.3 Zusammenhang von GDF-15 mit Echoparametern..........................................67 
4.3.4 Fähigkeit der untersuchten Biomarker zur Detektion einer kardialen Dysfunktion

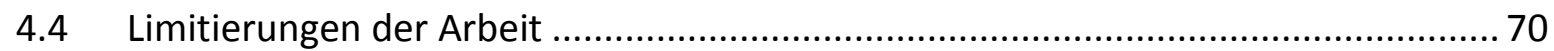

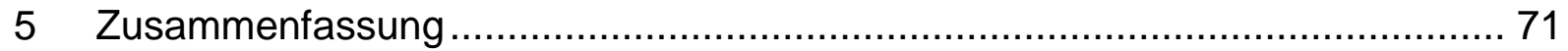

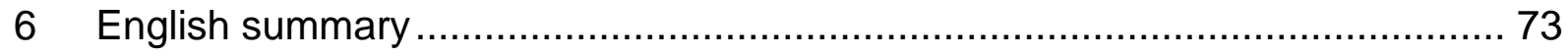

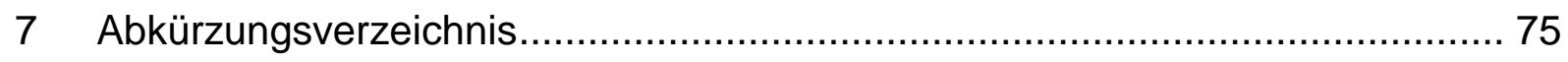

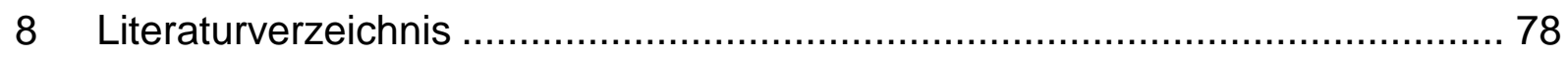




\section{Einleitung}

\subsection{Epidemiologie}

Herzinsuffizienz (HF) ist eine häufige Erkrankung, von der ungefähr $1 \%$ aller Menschen über 40 Jahre betroffen ist (Cleland et al. 2001). Die Prävalenz dieser Erkrankung verdoppelt sich mit jeder weiteren Lebensdekade und erreicht rund $10 \%$ bei über 70 -Jährigen (Cleland et al. 2001, Cortina et al. 2001). In entwickelten Ländern stellt sie bei Patienten von 65 Jahren oder älter den häufigsten Grund für einen stationären Krankenhausaufenthalt dar (Rodríguez-Artalejo et al. 1997, Brotons et al. 1998).

In den vergangenen Dekaden haben die Prävalenz und die stationären Aufnahmen aufgrund von HF in entwickelten Ländern stetig zugenommen und es ist davon auszugehen, dass diese Entwicklung anhält (McMurray und Stewart 2000, Rodríguez-Artalejo et al. 1997).

Die Inzidenz der HF steigt mit dem Alter und erreicht 1\% bei Patienten, die älter als 65 Jahre sind (Ho et al. 1993). So war beispielsweise im Jahr 2000 die HF in Spanien für 4\% aller Todesfälle bei Männern und sogar für $8 \%$ aller Todesfälle bei Frauen verantwortlich (Boix et al. 2002).

Herzinsuffiziente Patienten lassen sich in zwei große Gruppen einteilen: erstens in Patienten mit reduzierter linksventrikulärer Ejektionsfraktion (LVEF), welche als Patienten mit Herzinsuffizienz mit reduzierter Ejektionsfraktion (HFREF) bezeichnet werden, und zweitens in Patienten mit HF und erhaltener LVEF. Diese werden als Patienten mit Herzinsuffizienz mit erhaltener Ejektionsfraktion bezeichnet (HFPEF) (Liu et al. 2013).

Die zugrunde liegende Pathophysiologie gilt jedoch noch als umstritten und nicht vollständig geklärt (Burkhoff et al. 2003, Zile und Lewinter 2007, Kitzman 2008). Dieser hohe Unsicherheitsgrad hinsichtlich der Pathophysiologie der Erkrankung spiegelt sich gut darin wider, dass die bisherige Bezeichnung "diastolische Dysfunktion“ (DD) zunehmend ungebräuchlich wird (Vasan und Levy 2000) und stattdessen die eher beschreibende Bezeichnung „Herzinsuffizienz mit erhaltener Ejektionsfraktion“ (HFPEF) verwendet wird (Paulus et al. 2007).

Epidemiologische Studien haben gezeigt, dass etwa die Hälfte aller Patienten mit HF eine HFPEF hat (Owan et al. 2006, Hogg et al. 2004). Der Anteil an Patienten mit HFPEF variiert allerdings in Studien von $40-71 \%$ bei einem Durchschnitt von 56\% (Hogg et al. 2004); so leidet die Vergleichbarkeit der Studien an unterschiedlichen Definitionen einer HF und dem Fehlen eines klaren Grenzwertes für die Bestimmung einer erhaltenen Ejektionsfraktion (EF). In der Cardiovascular Health Study hatten $80 \%$ der Patienten eine LVEF > 45\%, aber nur 
$55 \%$ hatten eine LVEF > 55\% (Kitzman et al. 2001). Bei in Krankenhäusern durchgeführten Kohortenstudien war der Anteil von Patienten mit HFPEF geringfügig niedriger und lag zwischen 24-55\% bei einem Durchschnitt von 41\% (Hogg et al. 2004).

Patienten mit HFPEF sind meist älter als jene mit HFREF und waren in den allermeisten Studien in der Mehrzahl Frauen.

HFPEF scheint in China und Indien besonders verbreitet zu sein. Dies kann möglicherweise auf die dortige hohe Prävalenz des Bluthochdrucks zurückzuführen sein (Yip et al. 1999). Die zunehmende Alterung der Bevölkerung in Asien, verbunden mit einem oft schlecht behandelten Bluthochdruck, lässt einen starken Anstieg von Patienten mit HFPEF in diesen Ländern vermuten (Sanderson und Tse 2003).

Die Morbidität, Hospitalisierungsrate und die Behandlungskosten sind bei Patienten mit HFREF und Patienten mit HFPEF ähnlich (Hogg et al. 2004).

In der Cardiovascular Health Study war das attributable Risiko größer für Patienten mit HFPEF als für jene mit HFREF, wobei dies teilweise durch die höhere Prävalenz von HFPEF bei älteren Menschen erklärt wird (Gottdiener et al. 2002). Diese Ergebnisse sind mit Owan et al. (2006) und Bhatia et al. (2006) vergleichbar.

Angaben zur Mortalität variieren stark. So betrug die jährliche Mortalitätsrate in der Framingham-Heart-Studie $8,7 \%$ für Patienten mit HFPEF gegenüber $3 \%$ in der Kontrollgruppe. Die jährliche Mortalitätsrate für Patienten mit HFREF hingegen lag bei 18,9\% gegenüber 6,2\% in der Kontrollgruppe (Vasan et al. 1999).

\section{2 Ätiologie}

Zahlreiche Risikofaktoren werden mit der Entwicklung einer HFPEF assoziiert. Es handelt sich dabei meist um etablierte kardiovaskuläre Risikofaktoren.

In der Krankengeschichte findet sich typischerweise eine Hypertonie mit linksventrikulärer Hypertrophie (Hogg et al. 2004). Tatsächlich ist bei bis zu $88 \%$ der Patienten mit HFPEF eine Hypertonie festzustellen (McMurray et al. 2008).

Die Hypertonie ihrerseits begünstigt besonders in Verbindung mit erhöhten linksventrikulären Füllungsdrücken und einem vergrößerten linken Vorhof das Auftreten von Vorhofflimmern und so kommt dieses auch deshalb häufiger bei Patienten mit HFPEF vor (Owan et al. 2006). 
Das Einsetzen von Vorhofflimmern bei Patienten mit Hypertonie könnte daher der auslösende Faktor für die Entwicklung von Symptomen einer HF sowie der folgenden Hospitalisierung sein.

Ferner leiden ca. 40\% der Patienten mit einer HFPEF unter Übergewicht im Sinne eines Body Mass Index (BMI) von über $30 \mathrm{~kg} / \mathrm{m}^{2}$ (Owan et al. 2006, McMurray et al. 2008). Ebenfalls findet sich mit erhöhter Wahrscheinlichkeit eine Anämie oder eine Niereninsuffizienz (Edelmann et al. 2011).

Die Prävalenz von Diabetes ist mit 30\% bei Patienten mit HFPEF erhöht und die Prävalenz einer koronaren Herzkrankheit (KHK) beträgt je nach Studie ca. 50\% (Owan et al. 2006, McMurray et al. 2008).

Betrachtet man im Umkehrschluss das jeweilige relative Risiko, so stellt sich dieses wie folgt dar: linksventrikuläre Hypertrophie $(7,6)$, arterielle Hypertonie $(2,8)$, Übergewicht $(1,6)$, Diabetes $(2,3)$ und Myokardinfarkt in der Krankengeschichte (4,3) (Fischer et al. 2003).

Ein weiterer Risikofaktor, der mit der Entwicklung einer HFPEF in Verbindung gebracht wird, ist das obstruktive Schlafapnoesyndrom (OSAS), wobei dieses auch mit der HFREF sowie anderen kardiovaskulären Erkrankungen wie der Hypertonie in Verbindung gebracht wird (Naughton 2003).

\subsection{Pathophysiologie}

Als Ursache für die HFPEF werden zurzeit pathologische Veränderungen angesehen, welche zu einer Relaxations-, Füllungs- und Dehnbarkeitsstörung und damit zu einer DD des linken Ventrikels führen. Hierzu gehört die linksventrikuläre Hypertrophie, welche die Füllung des linken Ventrikels in der Diastole beeinträchtigt.

Auch Veränderungen der extrazellulären Matrix (EZM) können die diastolische Funktion beeinträchtigen. So führt ein höherer Anteil an Kollagenfasern an der EZM zu einer geringeren Dehnbarkeit des linken Ventrikels (Querejeta et al. 2004). Außerdem kommt es zu einer Kreuzvernetzung zwischen den Kollagenfasern, wodurch die Dehnbarkeit weiter abnimmt. Dieses Problem tritt besonders bei Diabetikern auf (van Heerebeek et al. 2008).

Ischämie ist ein weiterer Faktor, welcher die Ausbildung einer DD fördert. Da zu einer aktiven Relaxation viel Energie benötigt wird, führt eine Ischämie zu einer verlangsamten Relaxation. Auf Dauer führt die Ischämie auch zu einer kardialen Hypertrophie sowie zu Umbauprozessen in der EZM. Somit kommt es auch zu einer Dehnbarkeitsstörung des linken Ventrikels (Thune und Solomon 2006). 
Ebenso spielen linksatriale Funktionsstörungen eine Rolle. So führt eine erhöhte linksventrikuläre Steifigkeit zu einer erhöhten Arbeitsbelastung des linken Vorhofs. Langfristig kommt es zu einer Beeinträchtigung der linksatrialen Funktion und letztendlich zu einer Vergrößerung des linken Vorhofs (Geske et al. 2007). Ein vergrößerter linker Vorhof wiederum erhöht die Gefahr, dass es zu Vorhofflimmern kommt. Vorhofflimmern hat besonders bei Patienten mit HFPEF einen Einfluss auf die Morbidität und Mortalität.

Ferner werden intrazelluläre Veränderungen in den Myozyten mit einer Veränderung der linksventrikulären Dehnbarkeit in Verbindung gebracht. So kann die vermehrte Expression der weniger dehnbaren Isoform des Zytoskelettproteins Titin bei Patienten mit HFPEF nachgewiesen werden (van Heerebeek et al. 2006). Auch findet sich eine Veränderung in der Kalziumhämostase der Kardiomyozyten, was zu einer erhöhten Kalziumkonzentration während der Diastole führt (Zile und Brutsaert 2002).

Alle aufgeführten pathophysiologischen Veränderungen beeinträchtigen die diastolische Füllung, dilatieren den linken Vorhof und vermindern die Dehnbarkeit des linken Ventrikels, was zur Ausbildung einer DD führt.

Es gibt aber auch weitere Veränderungen, welche die Ausprägung der Symptomatik einer HFPEF fördern. Hierzu gehören Veränderungen der arteriellen-ventrikulären Kopplung. Hierbei handelt es sich um das Zusammenspiel der Ventrikel mit dem arteriellen System, welches eine zentrale Determinante in der Herz-Kreislauf-Leistung ist. Sie ist definiert durch das Verhältnis des arteriellen zum ventrikulären Widerstand. Mit zunehmendem Alter kommt es im arteriellen Gefäßsystem zu einer abnehmenden Elastizität der Gefäße, und die Fähigkeit zur vasomotorischen Autoregulation in der Peripherie nimmt ab. Hierdurch wird das Herz durch eine höhere Pulsfrequenz und eine höhere spät-systolische Last belastet. Weit verbreitete Erkrankungen wie Hypertonie, Diabetes oder Nierenerkrankungen können diesen Zustand verschlimmern.

Besonders bei älteren Patienten mit HFPEF kann die Störung der arteriellen-ventrikulären Kopplung eine wichtige Ursache einer reduzierten körperlichen Belastbarkeit sein (Kawaguchi et al. 2003).

Ein weiterer Faktor, welcher die Ausprägung einer HFPEF fördert, ist die chronotrope Inkompetenz. Hierbei handelt es sich um einen inadäquaten Anstieg der Belastungsherzfrequenz bezogen auf die metabolisch-hämodynamischen Anforderungen bei körperlicher Belastung. Chronotrope Inkompetenz hemmt bei Patienten mit HFPEF das Schlagvolumen des Herzens während der körperlichen Belastung, besonders dann wenn die Patienten auch übergewichtig oder Diabetiker sind (Bourlaug et al. 2006). 
Ferner findet sich bei Patienten mit HFPEF, bedingt durch elektrische Leitungsverzögerungen, häufiger systolische und diastolische Asynchronie (Wang et al. 2007).

Zusammenfassend lässt sich feststellen, dass unterschiedliche pathophysiologische Veränderungen für die Entwicklung einer HFPEF in Frage kommen. Dies lässt die Gruppe der Patienten mit HFPEF eher heterogen erscheinen.

\subsection{Diagnose}

Um die Diagnose HFPEF stellen zu können, müssen nach Empfehlungen der European Society of Cardiology drei Bedingungen erfüllt sein (Paulus et al. 2007). Es müssen (1) Symptome einer HF vorhanden sein, (2) die systolische Funktion muss erhalten oder nur leicht beeinträchtigt sein und (3) Zeichen einer linksventrikulären DD müssen vorliegen.

Zu den klinischen Zeichen und Symptomen der HF (1) gehören Lungenödem, pulmonale Rasselgeräusche, Hepatomegalie, Knöchelödeme und Luftnot. Bei der HFPEF ist Luftnot aufgrund des pulmonalen Rückstaus meist das sich als erstes manifestierende Symptom. Hierbei ist es notwendig zu unterscheiden, wann die Luftnot auftritt, beispielsweise nachts oder bei Belastung. Die Tatsache, dass Patienten mit HFPEF häufig übergewichtig sind oder ein fortgeschrittenes Lebensalter erreicht haben, macht die Interpretation der Ursache der Luftnot schwer (Edelmann et al. 2011). Eine Objektivierung der eingeschränkten körperlichen Belastbarkeit ist beispielsweise mithilfe des 6-Minuten-Gehtests oder einer Spiroergometrie möglich.

Das Vorliegen einer normalen oder nur leicht beeinträchtigten systolischen Funktion (2) wird durch eine $E F \geq 50 \%$ angezeigt. Um eine signifikante linksventrikuläre Überblähung auszuschließen, gilt als weiteres Kriterium, dass der linksventrikuläre enddiastolische Volumenindex (LVEDVI) $\leq 97 \mathrm{ml} / \mathrm{m}^{2}$ sein muss.

Die Diagnose einer DD (3) gestaltet sich hingegen schwieriger und erfordert spezielle echokardiografische Messungen oder invasive Diagnostik.

So kann der Nachweis einer DD invasiv mithilfe eines Herzkatheters erbracht werden. Invasiv erhobene Messwerte, welche eine DD beweisen, sind: ein linksventrikulärer enddiastolischer Druck (LVEDP) > $16 \mathrm{mmHg}$, ein mittlerer pulmonalkapillärer Verschlussdruck $(\mathrm{mPCWP})>12 \mathrm{mmHg}$, eine linksventrikuläre Relaxationszeit $\mathrm{T}>48 \mathrm{~ms}$ und eine diastolische linksventrikuläre Steifigkeitskonstante $>0,27$. Der invasive Nachweis einer linksventrikulären DD wird als eindeutiger Nachweis einer HFPEF angesehen. Allerdings ist der routinemäßige Nachweis einer HFPEF mittels invasiv erhobener Parameter nicht möglich, wodurch den nichtinvasiven Parametern im klinischen Alltag eine führende Rolle zukommt. 
Besondere Bedeutung kommt hierbei der Gewebedopplerechokardiografie zu. Der linksventrikuläre Füllungsindex (E/E'), welcher sich aus dem frühdiastolischen Mitralstromeinfluss (E) und der frühdiastolischen Mitralringbewegung ( $\left.E^{\prime}\right)$ zusammensetzt, korreliert eng mit dem linksventrikulären Füllungsdruck und der diastolischen Steifigkeit und ist daher der zentrale Parameter zum nichtinvasiven Nachweis einer HFPEF.

Ein linksventrikulärer Füllungsindex $E / E^{\prime}>15$ steht für einen erhöhten linksventrikulären Füllungsdruck, und ein $E / E^{\prime}<8$ steht für einen normalen linksventrikulären Füllungsdruck. Daher kann bei einem E/E' > 15 die Diagnose einer HFPEF gestellt werden.

Für den Fall, dass E/E' nun zwar < 15 ist, aber > 8, kann die Diagnose einer HFPEF mithilfe weiterer echokardiografischer Parameter oder von Laborparametern gestellt werden.

So kann die Diagnose einer HFPEF gestellt werden, wenn zusätzlich der linksatriale Volumenindex zur Körperoberfläche (LAVI) auf $\geq 40 \mathrm{ml} / \mathrm{m}^{2}$ vergrößert ist.

Ebenfalls kann die Diagnose einer HFPEF trotz eines E/E' $<15$ gestellt werden, wenn sich Vorhofflimmern nachweisen lässt oder sich Zeichen einer linksventrikulären Hypertrophie im Sinne eines erhöhten linksventrikulären Masseindex (LVMI) von $\geq 122 \mathrm{~g} / \mathrm{m}^{2}$ finden.

Aus dem frühdiastolischen Mitralstromeinfluss $(E)$ und dem atrialen Mitralstromeinfluss $(A)$ wird der Quotient E/A gebildet. Bei einem Quotienten E/A $\geq 0,5$ kann auch in Verbindung mit einem $E / E^{\prime}<15$ die Diagnose einer HFPEF gestellt werden.

Eine verlängerte Dezelerationszeit $\geq 280$ ms lässt ebenfalls die Diagnose einer HFPEF zu, auch bei einem $E / E^{\prime}<15$.

Der Biomarker brain natriuretic peptide (BNP) korreliert mit den Stadien einer diastolischen Dysfunktion (Tschöpe et al. 2005). Zwar lässt sich mit erhöhten Konzentrationen von BNP allein keine DD nachweisen (Angermann und Ertl 2004), jedoch spricht ein positives BNP in Verbindung mit einem $E / E^{\prime}<15$, aber $>8$ für eine HFPEF. Als positiv gelten Konzentrationen von NT-proBNP $\geq 220 \mathrm{pg} / \mathrm{ml}$ oder BNP $\geq 200 \mathrm{pg} / \mathrm{ml}$.

Zur besseren Übersicht werden die Diagnosekriterien in einem Flussdiagramm im Folgenden noch einmal aufgeführt. 


\section{Diagnose der DHF}

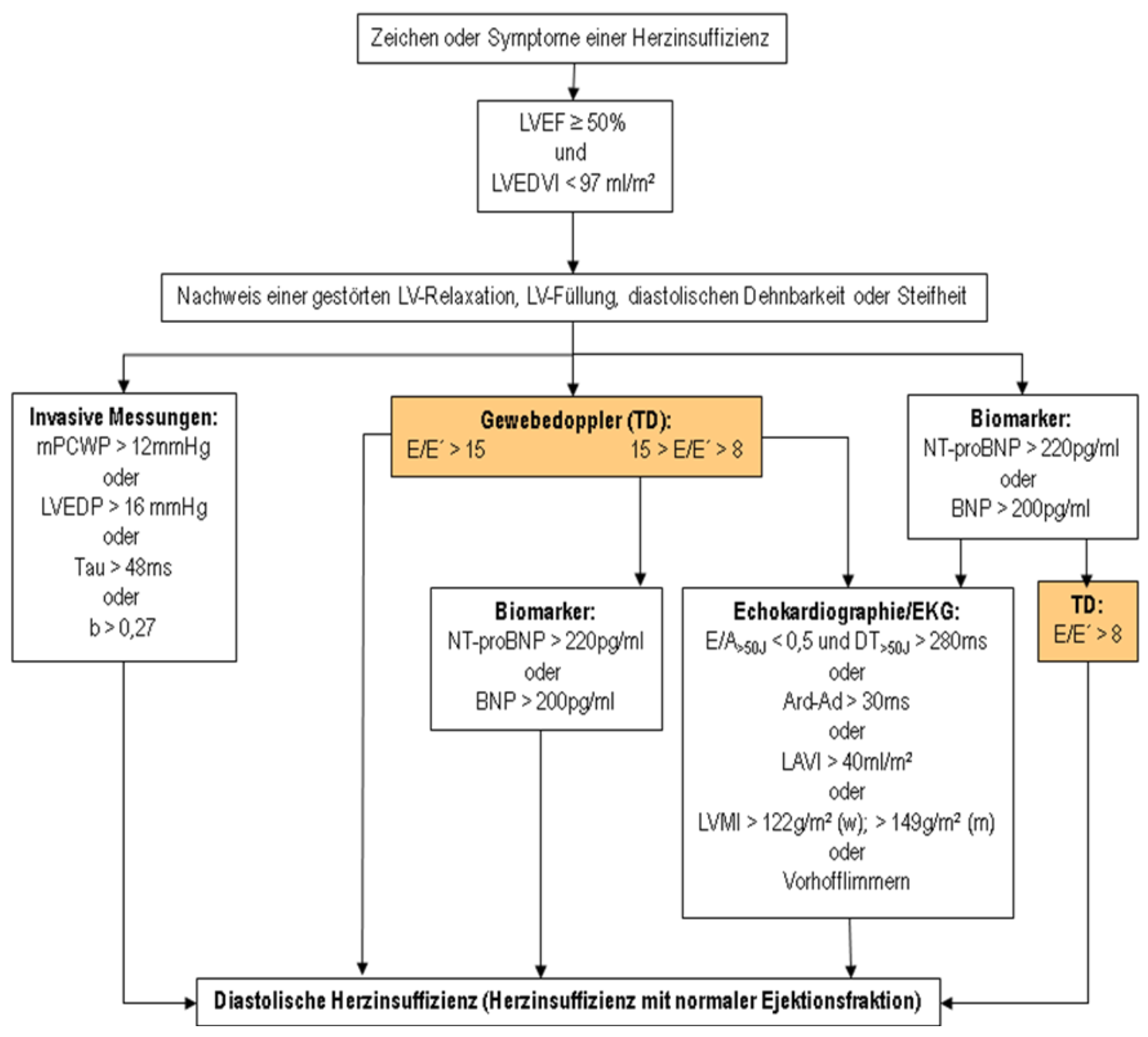

Abbildung 1: Flussdiagramm zur Diagnosestellung bei DD und HFPEF, adaptiert nach Paulus et al. 2007, Seite 2542. 


\subsection{Biomarker}

\subsubsection{GDF-15}

Der growth and differentiation factor 15 (GDF-15) ist Teil der großen transforming growth factor B-Gruppe (TGF-ß). Diese Gruppe umfasst rund 40 Moleküle. Sie vermitteln vielfältige biologische Antworten. So kontrollieren sie beispielsweise die Proliferation epithelialer Zellen, stimulieren die Bildung der EZM und können Immunantworten unterdrücken (Heinrich et al. 2007). GDF-15 selbst ist ein $12 \mathrm{kDa}$ schweres Molekül, welches auch als über eine Disulfidbrücke verbundenes Dimer vorkommt.

Es kommt in hohen Konzentrationen in der Prostata und in der Plazenta vor. In anderen Organen, so auch im Herz, kommt es normalerweise nicht vor (Bootcov et al. 1997, Tan et al. 2000).

Allerdings wird die Expression von GDF-15 schnell durch Interleukin 1 (IL-1), Tumornekrosefaktor a (TNFa) und TGFB in Makrophagen induziert, wodurch die Aktivierung von Makrophagen sowie die Entzündung eingeschränkt wird (Bootcov et al. 1997).

Auch das Tumorsuppressorgen p53 induziert die Expression von GDF-15, und dieses wirkt dann als wachstumsinhibierend in Tumorzellen (Tan et al. 2000).

In Kardiomyozyten, welche nach Ischämie reperfundiert werden, wird die Expression von GDF-15 induziert (Kempf et al. 2006). Auch andere kardiovaskuläre Ereignisse, die mit oxidativem Stress einhergehen, verursachen die Expression von GDF-15. Hierzu gehören Drucküberlastung, Arteriosklerose (Brown et al. 2002) und systolische Herzinsuffizienz (Xu et al. 2006).

Transgene, GDF-15-defiziente Mäuse zeigten vergrößerte Herzen, was einer überhöhten Hyperplasie zugeschrieben wurde, mit der Folge einer verminderten linksventrikulären Funktion bei Drucküberlastung ( $\mathrm{Xu}$ et al. 2006) und einem größeren myokardialen Infarktgebiet bei Reperfusion nach einer Ischämie (Kempf et al. 2006). Umgekehrt zeigten transgene GDF-15-überexprimierende Mäuse eine Resistenz gegenüber überlastungsinduzierter Hypertrophie (Xu et al. 2006). Daraus lässt sich der Schluss ziehen, dass GDF-15 einen protektiven Effekt auf das Herz hat.

Studien legen den Einsatz von GDF-15 zur Risikoabschätzung (risk stratification) bei einer akuten KHK (Wollert et al. 2007a, Wollert et al. 2007b, Eggers et al. 2008) oder einer Lungenembolie (Lankeit et al. 2008) nahe.

Bei der HFREF findet sich eine erhöhte Konzentration von GDF-15, welche auch für die Prognose von Bedeutung ist (Kempf et al. 2007a, Kempf et al. 2007b). 
Stahrenberg et al. (2010) zeigen, dass die Konzentration von GDF-15 bei HFPEF in einem ähnlichen Ausmaß wie bei HFREF erhöht ist und es Hinweise darauf gibt, dass GDF-15 auch zur Diagnose einer HFPEF hilfreich sein könnte. Diesem Ansatz soll in der vorliegenden Arbeit weiter nachgegangen werden.

\subsubsection{NT-proBNP}

Brain natriuretic peptide (BNP) wurde 1988 erstmals in Schweinegehirnen entdeckt (Sudoh et al. 1988). BNP wird aber auch in den Myozyten der Ventrikel gebildet als Reaktion auf eine Dehnung der Ventrikel in der Diastole. Seine Sekretion bewirkt Vasodilatation, eine gesteigerte Diurese und eine verbesserte linksventrikuläre Relaxation.

Zunächst entsteht aus dem aus 134 Aminosäuren bestehenden präproBNP durch Spaltung proBNP. Dieses wird dann in das aktive C-terminale Fragment BNP und das inaktive Nterminale Fragment NT-proBNP gespalten. Das inaktive NT-proBNP hat eine deutlich längere Halbwertszeit im Blut, weshalb es auch zur Quantifizierung dem BNP selbst vorgezogen wird (Piechota et al. 2008).

Die Konzentration von BNP und NT-proBNP steigt mit dem Grad der linksventrikulären diastolischen Dysfunktion (LVDD). So wurden ansteigende Konzentrationen bei Patienten gefunden, die bei der echokardiographischen Gewebedoppleruntersuchung das Bild einer beeinträchtigten linksventrikulären Relaxation, Pseudonormalisation oder Restriktion zeigten (Mottram et al. 2003, Lubien et al. 2002, Bursi et al. 2006).

Trotz ihrer Aussagekraft bei der Beurteilung einer symptomatischen isolierten LVDD eignen sich die natriuretischen Peptide kaum zum präklinischen Screening auf LVDD. Dies liegt daran, dass auch multiple andere Faktoren die Konzentrationen der natriuretischen Peptide im Blut beeinflussen. So sind die Konzentrationen bei Frauen höher als bei Männern und steigen generell mit dem Alter an (McDonagh et al. 2004). Fettleibigkeit geht hingegen mit niedrigeren Konzentrationen von BNP einher (Daniels et al. 2006).

Hinzu kommt, dass auch eine Druckerhöhung im rechten Vorhof einen Anstieg der natriuretischen Peptide auslösen kann. Dazu kann es durch pulmonale Hypertonie beispielsweise als Folge einer Lungenembolie oder einer chronisch obstruktiven Lungenerkrankung kommen.

Auch verschiedene Komorbiditäten wie zum Beispiel Sepsis (Jones und Kline 2003) oder Leberinsuffizienz (La Villa et al. 1992) lassen die Konzentrationen der natriuretischen Peptide ansteigen. 
Ferner erhöht sich die Konzentration, sobald die glomeruläre Filtrationsrate (GFR) der Niere unter $60 \mathrm{ml} / \mathrm{min}$ fällt (Tsutamoto et al. 2006).

Aus diesen Gründen reichen erhöhte Konzentrationen von BNP und NTproBNP nach den Richtlinien der European Society of Cardiology (ESC) nicht für den Nachweis einer LVDD, sondern es bedarf zusätzlich weiterer nichtinvasiv erhobener Parameter. Sie eignen sich jedoch zum Ausschluss einer HFPEF. Nach den Leitlinien der ESC zur Diagnose einer HFPEF gelten als Grenzwerte für positiv prädiktive Werte für NTproBNP $220 \mathrm{pg} / \mathrm{ml}$ und für BNP 200 pg/ml. Als Grenzwerte für negativ prädiktive Werte gelten für NTproBNP 120 pg/ml und für BNP 100 pg/ml (Paulus et al. 2007).

\subsubsection{ANP und NT-proANP}

Das atriale natriuretische Peptid (ANP) wurde 1981 entdeckt. Es besteht aus 28 Aminosäuren (de Bold et al. 1981).

Die Synthese von ANP erfolgt hauptsächlich im linken Vorhof. Die Freisetzung von ANP erfolgt bei Druckerhöhung im linken Vorhof, vermittelt durch Dehnungsreize. An den Nieren bewirkt ANP eine verstärkte Diurese und Natriurese. Ferner hemmt es die Freisetzung von Aldosteron in den Nebennieren.

Bei der Synthese von ANP entsteht, ähnlich einigen weiteren in dieser Arbeit bestimmten Hormonen, ein Spaltprodukt, welches Rückschlüsse auf die Serumkonzentration von ANP erlaubt. Zunächst erfolgt die Synthese eines biologisch inaktiven, aus 126 Aminosäuren bestehenden Propeptides, des sogenannten proANP. Im Folgenden wird durch eine Endoprotease das biologisch aktive C-terminale Fragment abgespalten (Piechota et al. 2008). Es verbleibt der N-terminale Teil des proANP, genannt NT-proANP, welcher eine wesentlich längere Halbwertszeit als ANP selbst besitzt und daher als Marker für ANP vorgeschlagen wird (Buckley et al. 1999).

Zwar war ANP im Vergleich zu BNP in der Vergangenheit relativ selten Gegenstand klinischer Studien zur HFREF, es besitzt jedoch sowohl einen diagnostischen als auch einen prognostischen Wert hinsichtlich einer manifesten HF oder einer Dysfunktion. Lermann et al. (1993) zeigten, dass NT-proANP eine Sensitivität von 90\% und eine Spezifität von 92\% bezüglich der Erkennung einer symptomlosen linksventrikulären Dysfunktion aufweist. Beim Vorliegen einer manifesten HF konnten bereits früh erhöhte Werte gemessen werden, die mit der Schwere der Erkrankung korrelierten (Burnett et al. 1986). 
Die Bedeutung der Konzentration von NT-proANP bei Patienten mit DD und HFPEF ist bisher ungeklärt. Aufgrund des aufgeführten Zusammenhangs von NT-proANP und der HFREF könnte sich NT-proANP jedoch zur Diagnosefindung einer HFPEF eignen.

\subsubsection{Adrenomedullin und MR-proADM}

Adrenomedullin (ADM) findet sich in hohen Konzentrationen im Nebennierenmark, der Lunge und dem linken Vorhof (Kitamura et al. 1993). Synthese und Sekretion erfolgen hierbei vor allem im Endothel (Sugo et al. 1994).

Adrenomedullin ist ein aus 52 Aminosäuren bestehendes Peptid mit vasodilatatorischer und hypotensiver Wirkung. Erstmalig entdeckt wurde es in einem Phäochromozytom (Kitamura et al. 1993).

Erhöhte Serumkonzentrationen von ADM finden sich neben anderen Krankheitsbildern wie bei einer Sepsis auch beim Vorliegen einer HF. So zeigte sich beispielsweise bei Kobayashi et al. (1996) die Serumkonzentration von 49 Patienten mit HF im Vergleich zu gesunden Kontrollprobanden erhöht.

Bei Patienten mit einer KHK fand sich eine negative Korrelation zwischen der Serumkonzentration des mitregionalen proAdrenomedullin (MR-proADM) und der LVEF.

Yu et al. (2001) untersuchten ein Kollektiv aus insgesamt 77 Patienten mit HF, von denen 31 eine isolierte DD mit einer LVEF > 50\% und 46 eine LVEF $<50 \%$ aufwiesen. Hierbei waren die Serumkonzentrationen von Adrenomedullin bei Patienten mit isolierter DD gegenüber Kontrollprobanden signifikant erhöht.

Edelmann et al. (2011) beschreiben einen Zusammenhang zwischen der Konzentration von ADM und dem Vorliegen einer DD. Der beschriebenen Erhöhung der Serumkonzentration von ADM im Rahmen der DD und der HFPEF soll im Rahmen der vorliegenden Arbeit hinsichtlich einer möglichen diagnostischen Relevanz weiter nachgegangen werden.

\subsubsection{Endothelin-1 und CT-proET-1}

Bei der Bildung von Endothelin 1 (ET-1) entsteht zunächst aus dem Propeptid präproET-1 durch proteolytische Aktivität das biologisch inaktive bigET-1. Durch das Endothelin-Konversionsenzym entsteht dann aus bigET-1 das ET-1 (Xu et al. 1994). ET-1 bewirkt eine starke Vasokonstriktion sowohl in Arterien als auch in Venen. 
Die Halbwertszeit von ET-1 liegt bei lediglich 1-2 Minuten (Weitzberg et al. 1991). Hauptbildungsort ist das Gefäßendothel. ET-1 wird aber auch im Herzen, der Leber oder auch in den Astrozyten sezerniert (Shah 2007).

In einigen klinischen Studien wurde gezeigt, dass die Serumkonzentration von ET-1 zur Abschätzung einer HFREF sowie deren Mortalität und Prognose geeignet ist. So fanden sich bei Patienten mit HFREF im Vergleich zu Patienten gleichen Alters und Geschlechts erhöhte Konzentrationen von ET-1 (McMurray et al. 1992). Es fand sich in etwa eine Verdoppelung der Werte, unabhängig von vorhergehender körperlicher Aktivität. Bezüglich der Mortalität zeigten van Beneden et al. (2004), dass ET-1 ein guter unabhängiger Prädiktor für das Überleben von Patienten mit chronischer HF und reduzierter LVEF und NYHA-Klasse III-IV ist. Hier zeigte sich ET-1 sogar den natriuretischen Peptiden oder deren Propeptiden überlegen.

Der Stellenwert einer Erhöhung von ET-1 im Rahmen der DD und der HFPEF ist bisher ungeklärt. Aufgrund der beschriebenen Assoziationen von ET-1 und der HFREF könnte sich jedoch ET-1 auch bei der Diagnostik einer HFPEF als nützlich erweisen.

\subsubsection{Vasopressin und CT-proAVP}

Die Synthese von Vasopressin erfolgt im Hypothalamus. Anschließend wird Vasopressin, auch Antidiuretisches Hormon (ADH) genannt, im Hypothalamus gespeichert. In den Sammelrohren der Niere bewirkt es eine vermehrte Wasserretention. An den peripheren Gefäßen wirkt es vasokonstriktorisch und hat somit einen hypertonen Effekt (Singh Ranger 2002). An der Herzmuskulatur bewirkt es eine Hypertrophie (Tahara et al. 1998).

Vasopressin entsteht aus dem Propeptid PräproVasopressin. Dies geschieht zusammen mit zwei weiteren Peptiden, dem Neurophysin sowie dem Copeptin, dem C-terminalen Teil des Vorläuferhormons entsprechend, auch CT-proAVP genannt. Auch Vasopressin unterliegt einer schnellen Eliminierung und ist außerdem instabil. Ferner liegen bis zu $90 \%$ des Vasopressins im Plasma an Thrombozyten gebunden vor (Preibisz et al. 1983).

Francis et al. (1990) fanden bei Patienten mit einer LVEF $\leq 35 \%$ signifikant höhere Konzentrationen von Vasopressin als bei Kontrollprobanden mit normaler linksventrikulärer Funktion. Inwieweit dieses Ergebnis auf Patienten mit HFPEF übertragen werden kann, ist unklar. Aufgrund seiner diagnostischen Fähigkeiten bei der HFREF kommt es als Marker für das Vorliegen einer HFPEF zumindest in Frage. 


\subsection{Fragestellung}

Bei Patienten mit HFREF spielt die Verwendung von Biomarkern zur klinischen Beurteilung, Diagnose und Verlaufskontrolle eine zentrale Rolle. Die natriuretischen Peptide NTproBNP und BNP finden bereits im klinischen Alltag Verwendung und sind Teil der Richtlinien der ESC zur Diagnose einer HFPEF. Eine größer werdende Anzahl von Biomarkern wird auf ihre Verwendbarkeit bei einer HFPEF überprüft. Der Stellenwert von GDF-15 bei Patienten mit DD oder HFPEF ist bislang nicht ausreichend untersucht. Ziel dieser Arbeit ist es daher, die klinische Relevanz und diagnostische Fähigkeit von GDF-15-Konzentrationen im Plasma von Patienten mit HFPEF und von Patienten mit DD zu untersuchen und mit anderen etablierten Biomarkern zu vergleichen. 


\section{Material und Methoden}

\subsection{Patientenkollektiv}

Das Patientenkollektiv umfasst Patienten der Studie „Prävalenz und Verlauf der diastolischen Dysfunktion und der diastolischen Herzinsuffizienz" (Diast-CHF).

Die Studie wurde vom Kompetenznetz Herzinsuffizienz (KNHI) im Rahmen des Teilprojektes „Diastolische Dysfunktion“ (TP7) durchgeführt. Es handelte sich um eine epidemiologische, prospektive, multizentrische Kohortenstudie. Neben Göttingen waren die Zentren Lübeck, Würzburg und Berlin beteiligt. Die Patienten wurden in den Jahren 2004 und 2005 rekrutiert. Finanziell wurde die Studie durch das Bundesministerium für Bildung und Forschung gefördert. Ein positives Votum der Ethikkommission der Medizinischen Fakultät der Universität Göttingen lag vor.

In die Studie eingeschlossen werden konnten Patienten im Alter von 50-85 Jahren, sofern sie über mindestens einen Risikofaktor für das Auftreten einer diastolischen Funktionsstörung verfügten. Als Risikofaktoren galten arterielle Hypertonie, Diabetes mellitus, Schlafapnoesyndrom oder Zeichen der Arteriosklerose. Zeichen einer vorliegenden Arteriosklerose waren definiert als symptomatische periphere arterielle Verschlusskrankheit (pAVK), angiographisch nachgewiesene KHK, ein Herzinfarkt in der Krankengeschichte, Karotisstenose und ein stattgehabter Schlaganfall. Ebenfalls wurden Patienten eingeschlossen, bei denen die ärztlich gestellte und dokumentierte Diagnose einer HF bereits vorlag.

Alle Patienten mussten vor Einschluss in die Studie schriftlich ihr Einverständnis erklären. Da es sich um eine epidemiologische Studie handelte, waren die einzigen Ausschlusskriterien: mangelnde Kooperationsbereitschaft, unzureichende Kommunikationsfähigkeit, die Einwilligungsfähigkeit einschränkende Erkrankungen sowie eine geographisch zu weite Entfernung zum Studienzentrum.

Zu Studienbeginn erfolgte eine umfangreiche Untersuchung der Patienten einschließlich einer Echokardiografie. Die Diagnose einer HF wurde entweder aufgrund der Krankengeschichte oder nach der Framingham-Definition (Ho et al. 1993) gestellt. Die Einteilung in Patienten mit HFREF und in Patienten mit HFPEF erfolgte anhand echokardiografischer Kriterien. Prospektiv eingeschlossen wurde in Diast-CHF eine Gruppe gesunder Patienten. Diese wurde zu Vergleichszwecken herangezogen und ferner zur Ermittlung der Trennschärfe von GDF-15 bei der Untersuchung auf das Vorliegen einer diastolischen HF. 


\subsection{Untersuchungen}

\subsubsection{Anamnese}

Von jedem Patienten wurde eine ausführliche Anamnese erhoben. Zunächst wurde der Patient um einige soziodemographische Angaben gebeten. Dann wurde gefragt, ob in den vergangen 12 Monaten aufgrund einer HF der Hausarzt oder ein Kardiologe aufgesucht wurde oder ein stationärer Krankenhaus- oder Rehaaufenthalt nötig war. Anschließend wurde nach den folgenden kardiovaskulären Risikofaktoren gefragt: Diabetes mellitus, Hypertonie, Hyperlipidämie, Hyperurikämie, Schlafapnoesyndrom, Myokardinfarkt bei Verwandten ersten Grades vor dem 60. Lebensjahr. Ebenfalls erfasst wurden ein eventueller Alkoholkonsum sowie der Raucherstatus. Gefragt wurde auch nach den folgenden kardialen Diagnosen: KHK, stattgehabtem Myokardinfarkt, primären Herzklappenerkrankungen, angeborenen und erworbenen Herzfehlern, Vorhofflimmern sowie Kardiomyopathien und deren Ätiologie. In diesem Zusammenhang wurde der Patient auch gebeten, über eventuell erfolgte kardiovaskuläre Therapiemaßnahmen wie koronare Revaskularisation, Bypassoperationen, periphere Revaskularisation, Herzklappenersatz, Schrittmacher- oder Defibrillatorimplantation, Herztransplantation oder Reanimation Auskunft zu geben. Eventuelle Nebendiagnosen wurden ebenfalls erfasst. Konkret gefragt wurde nach PAVK inklusive der FontaineStadien, cerebrovaskulären Erkrankungen, Synkopen, COPD, primär pulmonaler Hypertonie, Leberzirrhose, chronisch viralen Hepatitiden, Humanes Immundefizienz-Virus (HIV)-Infektionen, Malignomen und Depression. Schließlich wurde die aktuelle Medikation in ihrer derzeitigen Dosierung notiert.

\subsubsection{Klinische Untersuchung}

Bei der klinischen Untersuchung wurden Körpergröße und Gewicht bestimmt. Der Body Mass Index (BMI) wurde nach Mosteller (1987) berechnet. Es folgte die Messung des Blutdrucks und der Herzfrequenz.

Bei der folgenden körperlichen Untersuchung wurde der Patient gezielt auf das Vorliegen von Major- und Minorkriterien der Framingham-Definition (Ho et al. 1993) untersucht und befragt. Der Untersucher beurteilte dann anhand der Major- und Minorkriterien, ob eine symptomatische HF vorlag. Zu den Majorkriterien gehören Halsvenenstauung, pulmonale Rasselgeräusche, hepatojugulärer Reflux, paroxysmale nächtliche Dyspnoe, ein dritter Herzton und der radiologische Nachweis einer Kardiomegalie. Zu den Minorkriterien zählen Belastungsdyspnoe, periphere Ödeme, nächtlicher Husten, Hepatomegalie, radiologischer Nachweis von Pleuraergüssen sowie das Vorliegen einer Tachykardie von > 120 Schlägen 
pro Minute. Voraussetzung für die Diagnose einer HF ist das Vorliegen von mindestens einem Majorkriterium oder von zwei Minorkriterien. Ebenfalls wurde untersucht, ob Aszites vorlag.

\subsubsection{6-Minuten-Gehtest}

Der 6-Minuten-Gehtest ist ein technisch sehr einfach durchzuführender Test, mit dem sich jedoch trotzdem eine valide Einschätzung sowohl der Prognose als auch der körperlichen Leistungsfähigkeit von Patienten mit HF vornehmen lässt (Guyatt et al. 1985). Standardisiert man den 6-Minuten-Gehtest, so sind die Ergebnisse gut reproduzierbar (Bittner et al. 1993).

Der Test wurde auf einer zuvor ausgemessenen, mindestens $20 \mathrm{~m}$ langen ebenen Strecke durchgeführt, deren beide Enden sichtbar markiert waren. Die Patienten wurden aufgefordert, innerhalb von 6 Minuten die für sie größtmögliche Strecke zwischen den beiden Endpunkten gehend zurückzulegen, also ohne dabei zu rennen oder zu joggen. Definitionsgemäß sollte dabei immer ein Bein auf dem Boden bleiben. Die Gehgeschwindigkeit konnte von den Patienten selbst bestimmt werden. Auch konnten sie gegebenenfalls für sie nötige Pausen einlegen und sich dabei auch auf Stühle am Rand der Gehstrecke setzen. Die Patienten wurden dann jedoch ermutigt, den Test fortzusetzen, sobald sie sich dazu in der Lage sahen. Die Zeit wurde während der Pause nicht angehalten.

Die Patienten hatten auch die Möglichkeit, den Test von sich aus abzubrechen, falls sie sich nicht in der Lage sahen weiterzumachen. In diesem Fall wurden der Abbruchgrund erfragt sowie die verstrichene Zeit und die bereits zurückgelegte Gehstrecke notiert. Alle zwei Minuten wurde durch den Versuchsleiter die verbliebene Zeit angesagt. Ferner wurde der Patient alle 30 Sekunden verbal ermutigt, den Test fortzuführen. Hierfür waren ausschließlich die folgenden beiden Formulierungen vorgesehen:

„Das machen Sie gut!“

„Immer weiter so!“

Während des gesamten Tests lief der Untersucher nicht mit, sondern blieb, um das Ergebnis nicht zu beeinflussen, in der Mitte der Teststrecke stehen. Nach Ablauf der 6 Minuten wurde der Patient gebeten, mit dem Gehen aufzuhören. Die zurückgelegte Distanz wurde dokumentiert und dabei auf ganze Meter gerundet. 


\subsubsection{Short Form Health Survey (SF-36)}

Der Short Form Health Survey ist ein Fragebogen, mit dessen Hilfe die die Gesundheit betreffende Lebensqualität eines Patienten gemessen werden kann.

In Form einer Selbsteinschätzungsskala geben die Patienten über ihr Befinden und ihre Funktionsfähigkeit Auskunft. Der SF-36 dient dazu, eine Aussage über den subjektiven Gesundheitszustand der Patienten machen zu können. Dieser subjektive Gesundheitszustand bzw. die gesundheitsbezogene Lebensqualität setzt sich aus den folgenden vier Komponenten zusammen: psychisches Befinden, körperliche Verfassung, soziale Beziehung und funktionelle Kompetenz (Wenger et al. 1984).

Der SF-36 besteht aus 36 Items, die sich in acht Subskalen unterteilen lassen. Diese Subskalen beinhalten die Bereiche allgemeine Gesundheitswahrnehmung, körperliche Schmerzen, körperliche Funktionsfähigkeit, Rollenfunktion in körperlicher Hinsicht, Rollenfunktion in emotionaler Hinsicht, psychische Gesundheit, soziale Funktionsfähigkeit und Vitalität. Alle Subskalen beziehen sich auf die letzten vier Wochen.

Zur Auswertung werden die Itemscores in den jeweiligen Subskalen summiert. Durch Summierung aller Itemscores erhält man den Gesamtscore für die Gesamtskala. Zum besseren Vergleich erfolgt die Angabe in Prozentwerten. Der erhaltene Wert gibt also den prozentualen Anteil des maximal erreichbaren Wertes wieder. Der höhere Score bildet somit eine bessere Lebensqualität ab.

Ausgearbeitet wurde der Fragebogen 1989 von John Ware. Die deutsche Übersetzung und Validierung des SF-36 erfolgte durch Bullinger (Bullinger 1995).

Die teilnehmenden Patienten wurden gebeten, den Fragebogen möglichst selbstständig, spontan und ehrlich auszufüllen. Es wurde darauf hingewiesen, dass die Beantwortung freiwillig ist.

\subsubsection{Elektrokardiogramm}

Bei jedem Patienten wurden die Herzaktionsströme in einem 12-Kanal-EKG nach den folgenden standardisierten Ableitungssystemen aufgezeichnet. Die Standardableitungen nach Einthoven wurden über bipolare Ableitungen gemessen. Die drei Elektroden wurden proximal der Handgelenke sowie oberhalb des linken Fußes angelegt. Ebenfalls bestimmt wurden die unipolaren Extremitätenableitungen nach Goldberger, welche genau in der Mitte zwischen den Einthoven-Ableitungen aufzuzeichnen sind. Bestimmt wurden aVR, aVL und aVF. Die unipolaren präkordialen Ableitungen nach Wilson wurden an Ableitungsstellen V1 
bis V6 abgeleitet. Die Aufzeichnung der Herzströme erfolgte mit einem Papiervorschub von $50 \mathrm{~mm} / \mathrm{s}$.

Zur Auswertung erfolgte das Ausmessen der PQ-Zeit, der QT-Zeit sowie des QRSKomplexes. Auffälligkeiten wie ein kompletter R-Verlust, pathologische Q-Zacken, diskordante T-Negativierungen und ST-Senkungen oder ST-Senkungen wurden gegebenenfalls dokumentiert. Der Sokolow- und der Lewis-Index wurden ebenfalls beurteilt. Ebenfalls erfolgte die Bestimmung von Frequenz und Rhythmus. Die EKG-Aufzeichnungen wurden auf Blockbilder untersucht.

\subsubsection{Echokardiographie}

Jeder Patient erhielt im Rahmen der Diast-CHF-Studie eine transthorakale echokardiographische Untersuchung in 2 Ebenen. Die Echokardiografie wurde in Linksseitenlage mit dem Echokardiografiegerät Philips Sonos 5500 durchgeführt. Die Archivierung der Untersuchungen erfolgte auf Videobändern und Ausdrucken. Grundlage für die Durchführung der echokardiographischen Untersuchung waren die Echokardiografierichtlinien für den harmonisierten Datensatz des Kompetenznetzes Herzinsuffizienz (KNHI) (Version vom 21.11.2003).

Neben anderen Parametern wurden die folgenden erhoben: E, A, E', A', S, D. Die systolische HF wurde definiert als eine LVEF $<50 \%$ nach Simpson.

Die diastolische HF wurde nach den folgenden Kriterien in 4 unterschiedliche, progrediente Schweregrade unterteilt. Diese werden im Folgenden beschrieben und ab-schließend zur Übersicht in einer Tabelle aufgeführt.

Das normale Füllungsmuster (Schweregrad 0) weist einen normalen linksventrikulären Einstrom und Pulmonalvenenfluss auf. Kennzeichen hierfür ist das Verhältnis der maximalen frühdiastolischen Einstromgeschwindigkeit zur Einstromgeschwindigkeit nach Vorhofkontraktion über der Mitralklappe $(E / A) \geq 1$.

Zudem mussten die folgenden drei Kriterien alle erfüllt sein: Verhältnis des maximalen systolischen zum maximalen diastolischen pulmonalvenösen Fluss $(S / D) \geq 1$, Verhältnis der maximalen frühdiastolischen Einstromgeschwindigkeit über der Mitralklappe zur frühdiastolischen maximalen Geschwindigkeit des Mitralklappenringes im Gewebedoppler $\left(E / E^{\prime}\right)<10$ und Verhältnis der maximalen frühdiastolischen Einstromgeschwindigkeit zur Einstromgeschwindigkeit nach der Vorhofkontraktion über der Mitralklappe während des ValsalvaManövers (E/Avalsalva) $\geq 1$.

Die verzögerte Relaxation (Schweregrad I) ist mit $E / A<1$ definiert. 
Die Pseudonormalisierung (Schweregrad II) ist mit einem $E / A \geq 1$, aber $<2$ sowie einem der folgenden drei Kriterien definiert: Verhältnis des maximalen systolischen zum maximalen diastolischen pulmonalvenösen Fluss $(S / D)<1$, Verhältnis der maximalen frühdiastolischen Einstromgeschwindigkeit über der Mitralklappe zur frühdiastolischen maximalen Geschwindigkeit des Mitralklappenringes im Gewebedoppler $\left(E / E^{\prime}\right) \geq 10$ und Verhältnis der maximalen frühdiastolischen Einstromgeschwindigkeit zur Einstromgeschwindigkeit nach der Vorhofkontraktion über der Mitralklappe während des Valsalva-Manövers (E/Avalsalva) $<1$.

Das restriktive Füllungsmuster (reversibel = Schweregrad III, irreversibel = Schweregrad IV) ist definiert durch ein $E / A \geq 2$ sowie eines der beiden folgenden Kriterien: Verhältnis des maximalen systolischen zum maximalen diastolischen pulmonalvenösen Fluss $(S / D)<1$, Verhältnis der maximalen frühdiastolischen Einstromgeschwindigkeit über der Mitralklappe zur frühdiastolischen maximalen Geschwindigkeit des Mitralklappenringes im Gewebedoppler $\left(E / E^{\prime}\right) \geq 10$. Die Differenzierung zwischen einem reversiblen, restriktiven Füllungsmuster und einem irreversiblen, restriktiven Füllungsmuster erfolgt durch E/Avalsalva. Ist E/Avalsalva < 1, so handelt es sich um ein reversibles Füllungsmuster (Schweregrad III). Ist $E / A$ valsalva $\geq 1$ liegt ein irreversibles restriktives Füllungsmuster (Schweregrad IV) vor. Beim Valsalva-Manöver wird der Patient gebeten, zunächst maximal einzuatmen. Hierauf führt der Patient eine Bauchpresse durch und spannt gleichzeitig bei geschlossener Glottis die Exspirationsmuskulatur maximal an. Hierdurch kommt es zu einer Druckerhöhung in Thorax und Abdomen, wodurch der venöse Rückfluss und in der Folge das Schlagvolumen stark reduziert werden.

\begin{tabular}{|c|c|c|c|c|}
\hline & $\begin{array}{l}\text { Grad } 0 \\
\text { (normal) }\end{array}$ & $\begin{array}{l}\text { Grad I } \\
\text { (verzögerte } \\
\text { Relaxation) }\end{array}$ & $\begin{array}{l}\text { Grad II } \\
\text { (pseudonormale } \\
\text { Füllung) }\end{array}$ & $\begin{array}{l}\text { Grad III/Grad IV } \\
\text { (reversibles/irreversibles } \\
\text { restriktives Füllungsmuster) }\end{array}$ \\
\hline $\mathrm{E} / \mathrm{A}$ & $\geq 1$ & $<1$ & $\geq 1$ und $\leq 2$ & $\geq 2$ \\
\hline & 3/3 Kriterien & & 1/3 Kriterien & 1/2 Kriterien und Valsalva \\
\hline E/é (lateral) & $<10$ & & $\geq 10$ & $\geq 10$ \\
\hline S/D & $\geq 1$ & & $<1$ & $<1$ \\
\hline E/AValsalva & $\geq 1$ & & $<1$ & $<1$ \\
\hline
\end{tabular}

Bei erhaltener LV-Funktion und vorhandener DD wurde bei gleichzeitigem Vorliegen klinischer Symptome der HF wie Lungenödem, Knöchelödem und Luftnot unter Einbeziehung der invasiv erhobenen Parameter linksventrikulärer enddiastolischer Druck (LVEDD), mittlerer pulmonalkapillärer enddiastolischer Druck (mPCWP), linksventrikulärer Relaxationszeit $\mathrm{T}$ und der diastolischen linksventrikulären Steifigkeitskonstante $\mathrm{b}$, der Laborparameter NT-proBNP und BNP sowie weiterer echokardiographischer Parameter wie z.B. dem linksatrialen Volumenindex (LAVI) und dem linksventrikulären Masseindex (LVMI) die Diagnose einer HFPEF gestellt, wie im Flussdiagramm auf Seite 7 dargestellt. 


\subsubsection{Basislabordiagnostik}

Von jedem Patienten wurde ein Basislabor bestimmt. Dieses umfasste die Leukozyten- und die Thrombozytenanzahl sowie den Hämatokrit- und den Hämoglobinwert. Ferner wurden die Elektrolyte Natrium und Kalium bestimmt. Bestimmt wurde auch Kreatinin. Die glomeruläre Filtrationsrate (GFR) wurde nach der vereinfachten Formel der MDRD-Studie (Levey et al. 2000) berechnet: GFR $\left(\mathrm{ml} / \mathrm{min} / 1,73 \mathrm{~m}^{2}\right)=186^{*}$ Serum-Kreatinin ${ }^{-1,154}{ }^{*}$ Alter $^{-0,203}$ [ 0,754 bei Frauen] [ ${ }^{\star} 1,21$ bei Patienten mit schwarzer Hautfarbe]. Ebenfalls bestimmt wurde das Gesamtcholesterin, LDL-Cholesterol und HDL-Cholesterol. Weitere Parameter waren Harnsäure, das basale Thyroidea-stimulierende Hormon (TSH) sowie das Glykohämoglobin $\left(\mathrm{HbA}_{1 \mathrm{c}}\right)$.

\subsection{Spezielle Labordiagnostik}

\subsubsection{Blutproben}

Die Blutabnahme erfolgte in nicht-nüchternem Zustand und erst nachdem die Patienten 30 Minuten entspannt geruht hatten. Zur Entnahme wurden EthylendiamintetraessisäureBlutentnahmeröhrchen (EDTA-Röhrchen) verwendet. Diese wurden unmittelbar nach der Blutentnahme 10 Minuten lang in einer Eppendorf Zentrifuge 5702R zentrifugiert. Anschließend wurde der Plasma-Überstand abpipettiert und bei $-80^{\circ} \mathrm{C}$ eingefroren. Aus diesem Plasma-Überstand wurden später sowohl NT-proBNP als auch GDF-15 bestimmt. Die Proben blieben bis zur endgültigen Analyse eingefroren. Während der notwendigen Transporte war die Kühlkette stets gewährleistet.

\subsubsection{GDF-15}

Die Bestimmung von GDF-15 erfolgte mit einem noch nicht kommerziell verfügbaren Test der Firma Roche Diagnostics (Mannheim, Deutschland). Hierbei handelt es sich um einen Immunoassay für GDF-15, der auf der Elektrochemilumniszenz-Technologie basiert. Dieser Elektrochemiluminiszenz-Immunoassay ist vergleichbar mit dem von Kempf (Kempf et al. 2007a) beschriebenen radiometrischen Immunoassay. Die Antikörper für beide Immunoassays sind identisch (Layer et al. 2010). Die Nachweisgrenze für GDF-15 lag hier bei 20 $\mathrm{ng} / \mathrm{L}$ (Kempf et. al 2007a). 


\subsubsection{NT-proBNP}

Die Bestimmung der Konzentrationen von NT-proBNP erfolgte mit dem Test Elecsys $®$ proBNP der Firma Roche Diagnostics (Mannheim, Deutschland).

Bei diesem Test handelt es sich um einen Elektrochemilumniszenz-Immunoassay. Dieser verwendet 2 polyklonale Antikörper, welche an das NT-proBNP in Form eines Sandwiches binden (Collinson et al. 2004). Ein Biotin-gekoppelter Antikörper bindet an das N-terminale Epitop der Aminosäuren 1-21 und dient als Capture-Antikörper. Ein weiterer Rutheniumkomplex-gekoppelter Antikörper bindet an das zentrale Epitop der Aminosäuren 39-50 und stellt den Detection-Antikörper dar.

Danach werden in einem zweiten Schritt Streptavidin-beschichtete magnetische Mikropartikel hinzugegeben, welche an die Biotin-gekoppelten Antikörper binden.
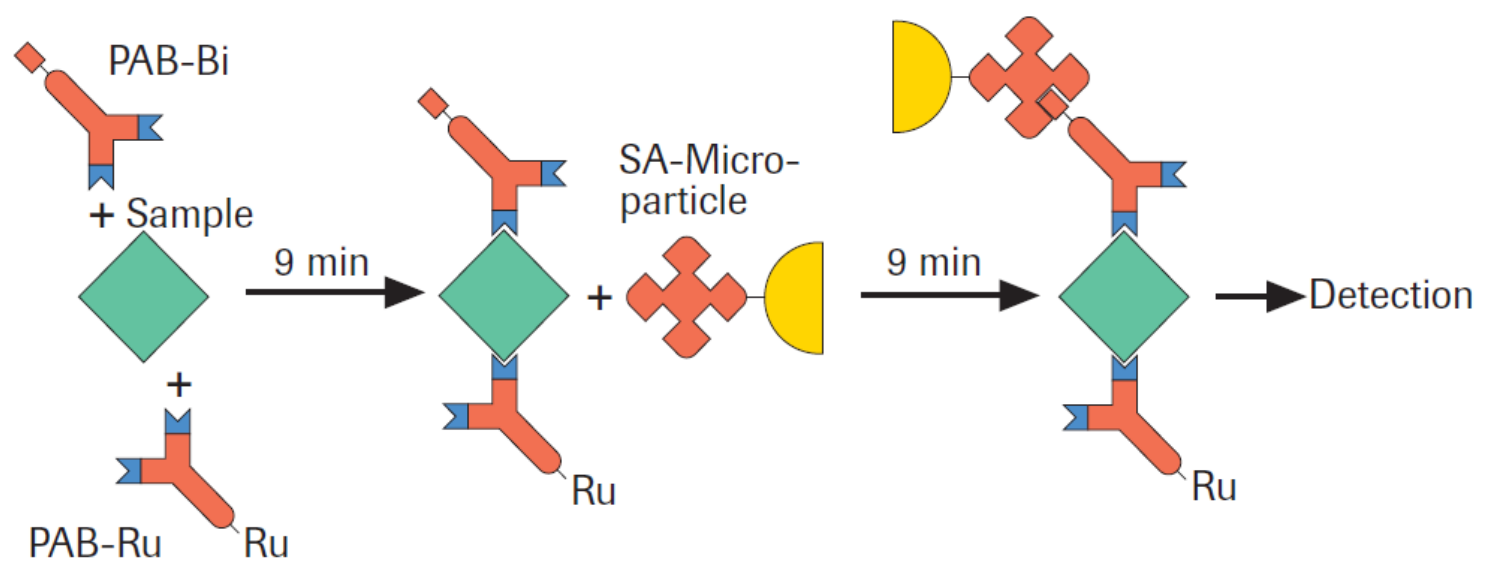

Abbildung 2: Die Funktionsweise von Elecsys $\AA$ proBNP wird schematisch dargestellt.

Danach wird die Probe in Messzellen gegeben, wo die magnetisch markierten Anteile von einem Magneten gebunden werden. Ungebundene Anteile werden anschließend ausgewaschen.

In einem letzten Schritt erfolgt nun die quantitative Messung von NTproBNP mithilfe des Detection-Antikörpers. Dabei wird in Gegenwart eines Puffers eine Spannung angelegt und das resultierende elektrochemiluminiszierende Signal wird mithilfe eines Photomultipliers gemessen.

Der Test weist eine gute analytische Performance auf (Sokoll et al. 2004). Der Vorteil dieses Verfahrens ist, dass durch den Einsatz von Antikörpern mit zwei verschiedenen Epitopen kleinere Spaltprodukte nicht erfasst werden. Hierdurch kann von genaueren Ergebnissen 
ausgegangen werden (Mueller et al. 2003). NTproBNP bleibt für mindestens ein Jahr stabil, wenn es bei $-80^{\circ} \mathrm{C}$ eingefroren und gelagert wurde (Nowatzke und Cole 2003). Vom Hersteller wird der Messbereich des Immunoassays mit 5-35000 pg/ml angegeben.

\subsubsection{ANP und MR-proANP}

ANP hat nur eine kurze Halbwertszeit, wodurch sich die Bestimmung von ANP selbst als fehleranfällig und aufwendig gestaltet. Daher werden Antikörper gegen Teile des langlebigeren Prohormons proANP eingesetzt.

In dieser Arbeit wurde ein immunoluminometrischer Assay der Firma B.R.A.H.H.S AG (Hennigsdorf, Deutschland) verwendet. Dabei sind die Antikörper dieses B.R.A.H.M.S SERISTRA® genannten Tests gegen die Aminosäuren 53-90 gerichtet, einen Teil der mittleren Region von proANP, welcher als MR-proANP bezeichnet wird (Morgenthaler et al. 2004). Die untere Nachweisgrenze wird vom Hersteller mit 6,0 pmol/l angegeben (Morgenthaler et. al 2004).

\subsubsection{Adrenomedullin und MR-proADM}

Bei der Synthese von Adrenomedullin entsteht aus dem Vorläufer präproAdrenomedullin das proAdrenomedullin. Die mittlere Region von proAdrenomedullin (MRproADM), welches aus den Aminosäuren 45-92 besteht, ist wesentlich stabiler als Adrenomedullin, welches lediglich eine kurze Halbwertszeit von ca. 22 Minuten hat (Meeran et al. 1997).

Daher ist MR-proADM das Ziel des in dieser Arbeit verwendeten immunoluminometrischen Assays. Der Test zur Bestimmung von MR-proADM wird als SEVADIL LIA® bezeichnet und von der Firma B.R.A.H.M.S. AG (Hennigsdorf, Deutschland) hergestellt. Die darin enthaltenen Antikörper richten sich gegen die Aminosäuren 68-86 bzw. 83-94. Der Messbereich dieses Tests reicht von 0,12-25 nmol// bei einer Sensitivität von $0,12 \mathrm{nmol} / \mathrm{l}$ (Morgenthaler et al. 2005).

\subsubsection{Endothelin-1 und CT-proET1}

Die Bestimmung von Endothelin-1 gestaltet sich durch die geringe Halbwertszeit von lediglich 1-2 Minuten (Weitzberg et. al 1991) als schwierig. Daher wird in der vorliegenden Arbeit das C-terminale Fragment von proEndothelin-1 (CT-proET1) bestimmt. Dieses Fragment unterliegt im Gegensatz zu Endothelin-1 keinem schnellen Umsatz (Struck et al. 2005). 
Verwendet wurde ein Verfahren der Firma B.R.A.H.M.S. (Hennigsdorf, Deutschland), genannt B.R.A.H.M.S. SEVACON LIA®. Hierbei kommt ein Sandwich-Assay zum Einsatz, welcher zwei polyklonale Antikörper gegen die Aminosäuren 168-212 des präproET-1 verwendet. Die untere Nachweisgrenze dieses Tests liegt bei 0,4 pmol/l (Papassotiriou et al. 2006).

\subsubsection{Vasopressin und CT-proAVP}

Auch bei der Messung von Vasopressin im Plasma besteht das Problem der Instabilität sowie der schnellen Eliminierung. Ferner liegen ca. 90\% des Vasopressins an Thrombozyten gebunden vor (Preibisz et al. 1983). Aus diesem Grund wird in der vorliegenden Arbeit das Copeptin als stöchiometrisches Äquivalent von Vasopressin gemessen. Bei Copeptin handelt es sich um den C-terminalen Teil des Vorläuferhormons von Vasopressin; daher wird es auch CT-proAVP genannt.

Zur Bestimmung von CT-proAVP wurde ein Sandwich-Assay der Firma B.R.A.H.M.S. AG (Hennigsdorf, Deutschland) verwendet. Dabei werden zwei polyklonale Antikörper verwendet, welche gegen die Aminosäuren 132-164 des präproVasopressins gerichtet sind. Der Hersteller gibt den Messbereich mit 2,25-1215 pmol/l an (Morgenthaler et al. 2006).

\subsection{Statistik}

Für die statistische Ausarbeitung wurde das Programm PASW Statistics in der Version 18.0 der Firma IBM SPSS Statistics eingesetzt.

Für die deskriptive Statistik wurde das Patientenkollektiv in Gruppen eingeteilt. Die Angabe der kategorischen Variablen erfolgte in Prozent. Bei kontinuierlichen Variablen mit schiefer Verteilung wurde der Median aufgeführt sowie das obere und untere Quartil. Die Ergebnisse wurden auf ganze Zahlen gerundet. Sofern dies angebracht schien, wurden einige Werte logarithmiert.

Um Gruppen miteinander zu vergleichen, wurden als nichtparametrischer Test der KruskalWallice-Test für kontinuierliche Variablen verwendet und der Chi-square-Test für kategorische Variablen. Um nach dem Schweregrad ihrer DD eingeteilte Gruppen hinsichtlich der gemessenen Konzentrationen von GDF-15 miteinander zu vergleichen, wurde der nichtparametrische Jonckheere-Terpstra-Test angewandt. Der Bivariate Pearsonsche Korrelationskoeffizient wurde verwendet, um zu untersuchen, ob sich erhobene Parameter möglicherweise untereinander beeinflussen. Allgemeine lineare Modelle wurden erstellt, um multi- 
variate Abhängigkeiten zu untersuchen. Die diagnostische Relevanz von GDF-15 sowie der anderen bestimmten Biomarker wurde mittels receiver operating characteristic-Kurven (ROC-Kurven) sowie der Fläche unter der Kurve (AUC) untersucht. Sensitivität, Spezifität und Odds ratio verschiedener Parameter für das Vorliegen einer HFPEF wurden berechnet. p-Werte $<0,05$ wurden als signifikant angesehen. 


\section{Ergebnisse}

\subsection{Deskriptive Statistik des Patientenkollektivs}

\subsubsection{Unterteilung des Patientenkollektivs}

Das Patientenkollektiv umfasst insgesamt 330 Patienten. Hiervon leiden 142 Patienten an HFPEF und 103 Patienten an DD. Die übrigen 85 Patienten wurden als Kontrollgruppe (KON) in das Patientenkollektiv aufgenommen. Diese Unterteilung in Patienten mit HFPEF, Patienten mit DD und in Kontrollen wird in den folgenden Tabellen zur besseren Übersicht beibehalten.

\subsubsection{Allgemeine und klinische Daten des Patientenkollektivs}

Die folgende Tabelle zeigt die grundlegenden Charakteristika des untersuchten Patientenkollektivs. Die Daten werden als Median [Interquartilsabstand] für stetige Variablen angegeben. Kategorische Variablen werden in ganzen Zahlen (Prozent) angegeben.

\begin{tabular}{|l|l|l|l|l|}
\hline & HFPEF & DD & KON & -Wert * \\
\hline Alter [Jahren] & $73[66 ; 78]$ & $61[54 ; 66] \#$ & $53[51 ; 56] \#$ & $<0,0005$ \\
\hline weibliches Geschlecht & $91(64 \%)$ & $61(59 \%)$ & $63(74 \%)$ & 0,097 \\
\hline BMI [kg/m²] & $30,1[26,7 ; 34,4]$ & $26,3[24,2 ; 29] \#$ & $23,9[21,8 ; 26,6] \#$ & $<0,0005$ \\
\hline RR systolisch [mmHg] & $147[130 ; 164]$ & $130[121 ; 143] \#$ & $124[117 ; 132] \#$ & $<0,0005$ \\
\hline RR diastolisch [mmHg] & $80[70 ; 90]$ & $80[73 ; 87]$ & $76[71 ; 83]$ & 0,087 \\
\hline Herzfrequenz [1/min] & $66[61 ; 74]$ & $74[68 ; 80] \#$ & $70[63 ; 77]$ & $<0,0005$ \\
\hline GFR [mL/min/1,73m²] & $64[53 ; 75]$ & $77[70 ; 92] \#$ & $79[769 ; 91] \#$ & $<0,0005$ \\
\hline
\end{tabular}

* p-Werte für die Unterschiede zwischen den 3 Gruppen, berechnet mit Kruskal-Wallis- bzw. Chi-square-Test

\# $\mathrm{p}<0,05$ vs. HFPEF, berechnet mit Bonferroni-adjustiertem Mann-Whitney-U oder Chisquare-Test

Tabelle 1: Die Tabelle zeigt die grundlegenden Charakteristika des untersuchten Patientenkollektivs. 


\subsubsection{Körperliche Leistungsfähigkeit und detaillierte Lebensqualität im Patientenkollektiv}

Die folgende Tabelle gibt Auskunft über die körperliche Leistungsfähigkeit im Patientenkollektiv. Aufgeführt sind der 6-Minuten-Gehtest sowie die einzelnen Subskalen des SF-36.

\begin{tabular}{|l|l|l|l|l|}
\hline & HFPEF & DD & KON & $p$-Wert * \\
\hline 6-Minuten-Gehtest & $431[344 ; 500]$ & $570[546 ; 600] \#$ & $598[570 ; 610] \#$ & $<0,0005$ \\
\hline SF-36 physische Funktion & $50[25 ; 70]$ & $95[80 ; 100] \#$ & $90[83 ; 97] \#$ & $<0,0005$ \\
\hline SF-36 körperliche Rollenfunktion & $25[0 ; 100]$ & $100[100 ; 100] \#$ & $100[100 ; 100] \#$ & $<0,0005$ \\
\hline SF-36 Schmerz & $51[31 ; 84]$ & $100[56 ; 100] \#$ & $92[74 ; 100] \#$ & $<0,0005$ \\
\hline SF-36 allgemeine Gesundheit & $50[42 ; 67]$ & $72[62 ; 81] \#$ & $77[72 ; 82] \#$ & $<0,0005$ \\
\hline SF-36 Vitalität & $45[30 ; 65]$ & $65[55 ; 75] \#$ & $70[56 ; 83] \#$ & $<0,0005$ \\
\hline SF-36 soziale Funktion & $75[63 ; 100]$ & $100[75 ; 100] \#$ & $88[63 ; 100]$ & 0,013 \\
\hline SF-36 emotionale Rollenfunktion & $100[0 ; 100]$ & $100[100 ; 100] \#$ & $100[33 ; 100]$ & 0,024 \\
\hline SF-36 psychisches Wohlbefinden & $72[56 ; 84]$ & $80[70 ; 88] \#$ & $82[62 ; 91]$ & 0,045 \\
\hline SF-36 Summenscore physisch & $36[28 ; 46]$ & $54[48 ; 56] \#$ & $54[51 ; 56] \#$ & $<0,0005$ \\
\hline SF-36 Summenscore psychisch & $53[42 ; 59]$ & $54[51 ; 57]$ & $55[45 ; 58]$ & 0,891 \\
\hline
\end{tabular}

* $p$-Werte für die Unterschiede zwischen den 3 Gruppen, berechnet mit Kruskal-Wallis-bzw. Chi-square-Test

\# $p<0,05$ vs. HFPEF, berechnet mit Bonferroni-adjustiertem Mann-Whitney-U oder Chisquare-Test.

Tabelle 2: Die Tabelle zeigt Parameter, welche über die körperliche Leistungsfähigkeit Auskunft geben. 


\subsubsection{Kardiovaskuläre Risikofaktoren im Patientenkollektiv}

In diesem Abschnitt werden die kardiovaskulären Risikofaktoren im Patientenkollektiv aufgeführt, soweit sie bei der Untersuchung bereits bekannt sind. Hierzu gehören: Diabetes mellitus, Hypertonie, Hyperlipidämie, koronare Herzkrankheit sowie Vorhofflimmern.

\begin{tabular}{|l|l|l|l|l|}
\hline & HFPEF & DD & KON & p-Wert * \\
\hline Diabetes mellitus & $43(30 \%)$ & $0(0 \%) \#$ & $0(0 \%) \#$ & $<0,0005$ \\
\hline Hypertonie & $132(93 \%)$ & $1(1 \%) \#$ & $0(0 \%) \#$ & $<0,0005$ \\
\hline Hyperlipidämie & $75(53 \%)$ & $0(0 \%) \#$ & $0(0 \%) \#$ & $<0,0005$ \\
\hline koronare Herzkrankheit & $49(35 \%)$ & $0(0 \%) \#$ & $0(0 \%) \#$ & $<0,0005$ \\
\hline Vorhofflimmern & $35(25 \%)$ & $1(1 \%) \#$ & $0(0 \%) \#$ & $<0,0005$ \\
\hline
\end{tabular}

* p-Werte für die Unterschiede zwischen den 3 Gruppen, berechnet mit Kruskal-Wallis- bzw. Chi-square-Test

\# $p<0,05$ vs. HFPEF, berechnet mit Bonferroni-adjustiertem Mann-Whitney-U oder Chisquare-Test

Tabelle 3: Die Tabelle zeigt die Häufigkeitsverteilung kardiovaskulärer Risikofaktoren im Patientenkollektiv. 


\subsubsection{Medikation im Patientenkollektiv}

In der folgenden Tabelle sind die Medikamente aufgeführt, welche aus einer kardiovaskulären Indikation heraus regelmäßig eingenommen werden.

\begin{tabular}{|l|l|l|l|l|}
\hline & HFPEF & DD & KON & p-Wert \\
\hline ACE-Hemmer & $69(49 \%)$ & $1(1 \%) \#$ & $0(0 \%) \#$ & $<0,0005$ \\
\hline AT 1 Rezeptor Blocker & $41(29 \%)$ & $0(0 \%) \#$ & $0(0 \%) \#$ & $<0,0005$ \\
\hline Aldosteronantagonisten & $7(5 \%)$ & $0(0 \%) \#$ & $0(0 \%) \#$ & 0,009 \\
\hline B-Blocker & $87(61 \%)$ & $1(1 \%) \#$ & $0(0 \%) \#$ & $<0,0005$ \\
\hline Thiazide & $69(49 \%)$ & $2(2 \%) \#$ & $0(0 \%) \#$ & $<0,0005$ \\
\hline Schleifendiuretika & $51(36 \%)$ & $0(0 \%) \#$ & $0(0 \%) \#$ & $<0,0005$ \\
\hline Digitalisglykoside & $21(15 \%)$ & $0(0 \%) \#$ & $0(0 \%) \#$ & $<0,0005$ \\
\hline Statine & $57(40 \%)$ & $0(0 \%) \#$ & $0(0 \%) \#$ & $<0,0005$ \\
\hline ASS & $58(41 \%)$ & $0(0 \%) \#$ & $1(1 \%) \#$ & $<0,0005$ \\
\hline
\end{tabular}

* p-Werte für die Unterschiede zwischen den 3 Gruppen, berechnet mit Kruskal-Wallis- bzw. Chi-square-Test

$\# p<0,05$ vs. HFPEF, berechnet mit Bonferroni-adjustiertem Mann-Whitney-U oder Chisquare-Test

Tabelle 4: Die Tabelle zeigt die Häufigkeitsverteilung verschiedener Substanzgruppen im Kollektiv. 


\subsubsection{Echokardiografische Parameter im Patientenkollektiv}

In diesem Abschnitt werden die echokardiographischen Parameter im Patientenkollektiv aufgeführt.

In der Patientengruppe mit HFPEF haben 48\% der Patienten eine DD vom Grad I, $28 \%$ eine DD vom Grad II oder III und bei $24 \%$ der Patienten war der Grad der DD aufgrund von Vorhofflimmern nicht messbar. In der Patientengruppe mit DD hatten 86\% der Patienten eine DD vom Grad I und 14\% der Patienten eine DD vom Grad II oder III. In der Kontrollgruppe hatte kein Patient eine DD.

\begin{tabular}{|l|l|l|l|l|}
\hline & HFPEF & DD & KON & p-Wert ${ }^{*}$ \\
\hline LVV-ED [mL] & $83,5[67,8 ; 109]$ & $86[69 ; 109]$ & $78[68 ; 94]$ & 0,115 \\
\hline LVV-ES [mL] & $33[25 ; 41]$ & $32[24 ; 44]$ & $29[24 ; 3,5] \#$ & 0.04 \\
\hline LVEF [\%] & $60[56 ; 65]$ & $61[56 ; 66]$ & $62[57 ; 68]$ & 0,509 \\
\hline Mitralisdoppler E-Welle [cm/s] & $83[68 ; 103]$ & $61[54 ; 76] \#$ & $7,5[66 ; 84] \#$ & $<0,0005$ \\
\hline Mitralisdoppler A-Welle [cm/s] & $87[71,5 ; 107,5]$ & $77[68 ; 86] \#$ & $57[51 ; 67] \#$ & $<0,0005$ \\
\hline Dezelerationszeit [ms] & $230[185 ; 300]$ & $245[220 ; 275]$ & $205[170 ; 225] \#$ & $<0,0005$ \\
\hline $\begin{array}{l}\text { Gewebedoppler lateral e'-Welle } \\
\text { [cm/s] }\end{array}$ & $7[5,5 ; 8,9]$ & $8,2[7,2 ; 10,3] \#$ & $11,5[9,8 ; 13,5] \#$ & $<0,0005$ \\
\hline $\begin{array}{l}\text { Gewebedoppler lateral a'-Welle } \\
\text { [cm/s] }\end{array}$ & $11[8,9 ; 12,3]$ & $12,4[10,3 ; 14,5] \#$ & $10,8[9,3 ; 12,5]$ & $<0,0005$ \\
\hline Gewebedoppler e'/a' & $0,6[0,5 ; 0,8]$ & $0,7[0,5 ; 0,9] \#$ & $1,1[0.8 ; 1,3] \#$ & $<0,0005$ \\
\hline Septumdicke (ED) [mm] & $13[12 ; 14]$ & $11[10 ; 12]$ & $10[9 ; 11]$ & $<0,0005$ \\
\hline Hinterwanddurchmesser (ED) [mm] $]$ & $12[11 ; 13]$ & $11[10 ; 11,7]$ & $10[9 ; 10]$ & $<0,0005$ \\
\hline E/A & $0,9[0,7 ; 1,1]$ & $0.8[0,7 ; 0,9]$ & $1,2[1,1 ; 1,4] \#$ & $<0,0005$ \\
\hline LVMI & $129[110,149]$ & $104[89 ; 118] \#$ & $92[83 ; 110] \#$ & $<0,0005$ \\
\hline LAVI & $30,8[23,9 ; 38,5]$ & $17,7[14,6 ; 21,3] \#$ & $17,5[13,1 ; 21,2] \#$ & $<0,0005$ \\
\hline E/E' lateral & $11,6[9,1 ; 14,5]$ & $7,5[6 ; 9,4] \#$ & $6,6[5,6 ; 8,1] \#$ & $<0,0005$ \\
\hline
\end{tabular}

* $p$-Werte für die Unterschiede zwischen den 3 Gruppen, berechnet mit Kruskal-Wallis- bzw. Chi-square-Test

$\# p<0,05$ vs. HFPEF, berechnet mit Bonferroni-adjustiertem Mann-Whitney-U oder Chisquare-Test

Tabelle 5: Die Tabelle zeigt die erhobenen echokardiografischen Parameter im Patientenkollektiv. 


\subsubsection{Neuropeptide im Patientenkollektiv}

In diesem Abschnitt werden verschiedene Neuropeptide aufgeführt, welche im Patientenkollektiv bestimmt wurden.

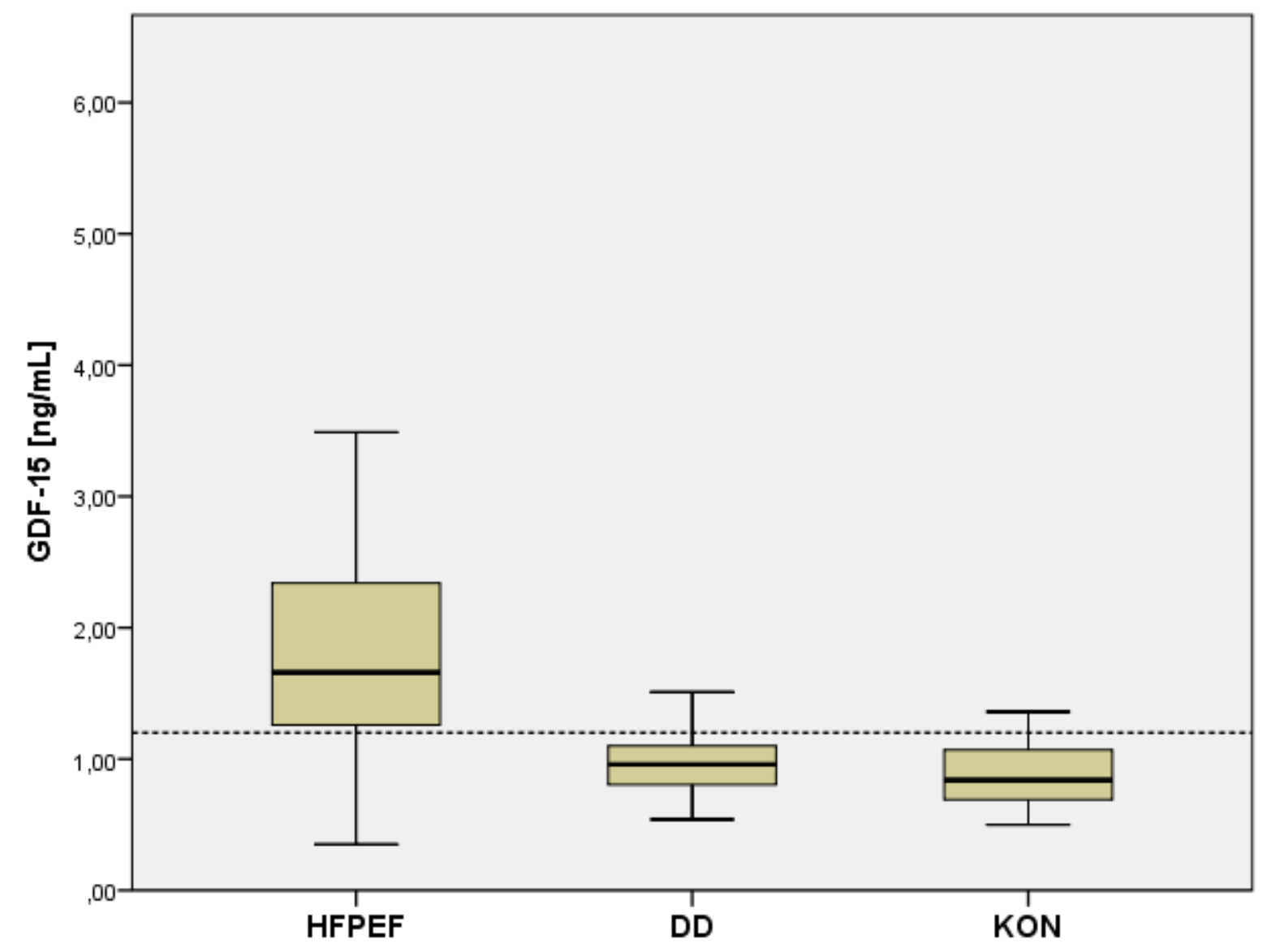

Abbildung 1: Auf der Ordinate sind die jeweiligen Serumkonzentrationen von GDF-15 für die HFPEF, DD und KON dargestellt. Die gestrichelte Linie stellt die obere Grenze des Normbereichs der Serumkonzentration von GDF-15 dar.

Es wird deutlich, dass die Serumkonzentration von GDF-15 bei Patienten mit HFPEF $(1,64$ $[1,24 ; 2,33] \mathrm{ng} / \mathrm{ml})$ im Vergleich zur Kontrollgruppe $(0,84[0,69 ; 1,1] \mathrm{ng} / \mathrm{ml})$ signifikant $(p<0,001)$ erhöht ist. Ebenfalls findet sich ein signifikanter $(p<0,001)$ Unterschied bei einem Vergleich von Patienten mit HFPEF und Patienten mit DD $(0,96[0,8 ; 1,1] \mathrm{ng} / \mathrm{ml})$. Auch der Unterschied bei einem Vergleich von Patienten mit DD und der Kontrollgruppe ist signifikant $(p=0,002)$. 
Der obere Normbereich der Serumkonzentration von GDF-15 endet bei 1,20 ng/ml (Kempf et al. 2007a). 79,5\% der Patienten mit HFPEF liegen über diesem Grenzwert.

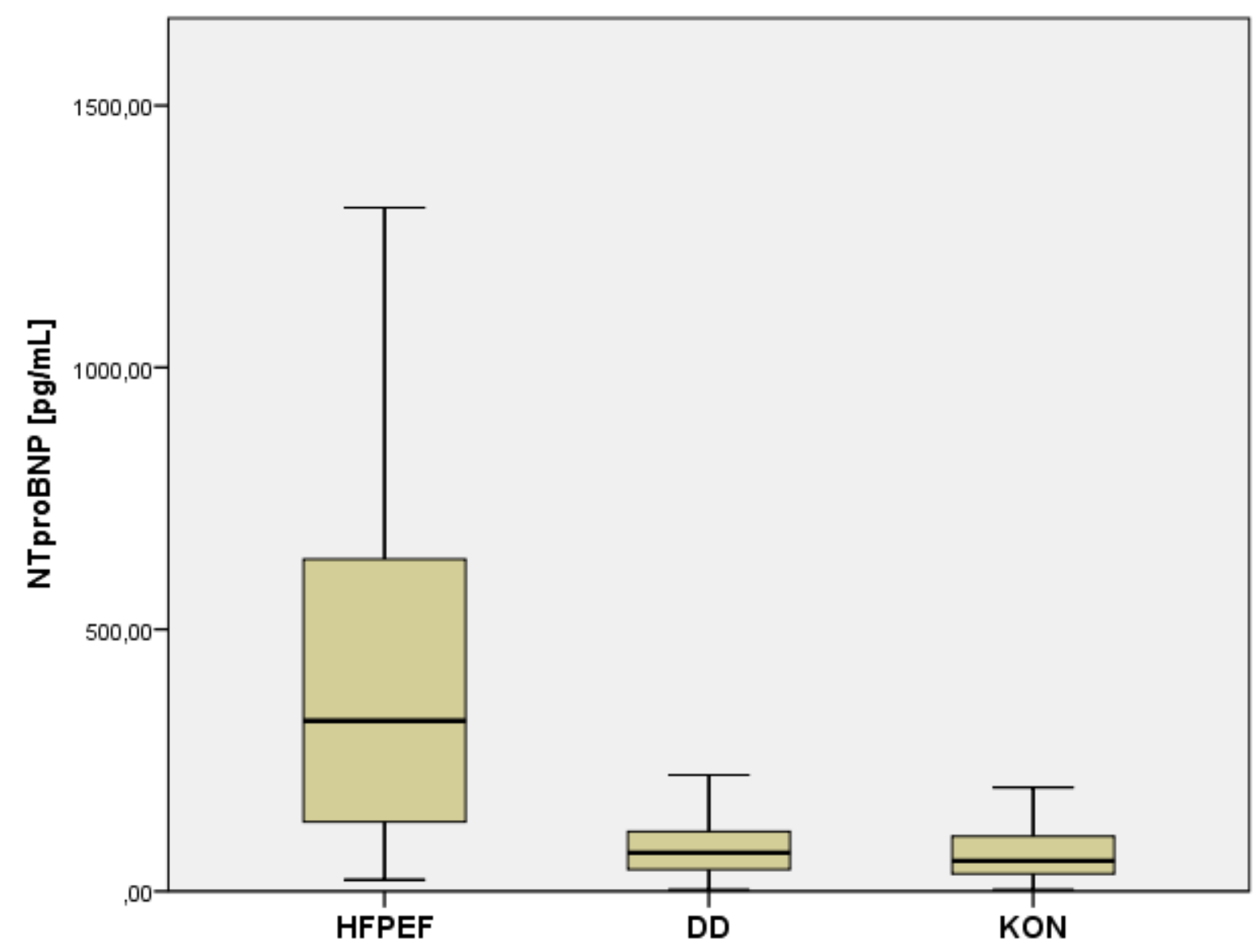

Abbildung 2: Auf der Ordinate sind die jeweiligen Serumkonzentrationen von NTproBNP für die HFPEF, DD und KON dargestellt.

Es wird deutlich, dass die Serumkonzentration von NTproBNP bei Patienten mit HFPEF (320 [126; 588] pg/ml) im Vergleich zur Kontrollgruppe (58 [33; 106] ng/ml) signifikant $(p<0,001)$ erhöht ist. Auch im Vergleich mit den Patienten mit DD $(74[41 ; 114] \mathrm{ng} / \mathrm{ml})$ weisen die Patienten mit HFPEF signifikant $(p<0,001)$ höhere Serumkonzentrationen von NTproBNP auf. 


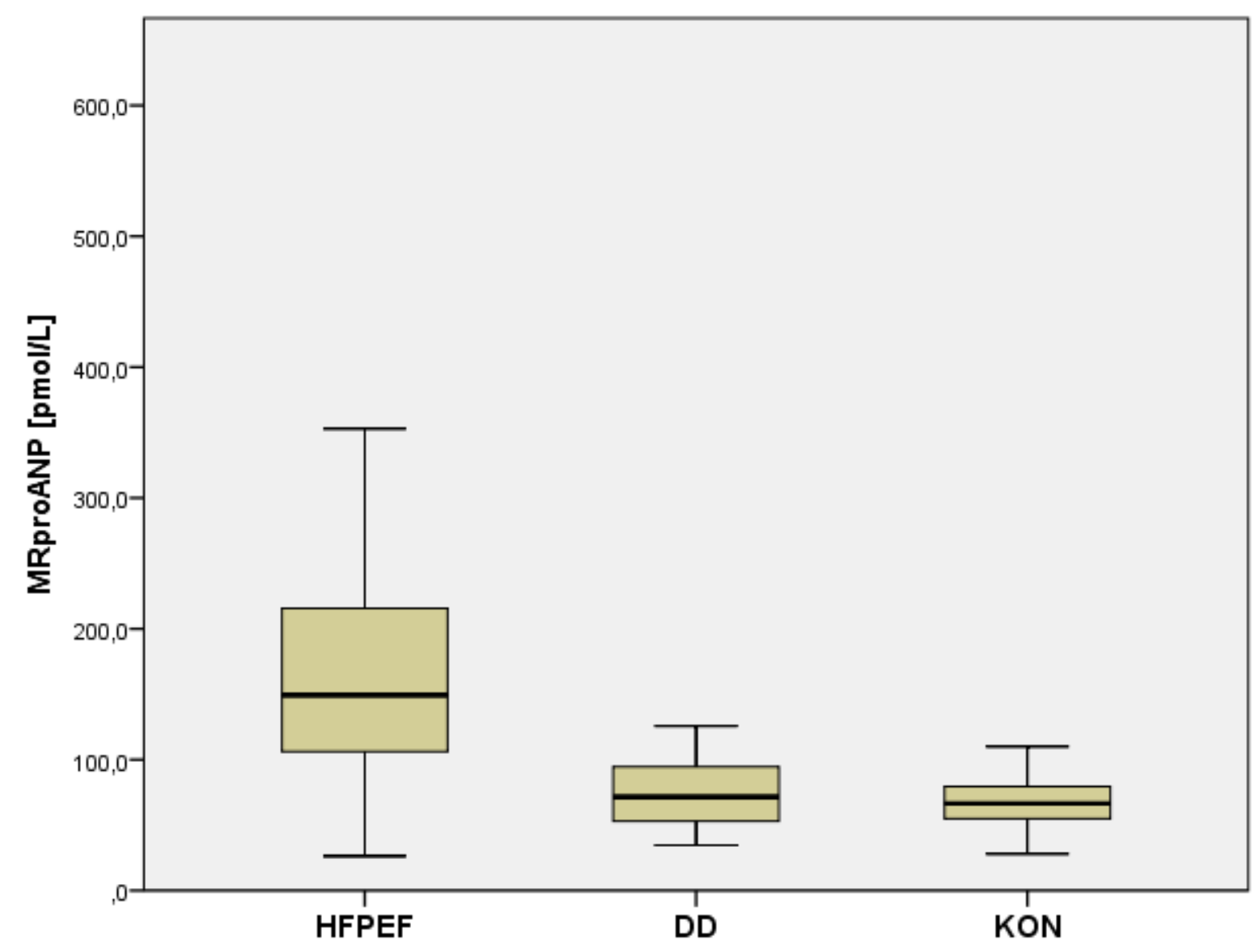

Abbildung 3: Auf der Ordinate sind die jeweiligen Serumkonzentrationen von MRproANP für die HFPEF, DD und KON dargestellt.

Es wird deutlich, dass die Serumkonzentration von MRproANP bei Patienten mit HFPEF (143 [102; 199] pmol/L) im Vergleich zur Kontrollgruppe (66 [55; 80] pmol/l) signifikant $(p<0,001)$ erhöht ist und auch im Vergleich zu Patienten mit DD $(71[52 ; 97]$ pmol/l) signifikant $(p<0,001)$ erhöht ist. 


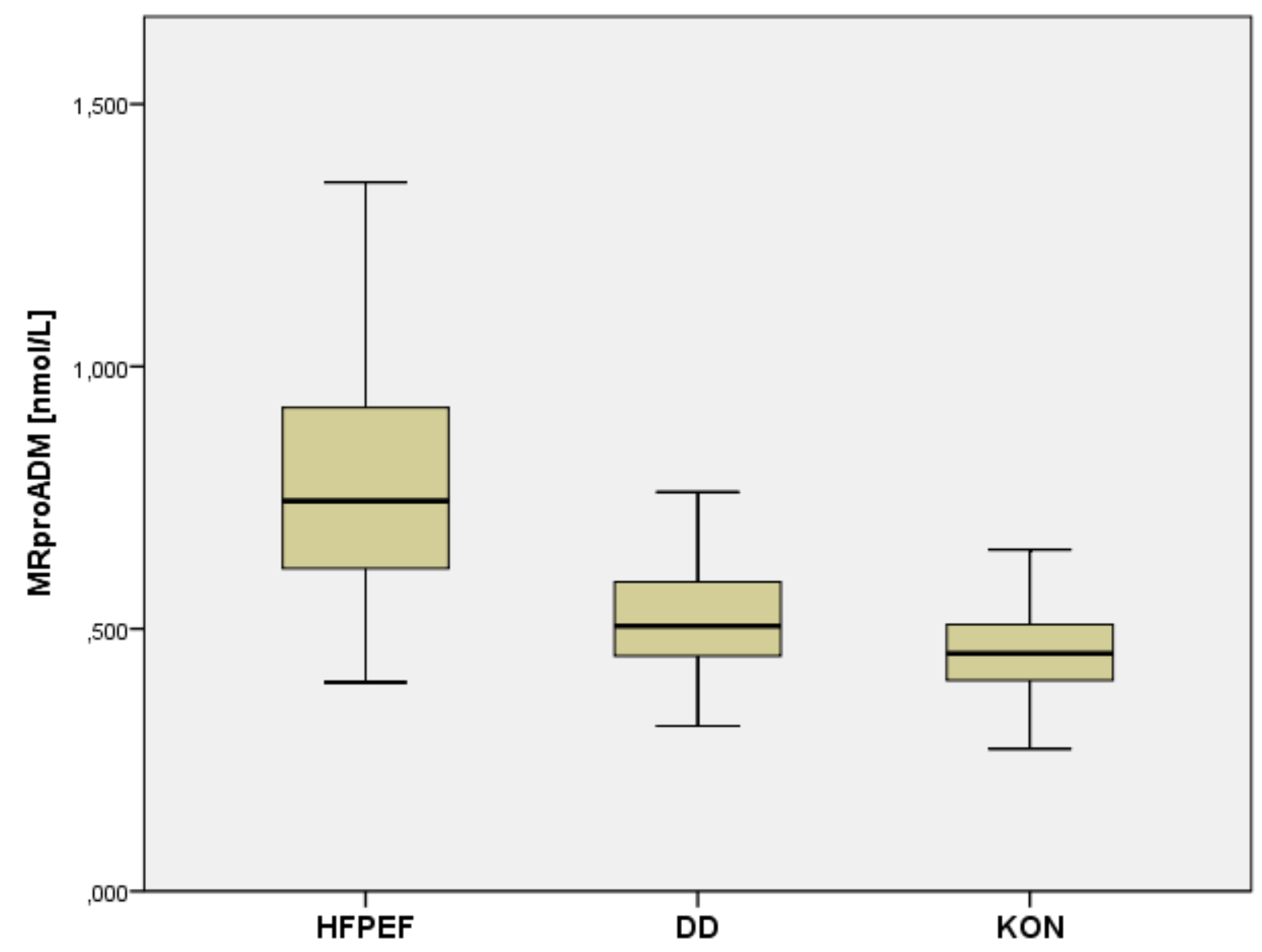

Abbildung 4: Auf der Ordinate sind die jeweiligen Serumkonzentrationen von MRproADM für HFPEF, DD und KON dargestellt.

Es wird deutlich, dass die Serumkonzentration von MRproADM bei Patienten mit HFPEF $(0,75[0,62 ; 0,91] \mathrm{ng} / \mathrm{ml})$ sowohl im Vergleich zur Kontrollgruppe $(0,45[0,4 ; 0,51] \mathrm{ng} / \mathrm{ml})$ als auch im Vergleich zu den Patienten mit DD $(0,51[0,45 ; 0,59] \mathrm{ng} / \mathrm{ml})$ signifikant $(p<0,001)$ erhöht ist. 


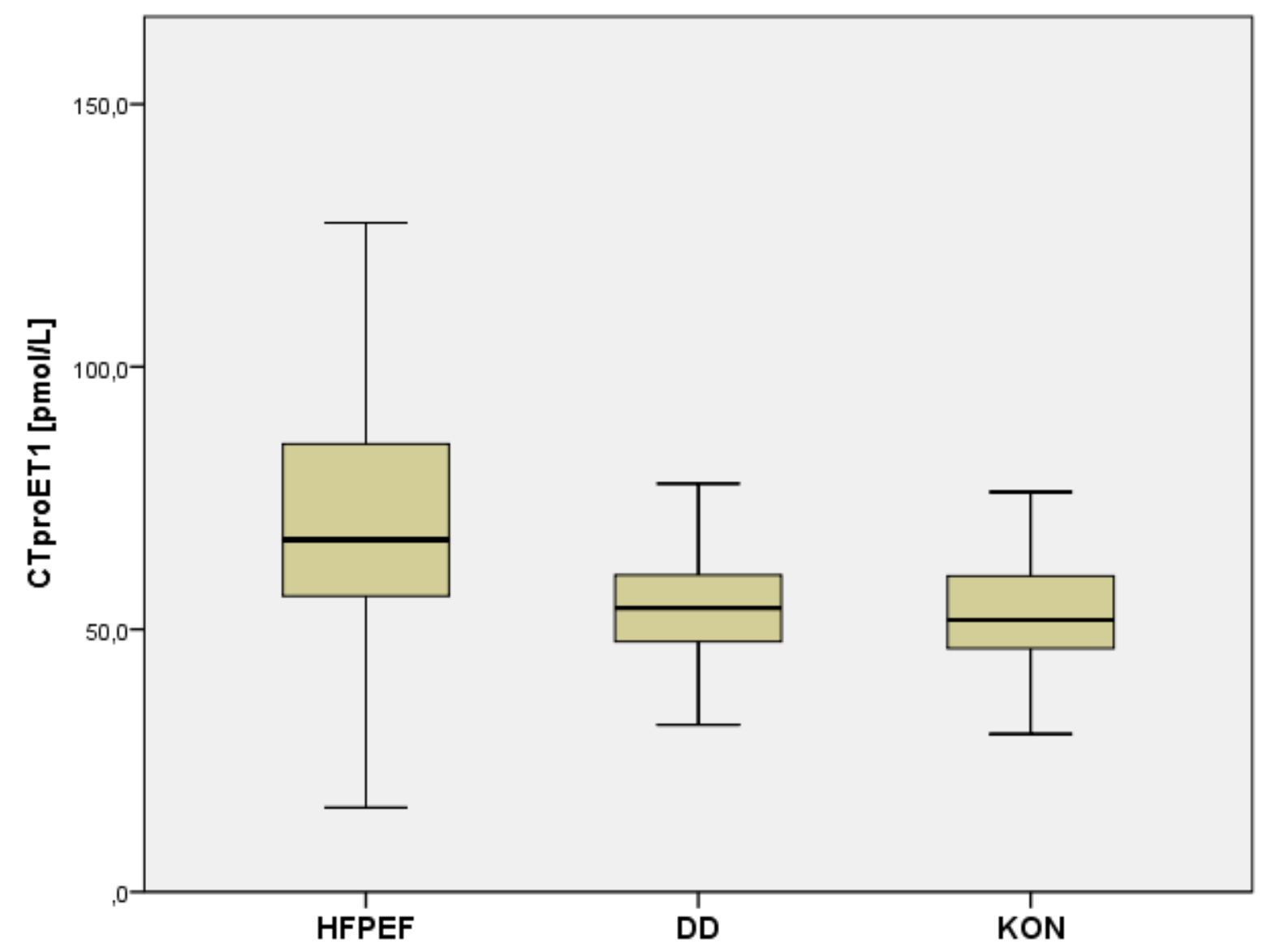

Abbildung 5: Auf der Ordinate sind die jeweiligen Serumkonzentrationen von CTproET1 für HFPEF, DD und KON dargestellt.

Die Serumkonzentration von CTproET1 bei Patienten mit HFPEF (65 [56; $83 \mathrm{ng} / \mathrm{ml})$ ist sowohl im Vergleich zur Kontrollgruppe (52 [46; 60] $\mathrm{ng} / \mathrm{ml}$ ) als auch im Vergleich zu den Patienten mit DD $(54[47 ; 61] \mathrm{ng} / \mathrm{ml})$ signifikant $(p<0,001)$ erhöht. 


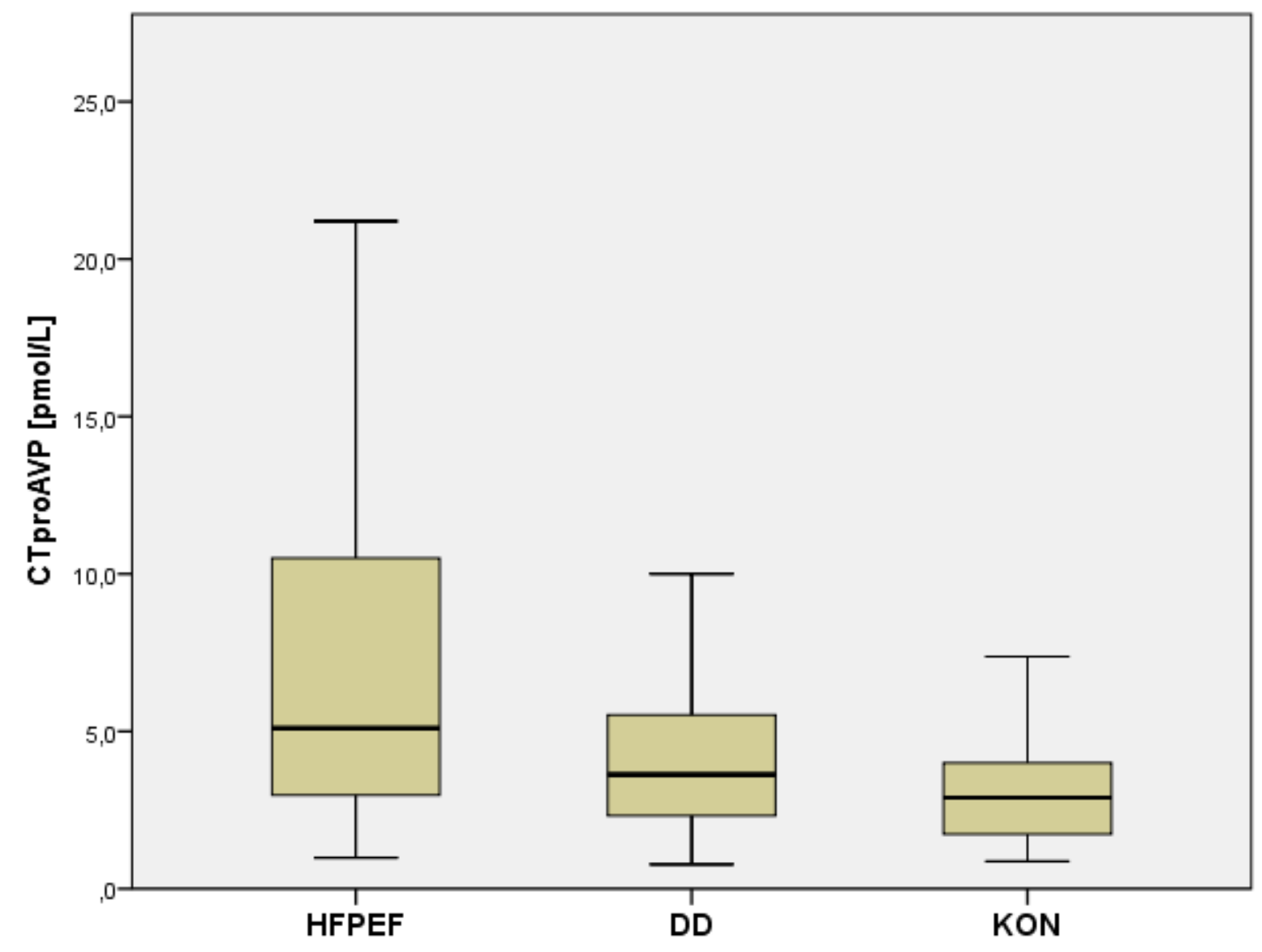

Abbildung 6: Auf der Ordinate sind die jeweiligen Serumkonzentrationen von CTproAVP für HFPEF, DD und KON dargestellt.

Hier wird deutlich, dass die Serumkonzentration von CTproAVP bei Patienten mit HFPEF $(5,3[3,1 ; 10,2] \mathrm{pmol} / \mathrm{l})$ sowohl im Vergleich zur Kontrollgruppe $(2,9[1,7 ; 4,1] \mathrm{pmol} / \mathrm{l})$ als auch im Vergleich zu den Patienten mit DD $(3,6[2,3 ; 5,8]$ pmol/l) signifikant $(p<0,001)$ erhöht ist. 


\subsection{Ergebnisse der speziellen Laboranalytik}

\subsubsection{Bivariate Korrelation von GDF-15 und demografischen sowie klinischen Faktoren}

Um diese unterschiedlichen Serumkonzentrationen von GDF-15 in den verschiedenen Gruppen bewerten zu können, wurde zunächst untersucht, welche der erhobenen Daten des Patientenkollektivs in einem möglichen Zusammenhang mit GDF-15 stehen.

Hierzu wurde der Korrelationskoeffizient nach Pearson berechnet. Zusätzlich wurde ein Konfidenzintervall auf einem Niveau von 95\% gebildet. Die GDF-15-Serumkonzentrationen wurden logarithmiert.

Zunächst wurden allgemeine und klinische Daten sowie Laborparameter untersucht. Ein starker gruppenübergreifender Zusammenhang fand sich zwischen einem höheren log GDF15 und steigendem Alter. Ein weiterer gruppenübergreifender inverser Zusammenhang findet sich zwischen einem erhöhten log GDF-15 und der GFR. 


\begin{tabular}{|c|c|c|c|c|}
\hline & HFPEF, DD, KON & HFPEF & DD & KON \\
\hline Alter & $0,705[0,651 ; 0,757]^{\star *}$ & $0,481[0,341 ; 0,593]^{\star *}$ & $0,352[0,072 ; 0,558]^{*}$ & $\begin{array}{l}-0,304[0,006 ; \\
0,570]^{*}\end{array}$ \\
\hline $\begin{array}{l}\text { weibliches } \\
\text { Geschlecht }\end{array}$ & $-0,160[-0,280 ;-0,027]^{*}$ & $\begin{array}{l}-0,192[-0,361 ;- \\
0,006]^{\star}\end{array}$ & $\begin{array}{l}-0,346[-0,581 ;- \\
0,049]^{*}\end{array}$ & $\begin{array}{l}-0,026[-0,300 ; \\
0,233]\end{array}$ \\
\hline BMI & $0,251[0,142 ; 0,382]^{\star *}$ & $-0,081[-0,236 ; 0,093]$ & $0,169[-0,082 ; 0,368]$ & $\begin{array}{l}-0,127[-0,364 ; \\
0,097]\end{array}$ \\
\hline RR systolisch & $0,393[0,297 ; 0,497]^{\star \star}$ & $0,124[-0,055 ; 0,266]$ & $0,230[-0,081 ; 0,462]$ & $\begin{array}{l}0,219[-0,101 ; \\
0,500]\end{array}$ \\
\hline RR diastolisch & $0,008[-0,133 ; 0,162]$ & $-0,019[-0,222 ; 0,171]$ & $0,165[-0,127 ; 0,404]$ & $\begin{array}{l}-0,156[-0,515 ; \\
0,239]\end{array}$ \\
\hline $\begin{array}{l}\text { Herzfrequenz } \\
\text { (Ruhe) }\end{array}$ & $-0,036[-0,181 ; 0,103]$ & $0,162[-0,015 ; 0,314]$ & $\begin{array}{l}-0,276[-0,544 ; \\
0,033]\end{array}$ & $\begin{array}{l}-0,065[-0,276 ; \\
0,159]\end{array}$ \\
\hline GFR & $-0,414[-0,577 ;-0,236]^{* *}$ & $\begin{array}{l}-0,275[-0,516 ;- \\
0,008]^{\star \star}\end{array}$ & $\begin{array}{l}-0,114[-0,301 \\
0,118]\end{array}$ & $\begin{array}{l}-0,129[-0,391 ; \\
0,095]\end{array}$ \\
\hline LDL-Cholesterin & $-0,159[-0,305 ;-0,013]^{*}$ & $\begin{array}{l}-0,222[-0,417 ;- \\
0,013]^{\star}\end{array}$ & $\begin{array}{l}-0,161[-0,405 \\
0,110]\end{array}$ & $\begin{array}{l}-0,087[-0,274 ; \\
0,121]\end{array}$ \\
\hline HDL-Cholesterin & $-0,202[-0,342 ;-0,065]^{* *}$ & $-0,091[-0,260 ; 0,025]$ & $\begin{array}{l}-0,153[-0,364 ; \\
0,108]\end{array}$ & $\begin{array}{l}-0,143[-0,412 ; \\
0,138]\end{array}$ \\
\hline Total Cholesterin & $-0,243[-0,377 ;-0,087]^{\star *}$ & $\begin{array}{l}-0,240[-0,423 ;- \\
0,050]^{\star *}\end{array}$ & $\begin{array}{l}-0,254[-0,465 ;- \\
0,009]\end{array}$ & $\begin{array}{l}-0,134[-0,346 \\
0,108]\end{array}$ \\
\hline Harnsäure & $0,374[0,226 ; 0,503]^{\star *}$ & $0,140[-0071 ; 0,327]$ & $\begin{array}{l}0,404[0,095 \\
0,630]^{\star *}\end{array}$ & $\begin{array}{l}0,119[-0,114 ; \\
0,381]\end{array}$ \\
\hline
\end{tabular}

Tabelle 6: Dargestellt sind die Korrelationskoeffizienten [Konfidenzintervalle] zwischen log GDF-15 und verschiedenen erhobenen Daten.

* Die Korrelationskoeffizienten sind auf einem Niveau von $p<0,05$ signifikant.

${ }^{* *}$ Die Korrelationskoeffizienten sind auf einem Niveau von $p<0,01$ signifikant. 


\subsubsection{Bivariate Korrelation von GDF-15 und körperlicher Leistungs- fähigkeit sowie Lebensqualität}

Im Folgenden wurden Parameter betrachtet, welche die körperliche Leistungsfähigkeit und die Lebensqualität abbilden.

Eine geringere körperliche Leistungsfähigkeit scheint gruppenübergreifend mit einem höheren log GDF-15 einherzugehen, was sich aus dem starken inversen Zusammenhang von log GDF-15 und der zurückgelegten Gehstrecke des 6-Minuten-Gehtests bzw. der niedrigeren SF-36 Punktzahl ergibt.

\begin{tabular}{|l|l|l|l|l|}
\hline & HFPEF, DD, KON & HFPEF & DD & KON \\
\hline \multirow{2}{*}{ 6-Minuten-Gehtest } & $-0,418[-0,570 ;-$ & $0,170[-0,399 ;$ & $0,179[-0,182 ;$ & $-0,101[-0,807 ;$ \\
& $0,254]^{\star *}$ & $0,072]$ & $0,495]$ & $0,632]$ \\
\hline SF-36 physische Funktion & $-0,389[-0,529 ;-$ & $-0,138[-0,330 ;$ & $0,265[-0,103 ;$ & $-0,099[-0,849 ;$ \\
& $0,236]^{* *}$ & $0,077]$ & $0,579]$ & $0,926]$ \\
\hline SF-36 körperliche & $-0,282[-0,454 ;-$ & $-0,004[-0,234 ;$ & $0,105[-0,327 ;$ & $-0,387[-0,933 ;-$ \\
Rollenfunktion & $0,108]^{\star *}$ & $0,230]$ & $0,470]$ & $0,126]$ \\
\hline SF-36 Schmerz & $-0,316[-0,449 ;-$ & $-0,163[-0,333 ;$ & $0,142[-0,267 ;$ & $0,280[-0,548 ;$ \\
& $0,171]^{* *}$ & $0,049]$ & $0,511]$ & $0,935]$ \\
\hline SF-36 allgemeine Gesundheit & $-0,343[-0,485 ;-$ & $-0,127[-0,309 ;$ & $-0,019[-0,399 ;$ & $-0,303[-0,989 ;$ \\
& $0,195]^{\star *}$ & $0,060]$ & $0,330]$ & $0,754]$ \\
\hline SF-36 Vitalität & $-0,277[-0,433 ;-$ & $-0,069[-0,290 ;$ & $-0,208[-0,502 ;$ & $0,274[-0,491 ;$ \\
& $0,106]^{\star *}$ & $0,180]$ & $0,138]$ & $0,928]$ \\
\hline SF-36 soziale Funktion & $-0,080[-0,261 ;$ & $0,060[-0,179 ;$ & $-0,221[-0,462 ;$ & $-0,026[-0,832 ;$ \\
& $0,089]$ & $0,286]$ & $0,073]$ & $0,778]$ \\
\hline SF-36 emotionale & $-0,128[-0,308 ;$ & $0,024[-0,189 ;$ & $-0,143[-0,373 ;$ & $0,136[-0,601 ;$ \\
Rollenfunktion & $0,053]$ & $0,240]$ & $0,147]$ & $0,748]$ \\
\hline SF-36 psychisches & $-0,085[-0,276 ;$ & $0,057[-0,190 ;$ & $0,000[-0,304 ;$ & $0,030[-0,767 ;$ \\
Wohlbefinden & $0,099]$ & $0,290]$ & $0,424]$ & $0,726]$ \\
\hline SF-36 Summenscore & $-0,409[-0,533 ;-$ & $-0,166[-0,342 ;$ & $0,219[-0,237 ;$ & $-0,115[-0,952 ;$ \\
physisch & $0,283]^{\star *}$ & $0,037]$ & $0,540]$ & $0,906]$ \\
\hline SF-36 Summenscore & $-0,001[-0,184 ;$ & $0,094[-0,159 ;$ & $-0,202[-0,434 ;$ & $0,120[-0,654 ;$ \\
psychisch & $0,174]$ & $0,322]$ & $0,074]$ & $0,921]$ \\
\hline
\end{tabular}

Tabelle 7: Dargestellt sind die Korrelationskoeffizienten [Konfidenzintervalle] zwischen log GDF-15 und verschiedenen erhobenen Daten.

* Die Korrelationskoeffizienten sind auf einem Niveau von $p<0,05$ signifikant.

** Die Korrelationskoeffizienten sind auf einem Niveau von $p<0,01$ signifikant. 


\subsubsection{Bivariate Korrelation von GDF-15 und der linksventrikulären Morphologie sowie systolischer und diastolischer Funktion}

Ebenfalls untersucht wurden die erhobenen Echoparameter. Auch hier fanden sich teils deutliche Zusammenhänge zwischen log GDF-15 und Echoparametern, die über die diastolische bzw. die systolische Funktion des Herzens Auskunft geben. Besonders deutliche Korrelationen fanden sich gruppenübergreifend für LAVI, LVMI und E/E'. Inverse Korrelationen fanden sich für e' und e'/a'. Diese Echoparameter sind für die Beurteilung der diastolischen Funktion bedeutsam.

\begin{tabular}{|c|c|c|c|c|}
\hline & HFPEF, DD, KON & HFPEF & DD & KON \\
\hline LVV-ED [ml] & $0,044[-0,077 ; 0,159]$ & $\begin{array}{l}-0,005[-0,285 \\
0,251]\end{array}$ & $\begin{array}{l}0,145[-0,056 ; \\
0,340]\end{array}$ & $\begin{array}{l}-0,122[-0,358 \\
0,077]\end{array}$ \\
\hline LVV-ES [ml] & $0,057[-0,057 ; 0,179]$ & $\begin{array}{l}-0,046[-0,285 \\
0,184]\end{array}$ & $\begin{array}{l}0,074[0,136 ; \\
0,285]\end{array}$ & $\begin{array}{l}-0,076[-0,334 ; \\
0,143]\end{array}$ \\
\hline LVEF [\%] & $-0,043[-0,188 ; 0,094]$ & $\begin{array}{l}-0,063[-0,349 \\
0,215]\end{array}$ & $\begin{array}{l}-0,018[-0,201 \\
0,176]\end{array}$ & $\begin{array}{l}0,045[-0,179 ; \\
0,280]\end{array}$ \\
\hline Mitralisdoppler E-Welle [cm/s] & $0,126[0,000 ; 0,244]$ & $\begin{array}{l}0,071[-0,172 \\
0,293]\end{array}$ & $\begin{array}{l}-0,129[-0,330 \\
0,073]\end{array}$ & $\begin{array}{l}-0,086[-0,269 \\
0,114]\end{array}$ \\
\hline Mitralisdoppler A-Welle [cm/s] & $0,355[0,220 ; 0,475]^{* *}$ & $\begin{array}{l}0,196[- \\
0,060 ; 0,438]\end{array}$ & $\begin{array}{l}0,022[-0,172 ; \\
0,252]\end{array}$ & $\begin{array}{l}-0,032[-0,241 ; \\
0,200]\end{array}$ \\
\hline Dezelerationszeit [ms] & $0,252[0,130 ; 0,365]^{\star *}$ & $\begin{array}{l}0,066[-0,167 ; \\
0,281]\end{array}$ & $\begin{array}{l}0,153[-0,054 ; \\
0,346]\end{array}$ & $\begin{array}{l}0,016[-0,205 ; \\
0,245]\end{array}$ \\
\hline $\begin{array}{l}\text { Gewebedoppler lateral e'-Welle } \\
{[\mathrm{cm} / \mathrm{s}]}\end{array}$ & $\begin{array}{l}-0,378[-0,474 ;- \\
0,274]^{\star *}\end{array}$ & $\begin{array}{l}-0,054[-0,265 ; \\
0,183]\end{array}$ & $\begin{array}{l}-0,034[-0,232 ; \\
0,173]\end{array}$ & $\begin{array}{l}-0,082[-0,309 \\
0,137]\end{array}$ \\
\hline $\begin{array}{l}\text { Gewebedoppler lateral a'-Welle } \\
{[\mathrm{cm} / \mathrm{s}]}\end{array}$ & $-0,037[-0,152 ; 0,067]$ & $\begin{array}{l}0,217[-0,005 ; \\
0,430]\end{array}$ & $\begin{array}{l}-0,038[-0,228 \\
0,160]\end{array}$ & $\begin{array}{l}-0,010[-0,211 ;- \\
0,189]\end{array}$ \\
\hline Gewebedoppler e'/a' & $\begin{array}{l}-0,252[-0,384 ;- \\
0,128]^{\star \star}\end{array}$ & $\begin{array}{l}-0,159[-0,376 ; \\
0,080]\end{array}$ & $\begin{array}{l}-0,026[-0,205 ; \\
0,141]\end{array}$ & $\begin{array}{l}0,009[-0,289 \\
0,223]\end{array}$ \\
\hline Septumdicke (ED) [mm] & $0,416[0,316 ; 0,512]^{\star *}$ & $\begin{array}{l}0,158[-0,056 ; \\
0,369]\end{array}$ & $\begin{array}{l}0,191[0,008 ; \\
0,350]\end{array}$ & $\begin{array}{l}-0,108[-0,375 ; \\
0,163]\end{array}$ \\
\hline $\begin{array}{l}\text { Hinterwanddurchmesser (ED) } \\
{[\mathrm{mm}]}\end{array}$ & $0,351[0,228 ; 0,457]^{\star *}$ & $\begin{array}{l}0,173[-0,031 ; \\
0,377]\end{array}$ & $\begin{array}{l}0,136[-0,061 ; \\
0,325]\end{array}$ & $\begin{array}{l}-0,135[-0,394 \\
0,150]\end{array}$ \\
\hline$E / A$ & $-0,139[-0,271 ; 0,001]^{*}$ & $\begin{array}{l}-0,045[-0,274 \\
0,166]\end{array}$ & $\begin{array}{l}-0,136[-0,345 ; \\
0,075]\end{array}$ & $\begin{array}{l}-0,006[-0,223 \\
0,200]\end{array}$ \\
\hline LVMI & $0,295[0,181 ; 0,408]^{\star *}$ & $\begin{array}{l}-0,038[-0,257 ; \\
0,192]\end{array}$ & $\begin{array}{l}0,181[-0,041 \\
0,383]\end{array}$ & $\begin{array}{l}-0,147[-0,403 \\
0,077]\end{array}$ \\
\hline LAVI & $0,323[0,220 ; 0,429]^{\star *}$ & $\begin{array}{l}-0,120[-0,357 \\
0,101]\end{array}$ & $\begin{array}{l}0,114[-0,113 ; \\
0,326]\end{array}$ & $\begin{array}{l}-0,130[-0,359 \\
0,095]\end{array}$ \\
\hline E/E' lateral & $0,374[0,280 ; 0,483]^{\star *}$ & $\begin{array}{l}0,025[-0,144 ; \\
0,260]\end{array}$ & $\begin{array}{l}-0,040[-0,273 \\
0,187]\end{array}$ & $\begin{array}{l}0,049[-0,171 ; \\
0,282]\end{array}$ \\
\hline
\end{tabular}

Tabelle 8: Dargestellt sind die Korrelationskoeffizienten [Konfidenzintervalle] zwischen log GDF-15 und den verschiedenen Echoparametern.

* Die Korrelationskoeffizienten sind auf einem Niveau von $p<0,05$ signifikant.

** Die Korrelationskoeffizienten sind auf einem Niveau von $p<0,01$ signifikant. 


\subsubsection{Bivariate Korrelation von GDF-15 und Neuropeptiden}

Schließlich wurde untersucht, ob ein Zusammenhang zwischen log GDF-15 und den bestimmten Neuropeptiden besteht. Die Neuropeptide wurden zu diesem Zweck ebenfalls logarithmiert.

Hier stellten sich gruppenübergreifend signifikante Zusammenhänge zwischen log GDF-15 und allen bestimmten Neuropeptiden dar.

\begin{tabular}{|l|l|l|l|l|}
\hline & HFPEF, DD, KON & HFPEF & DD & KON \\
\hline log NTproBNP & $0,563[0,477 ; 0,636]^{* *}$ & $0,322[0,148 ; 0,472]^{* *}$ & $0,149[-0,055 ; 0,343]$ & $0,201[0,020 ; 0,402]$ \\
\hline $\log$ MRproANP & $0,516[0,398 ; 0,620]^{* *}$ & $0,214[-0,023 ; 0,437]^{*}$ & $0,110[-0,098 ; 0,319]$ & $0,104[0,111 ; 0,306]$ \\
\hline $\log$ MRproADM & $0,673[0,570 ; 0,754]^{* *}$ & $0,466[0,287 ; 0,651]^{\star *}$ & $0,202[0,003 ; 0,400]^{\star}$ & $0,500[0,345 ; 0,635]^{\star *}$ \\
\hline $\log$ CTproET1 & $0,520[0,402 ; 0,635]^{* *}$ & $0,485[0,283 ; 0,670]^{* *}$ & $0,043[-0,134 ; 0,230]$ & $0,364[0,213 ; 0,640]^{* *}$ \\
\hline $\log$ CTproAVP & $0,413[0,289 ; 0,521]^{* *}$ & $0,282[0,088 ; 0,494]^{\star *}$ & $0,321[0,093 ; 0,525]^{\star *}$ & $0,142[-0,081 ; 0,326]$ \\
\hline
\end{tabular}

Tabelle 9: Dargestellt sind die Korrelationskoeffizienten [Konfidenzintervalle] zwischen log GDF-15 und den verschiedenen Neuropeptiden.

* Die Korrelationskoeffizienten sind auf einem Niveau von $p<0,05$ signifikant.

** Die Korrelationskoeffizienten sind auf einem Niveau von $p<0,01$ signifikant. 


\subsection{Zusammenhang zwischen GDF-15 und dem Grad der diastolischen Funktion, echokardiographischen Para- metern sowie der körperlichen Leistungsfähigkeit und Lebensqualität im Gesamtkollektiv}

Zur Untersuchung des Zusammenhangs von GDF-15 und dem Grad der diastolischen Dysfunktion wurde der Jonckheere-Terpstra-Test verwendet. Hierbei ergab sich ein auf einem Niveau von $p<0,001$ signifikanter Zusammenhang zwischen erhöhten Serumkonzentrationen von GDF-15 und dem Grad der diastolischen Dysfunktion. In der folgenden Grafik wird dieser Zusammenhang verdeutlicht.

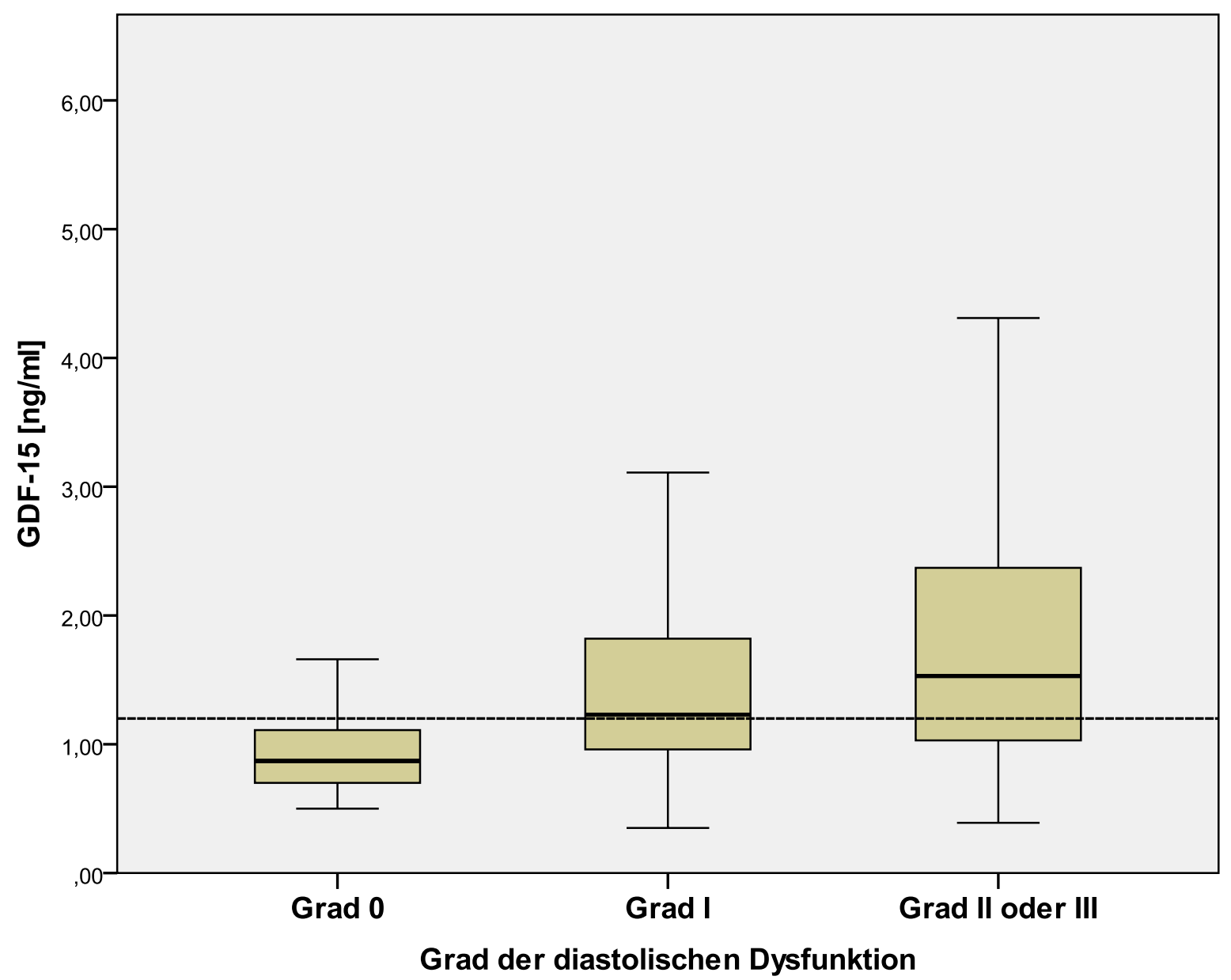

Abbildung 7: Auf der Ordinate sind die Serumkonzentrationen von GDF-15 für die unterschiedlichen Grade der diastolischen Dysfunktion abgebildet. Grad II und Grad III der diastolischen Dysfunktion wurden zusammengefasst. Die gestrichelte Linie stellt die obere Grenze des Normbereichs der Serumkonzentration von GDF-15 dar. 
Da es in der Vergangenheit und aktuell verschiedene Schemata zur Einteilung der diastolischen Dysfunktion gab und gibt, wurde auch der Zusammenhang von GDF-15 mit E/E' lateral als Parameter der diastolischen Funktion mithilfe des Jonckheere-Terpstra-Tests untersucht. Hierzu wurde auch E/E' in Gruppen zusammengefasst. Auch hier ergab sich auf einem Niveau von $p<0,001$ ein signifikanter Zusammenhang von GDF-15 mit E/E' lateral. Dieser Zusammenhang wird in der folgenden Abbildung verdeutlicht.

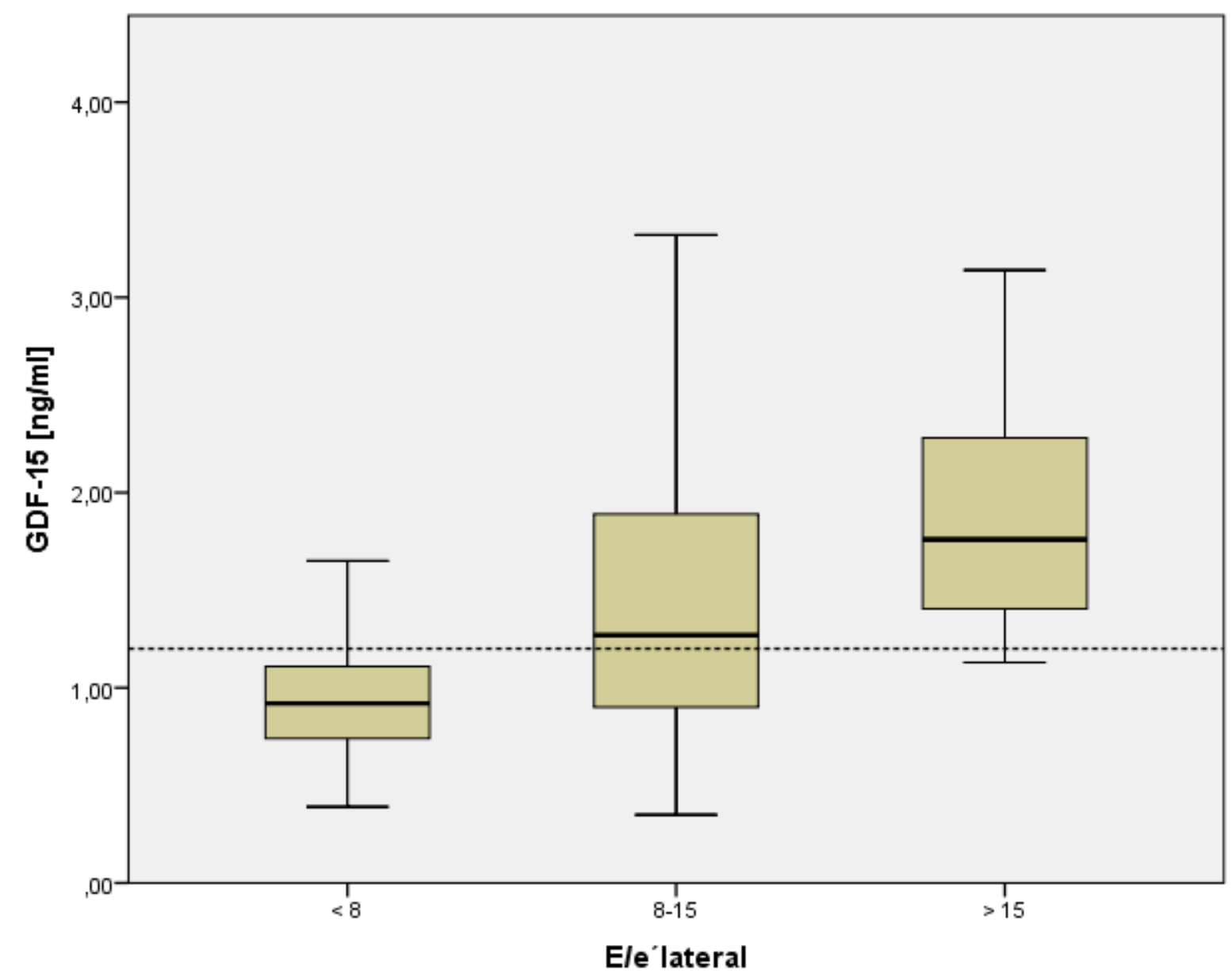

Abbildung 8: Auf der Ordinate sind die Serumkonzentrationen von GDF-15 für die jeweiligen Bereiche von E/E' dargestellt. Die gestrichelte Linie stellt die obere Grenze des Normbereichs der Serumkonzentration von GDF-15 dar, der obere Normbereich der Serumkonzentration von GDF-15 endet bei 1,20 ng/ml (Kempf et al. 2007a). 
Die folgende Grafik verdeutlicht den Zusammenhang zwischen der Serumkonzentration von GDF-15 und E/E'.

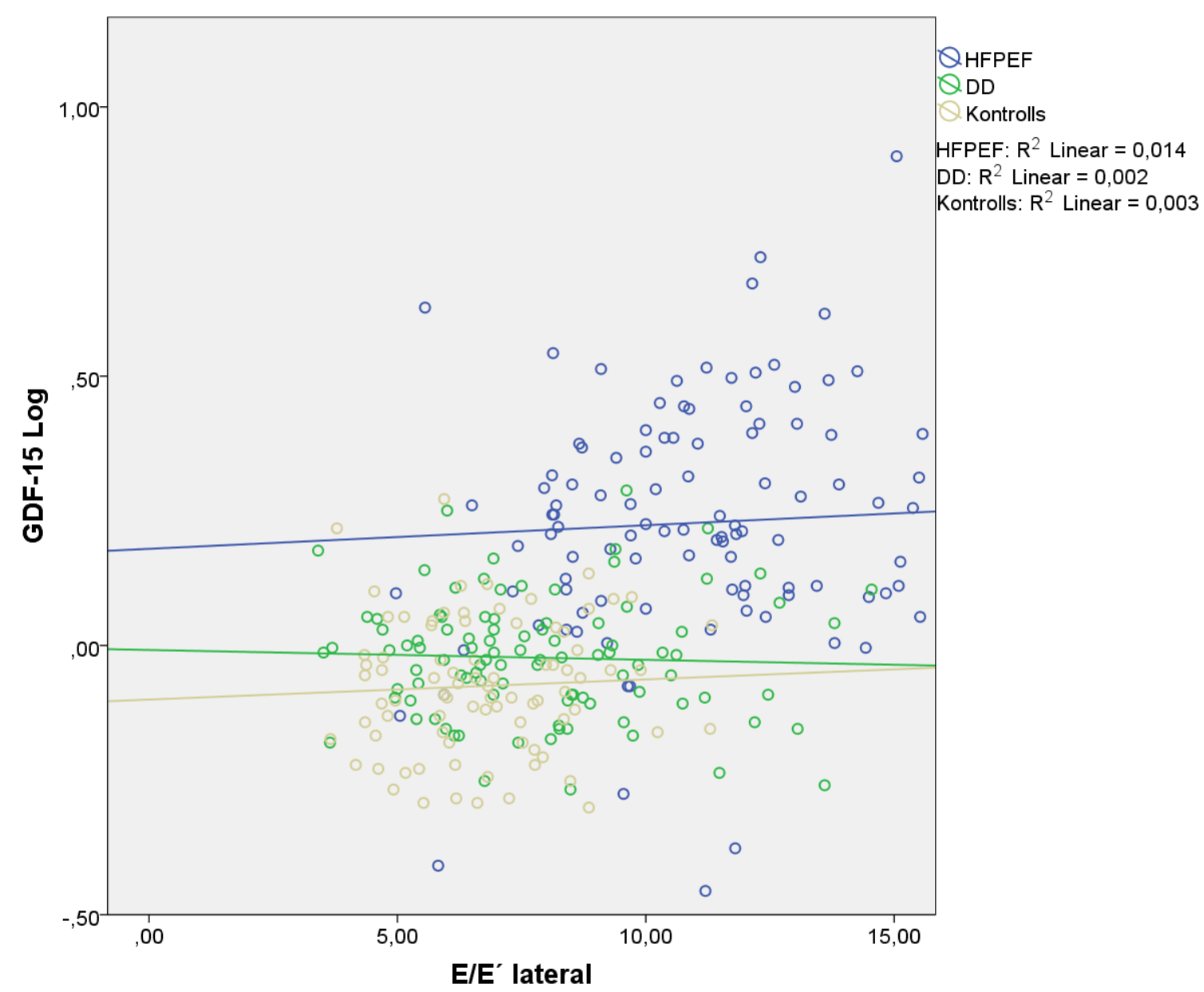

Abbildung 9: Auf der Abszisse ist E/E' lateral dargestellt, auf der Ordinate die dazugehörigen logarithmierten Serumkonzentrationen von GDF-15. 
Die folgende Grafik veranschaulicht den Zusammenhang zwischen log GDF-15 und dem linksatrialen Volumenindex (LAVI).

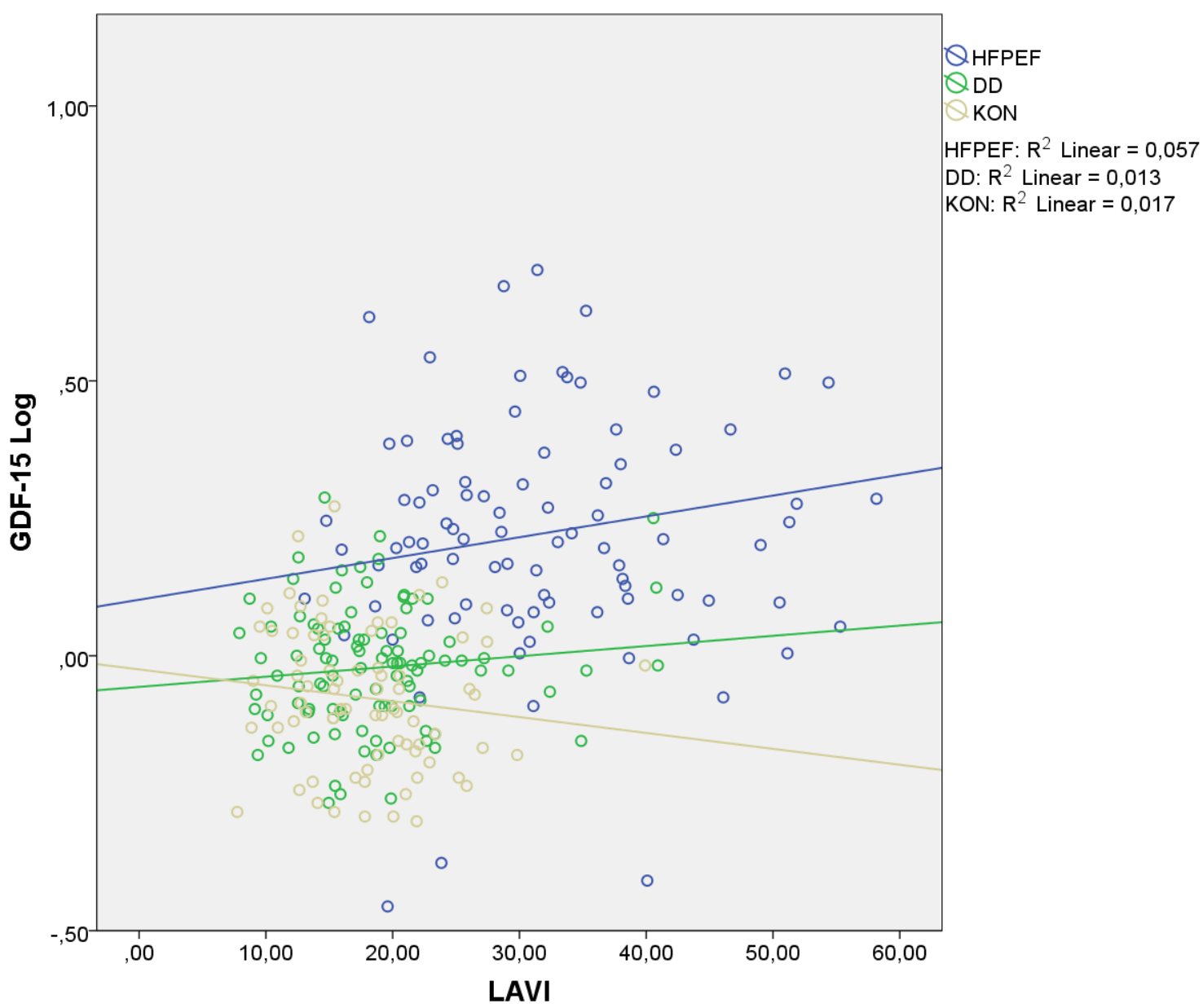

Abbildung 10: Auf der Abszisse ist der LAVI dargestellt, auf der Ordinate die dazugehörigen logarithmierten Serumkonzentrationen von GDF-15. 
Das folgende Diagramm bildet den Zusammenhang von log GDF-15 mit dem linksventrikulären Masseindex (LVMI) ab.

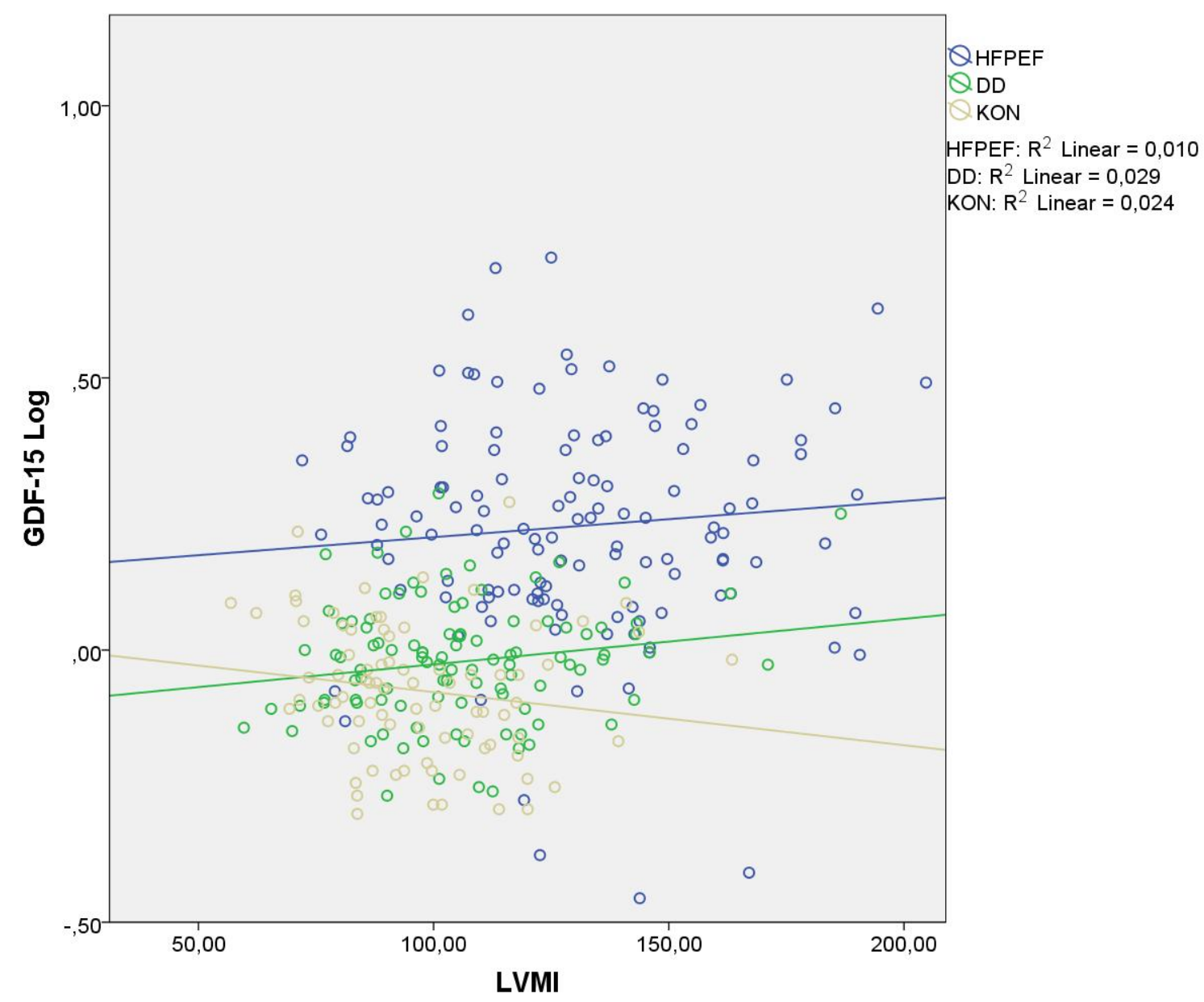

Abbildung 13: Auf der Abszisse ist der LVMI dargestellt, auf der Ordinate die dazugehörigen logarithmierten Serumkonzentrationen von GDF-15. 
Die folgende Grafik veranschaulicht den Zusammenhang zwischen log GDF-15 und dem Gewebedoppler lateral E'-Welle.

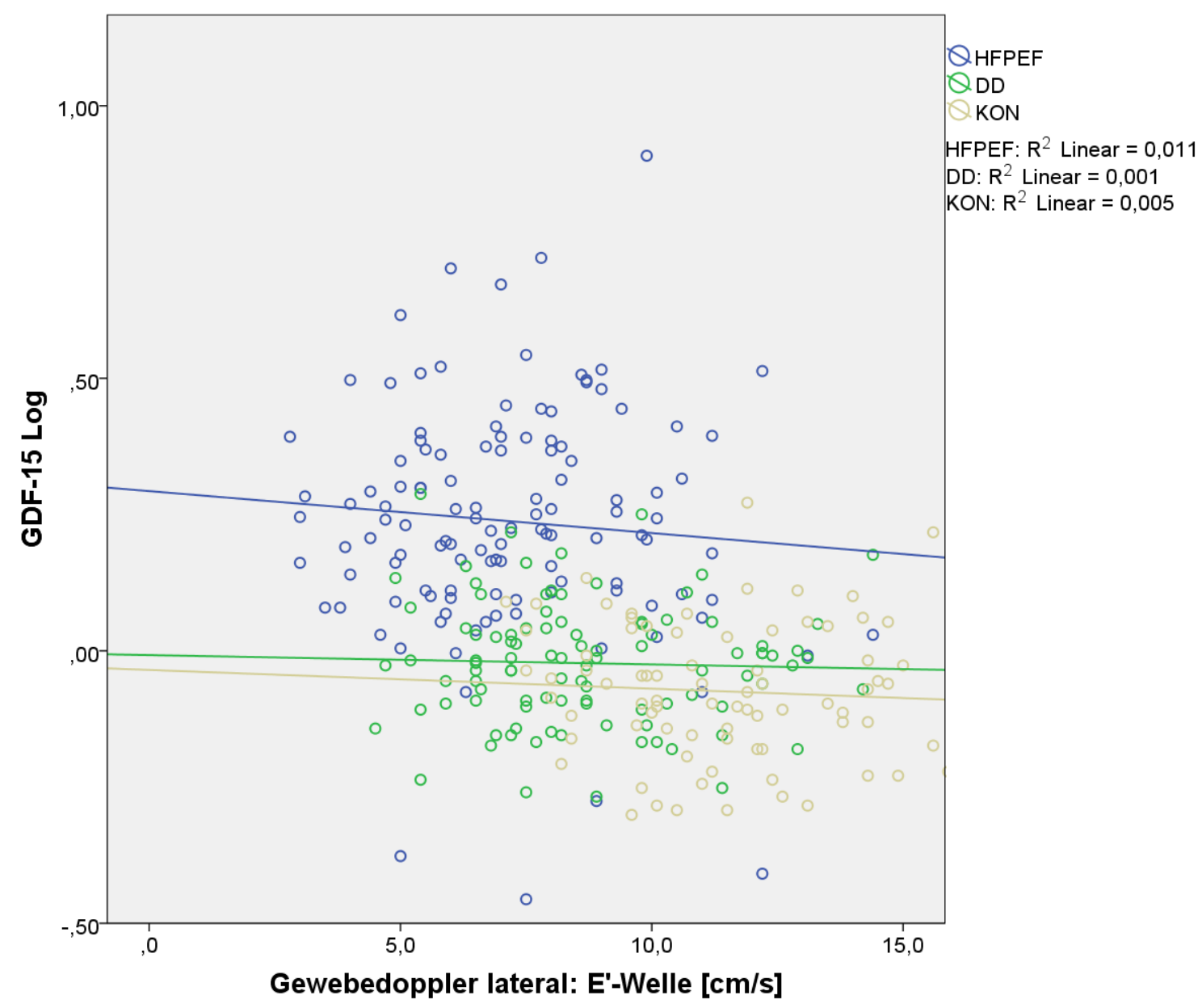

Abbildung 12: Auf der Abszisse ist die E'-Welle des Gewebedopplers lateral dargestellt, auf der Ordinate die dazugehörigen logarithmierten Serumkonzentrationen von GDF-15. 
Das folgende Schaubild dient der Veranschaulichung des Zusammenhangs zwischen log GDF-15 und dem Gewebedoppler E'/A'.

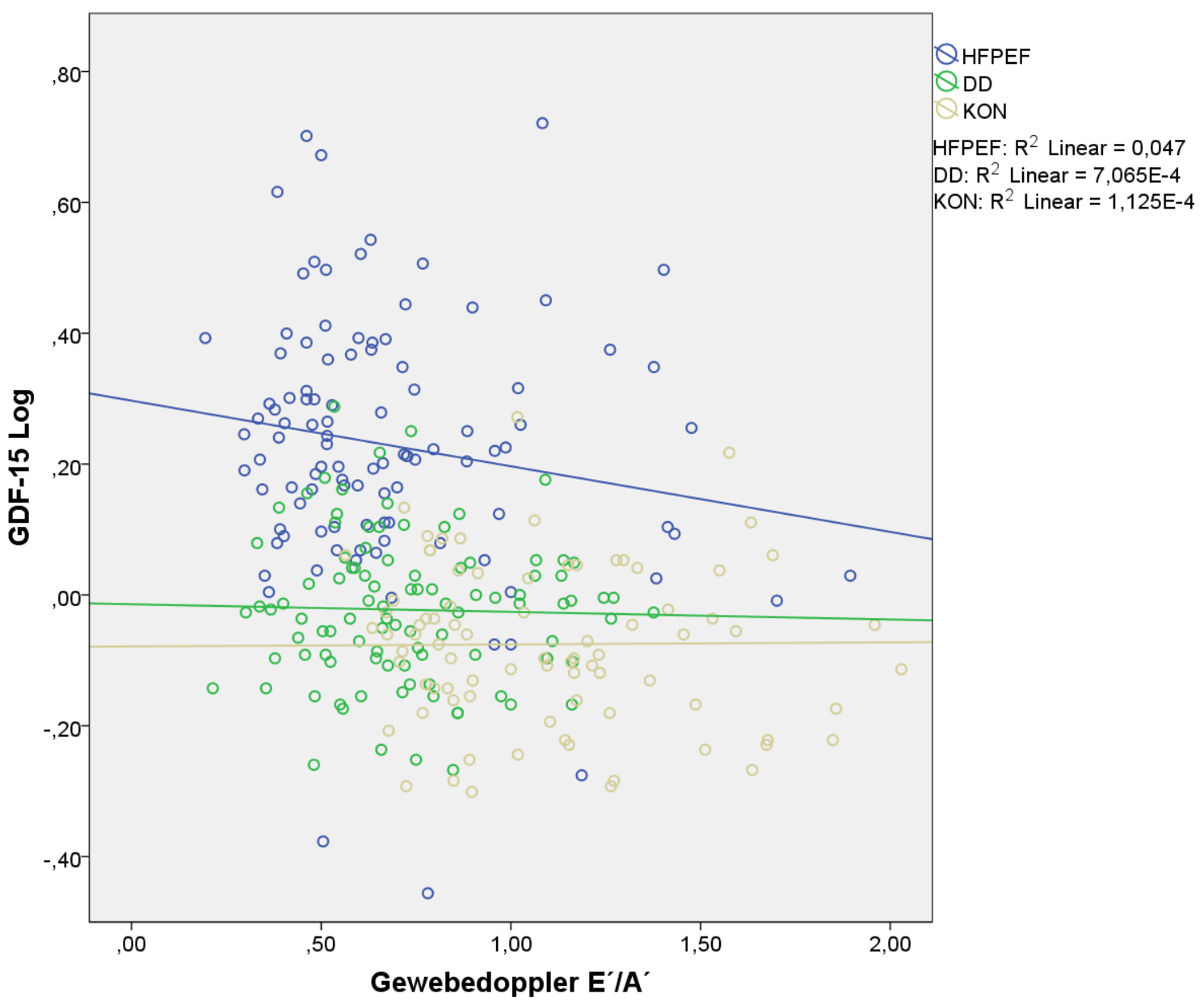

Abbildung 13: Auf der Abszisse ist der Gewebedoppler E'/A' dargestellt, auf der Ordinate die dazugehörigen logarithmierten Serumkonzentrationen von GDF-15. 
Das folgende Schaubild dient der Veranschaulichung des Zusammenhangs zwischen log GDF-15 und der Gehstrecke.

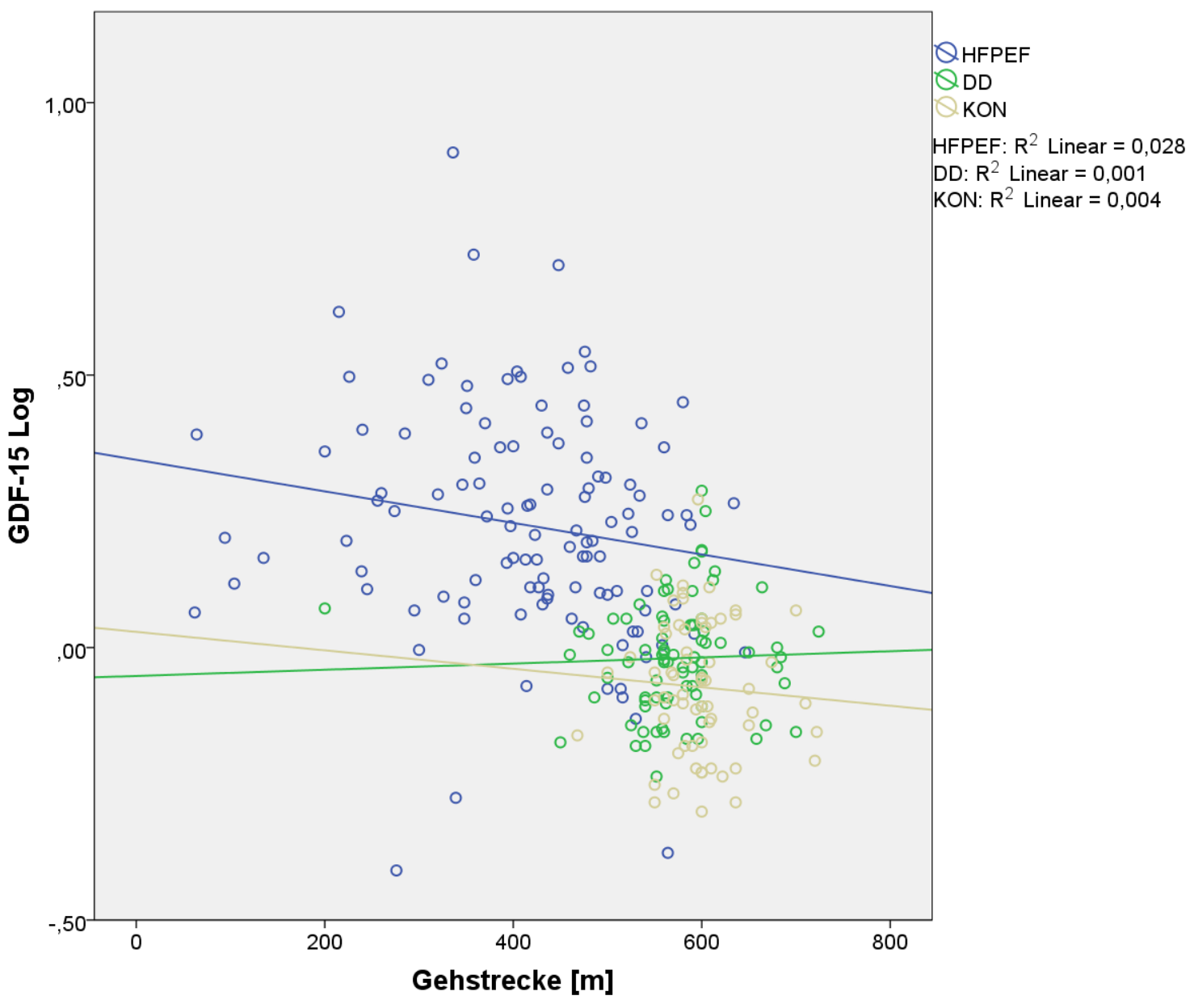

Abbildung 14: Auf der Abszisse ist die Gehstrecke dargestellt, auf der Ordinate die dazugehörigen logarithmierten Serumkonzentrationen von GDF-15. 
Das folgende Schaubild dient der Veranschaulichung des Zusammenhangs zwischen log GDF-15 und dem Summenscore physisch.

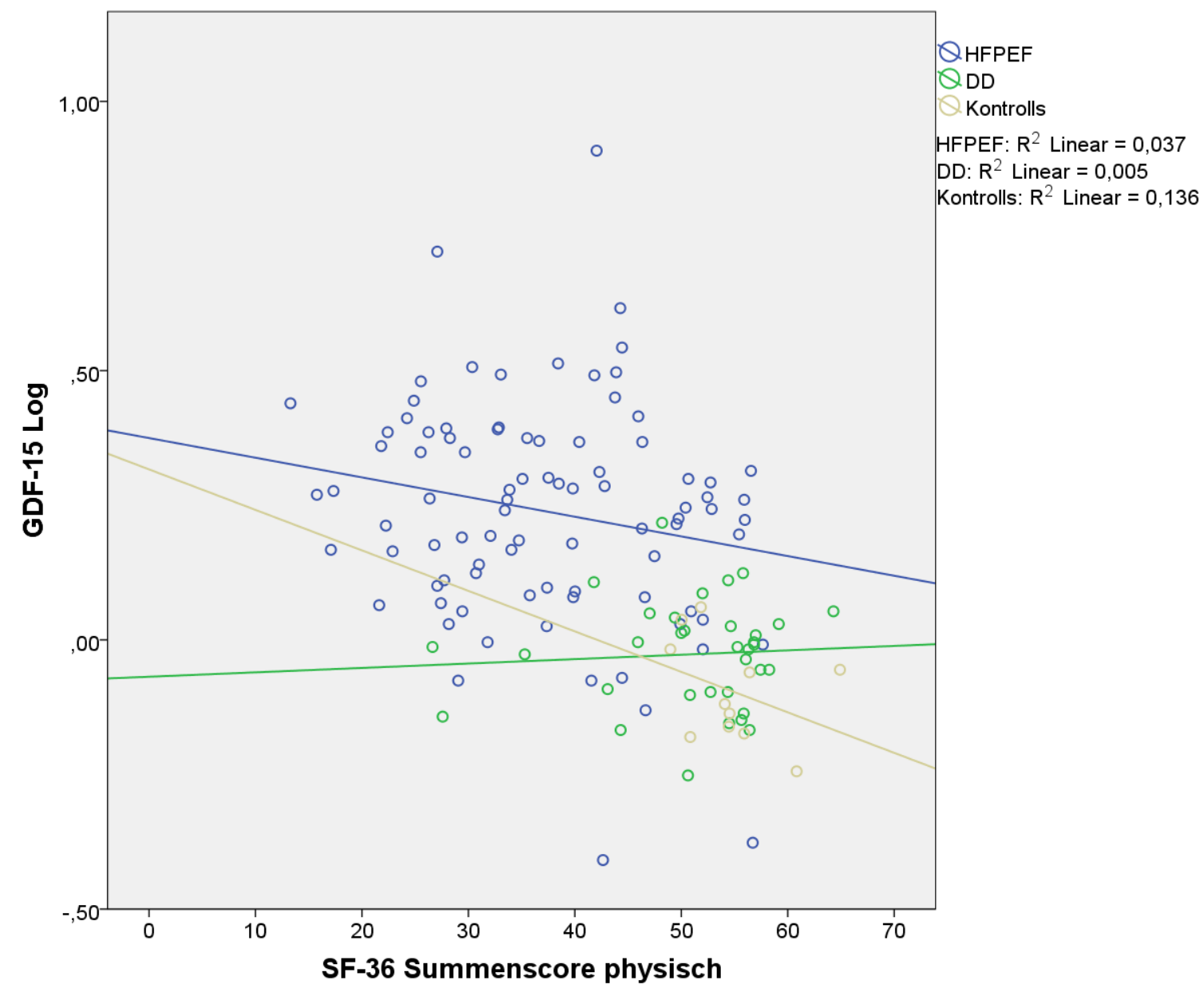

Abbildung 15: Auf der Abszisse ist SF-36 physisch dargestellt, auf der Ordinate die dazugehörigen logarithmierten Serumkonzentrationen von GDF-15. 
Das folgende Schaubild dient der Veranschaulichung des Zusammenhangs zwischen log GDF-15 und dem SF-36 psychisch.

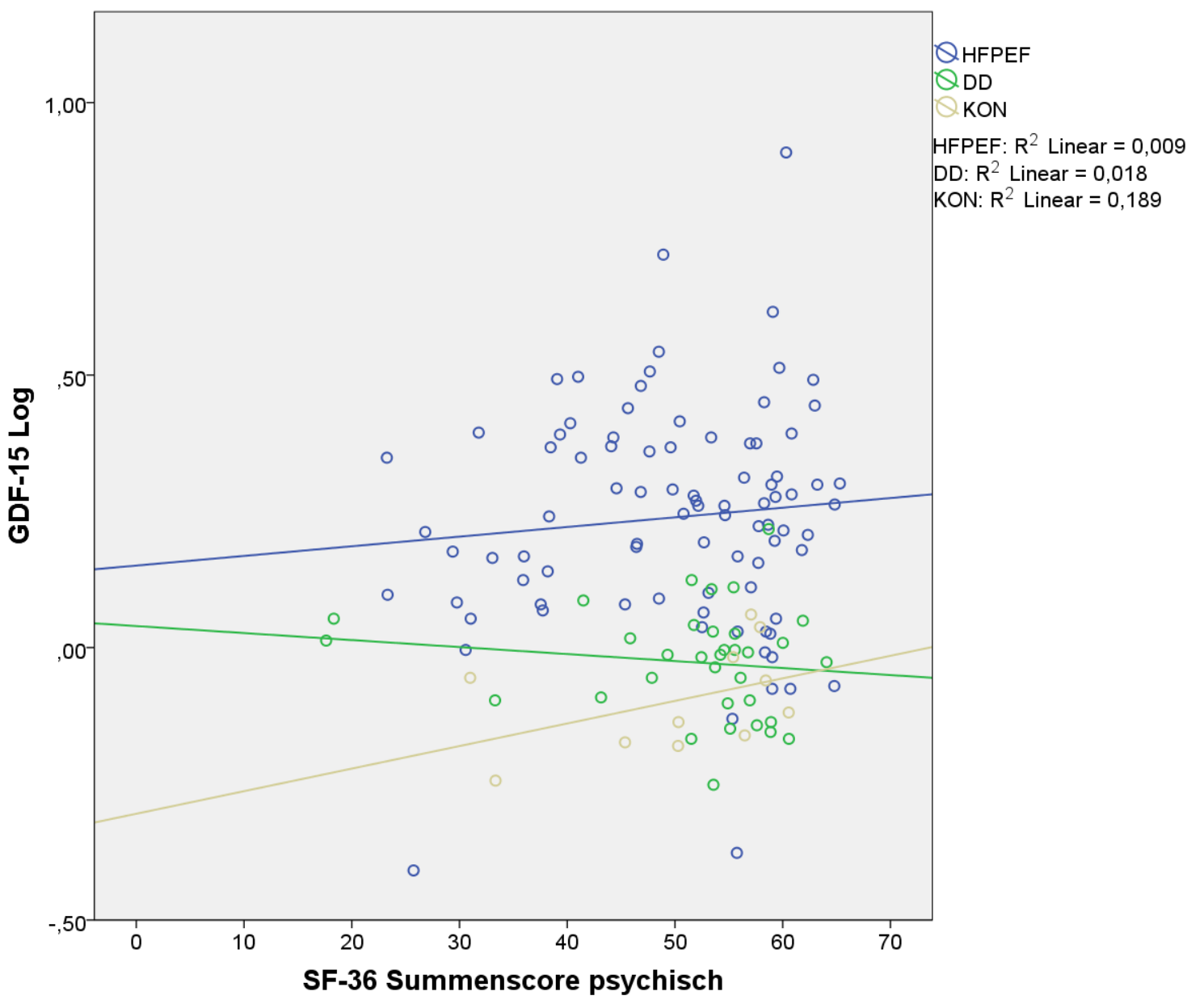

Abbildung 16: Auf der Abszisse ist SF-36 psychisch dargestellt, auf der Ordinate die dazugehörigen logarithmierten Serumkonzentrationen von GDF-15. 


\subsection{Zusammenhang zwischen GDF-15 und dem Vorliegen einer DD bzw. einer HFPEF unter Berücksichtigung klinischer und demografischer Kovariablen}

Um die Auswirkungen der erhobenen Patientendaten auf die Serumkonzentrationen zu untersuchen sowie wechselseitige Einflüsse zu erkennen, wurden allgemeine lineare Modelle erstellt.

\subsubsection{Zusammenhang von GDF-15 und DD unter Berücksichtigung klinischer und demografischer Kovariablen}

Zunächst wurde ein allgemeines lineares Modell erstellt, in welchem das Vorliegen einer DD als abhängige Variable verwendet wurde. Als unabhängige Variablen wurden neben log GDF-15 zunächst nur die sehr allgemeinen Variablen Alter und Geschlecht verwendet.

Wie erwartet fand sich ein signifikanter Zusammenhang zwischen dem Vorliegen einer DD und dem Geschlecht bzw. dem Alter. Allerdings ergab sich in diesem Modell weder für das Geschlecht noch für erhöhte Konzentrationen von GDF-15 ein signifikanter Zusammenhang mit dem Vorliegen einer DD.

\begin{tabular}{|c|c|c|c|c|c|c|}
\hline \multicolumn{7}{|c|}{ Koeffizienten $^{\mathrm{a}}$} \\
\hline \multirow{2}{*}{\multicolumn{2}{|c|}{ Modell }} & \multicolumn{2}{|c|}{ Nicht standardisierte Koeffizienten } & \multirow{2}{*}{$\begin{array}{c}\text { Standardisierte } \\
\text { Koeffizienten }\end{array}$} & \multirow[t]{2}{*}{$\mathrm{T}$} & \multirow[t]{2}{*}{ Sig. } \\
\hline & & $\begin{array}{c}\text { Regressions- } \\
\text { koeffizientB }\end{array}$ & Standardfehler & & & \\
\hline \multirow{4}{*}{1} & (Konstante) & $-1,041$ & ,343 & & $-3,038$ &, 003 \\
\hline & Alter $[\mathrm{J}]$ & ,030 & ,005 & ,406 & 5,660 &, 000 \\
\hline & Geschlecht &,- 068 & ,071 &,- 065 &,- 954 & ,342 \\
\hline & $\log$ GDF-15 & ,252 & ,304 &, 060 & ,829 & ,408 \\
\hline
\end{tabular}

a. Abhängige Variable: Vorliegen DD

Korrigiertes $\mathrm{r}^{2}=0,189$

Tabelle 10: Dargestellt ist ein multivariates allgemeines lineares Modell mit dem Vorliegen einer DD als abhängiger und Alter, Geschlecht und log GDF-15 als unabhängigen Variablen. 
Im Folgenden wurde der BMI in das allgemeine lineare Modell integriert. In diesem Modell hatten sowohl das Alter als auch der BMI einen signifikanten Einfluss auf das Vorliegen einer DD. Das Geschlecht und GDF-15 hatte auf dieses Modell keinen signifikanten Einfluss.

\begin{tabular}{|c|c|c|c|c|c|c|}
\hline \multicolumn{7}{|c|}{ Koeffizienten $^{\mathrm{a}}$} \\
\hline \multirow{2}{*}{\multicolumn{2}{|c|}{ Modell }} & \multicolumn{2}{|c|}{ Nicht standardisierte Koeffizienten } & \multirow{2}{*}{$\begin{array}{c}\begin{array}{c}\text { Standardisierte } \\
\text { Koeffizienten }\end{array} \\
\text { Beta }\end{array}$} & \multirow[t]{2}{*}{$\mathrm{T}$} & \multirow[t]{2}{*}{ Sig. } \\
\hline & & $\begin{array}{c}\text { Regressions- } \\
\text { koeffizientB }\end{array}$ & Standardfehler & & & \\
\hline \multirow{5}{*}{1} & (Konstante) & $-1,895$ & ,412 & & $-4,602$ &, 000 \\
\hline & Alter $[\mathrm{J}]$ & ,028 & ,005 & ,390 & 5,580 &, 000 \\
\hline & Geschlecht &,- 021 & ,072 &,- 020 &,- 295 & ,769 \\
\hline & $\log$ GDF-15 & ,243 & 294 & ,058 & ,826 & ,410 \\
\hline & $\mathrm{BMI}\left[\mathrm{kg} / \mathrm{m}^{2}\right]$ &, 033 &, 009 & ,255 & 3,850 &, 000 \\
\hline
\end{tabular}

a. Abhängige Variable: Vorliegen DD

Korrigiertes $r^{2}=0,243$

Tabelle 11: Dargestellt ist ein multivariates allgemeines lineares Modell mit dem Vorliegen einer DD als abhängiger und Alter, Geschlecht, log GDF-15 und BMI als unabhängigen Variablen. 


\subsubsection{Zusammenhang von GDF-15 und HFPEF unter Berücksichti- gung klinischer und demografischer Kovariablen}

Im Folgenden wurde ein weiteres allgemeines lineares Modell erstellt, in welchem das Vorliegen einer HFPEF als abhängige Variable verwendet wurde. Als unabhängige Variablen wurden neben log GDF-15 zunächst nur die sehr allgemeinen Variablen Alter und Geschlecht verwendet. Wie erwartet fand sich ein signifikanter Zusammenhang zwischen dem Vorliegen einer HFPEF und dem Alter. Ebenfalls zeigte sich ein signifikanter Zusammenhang zwischen dem Vorliegen einer HFPEF und log GDF-15. Es zeigte sich auch, dass in diesem Modell das Geschlecht ohne signifikanten Einfluss blieb.

Koeffizienten $^{a}$

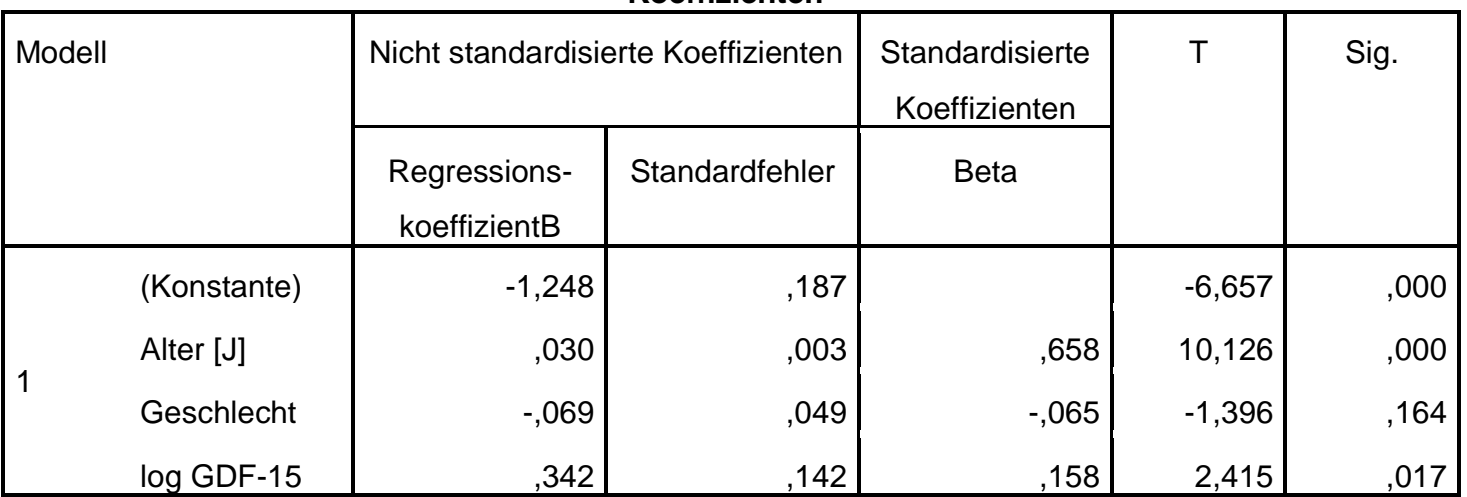

a. Abhängige Variable: Vorliegen HFPEF Korrigiertes $r^{2}=0,606$

Tabelle 12: Dargestellt ist ein multivariates allgemeines lineares Modell mit dem Vorliegen einer HFPEF als abhängiger und Alter und Geschlecht als unabhängigen Variablen. 
Im Folgenden wurden weitere erhobene Parameter in das allgemeine lineare Modell integriert. Im Einzelnen handelte es sich hierbei um den BMI und das Vorliegen einer KHK. Auch nach Aufnahme dieser neuen Variablen blieb ein signifikanter Zusammenhang zwischen log GDF-15 und dem Vorliegen einer HFPEF bestehen. Das Geschlecht hatte auf dieses Modell keinen signifikanten Einfluss.

Koeffizienten $^{a}$

\begin{tabular}{|c|r|r|r|r|r|}
\hline Modell & \multicolumn{2}{|l|}{ Nicht standardisierte Koeffizienten } & $\begin{array}{c}\text { Standardisierte } \\
\text { Koeffizienten }\end{array}$ & S & Sig. \\
\cline { 2 - 4 } & $\begin{array}{r}\text { Regressions- } \\
\text { koeffizientB }\end{array}$ & Standardfehler & \multicolumn{2}{|c|}{ Beta } & \\
\hline (Konstante) & $-1,740$ &, 183 & & $-9,496$ &, 000 \\
Alter [J] &, 024 &, 003 & 9,150 &, 000 \\
Geschlecht &,- 029 &, 044 &,- 027 &,- 649 &, 517 \\
log GDF-15 &, 267 &, 124 &, 124 & 2,160 &, 032 \\
KHK &, 144 &, 055 &, 114 & 2,629 &, 009 \\
BMl [kg/m²] &, 026 &, 004 &, 298 & 7,031 &, 000 \\
\hline
\end{tabular}

a. Abhängige Variable: Vorliegen HFPEF

Korrigiertes $\mathrm{r}^{2}=0,702$

Tabelle 13: Dargestellt ist ein multivariates allgemeines lineares Modell mit dem Vorliegen einer HFPEF als abhängiger und Alter, Geschlecht, log GDF-15, KHK und BMI als unabhängigen Variablen. 


\subsection{Eignung von GDF-15 als prädiktiver Wert zur Diagnose einer DD oder einer HFPEF}

\subsubsection{Vorhersage des Vorhandenseins einer DD anhand des Laborparameters GDF-15}

In diesem Kapitel wird untersucht, inwiefern sich die Serumkonzentration von GDF-15 sowie die der ebenfalls untersuchten Neuropeptide NTproBNP, MRproANP, MRproADM, CTproET1 und CTproAVP als diagnostische Parameter zur Detektion einer HFPEF eignen. Ebenfalls wird in diesem Kapitel untersucht, wie gut sich die Serumkonzentrationen von GDF-15 sowie NTproBNP, MRproANP, MRproADM, CTproET1 und CTproAVP zur Diskrimination zwischen dem Vorhandensein und der Abwesenheit der DD eignen.

Hierzu wurden receiver-operating-characteristic-Kurven (ROC-Kurven) erstellt. Dabei wurden für jeden Messpunkt jeweils die Sensitivität und die Spezifität gegeneinander aufgetragen. Ebenfalls wird die Fläche unter der Kurve (AUC) angegeben. Ein höherer Wert steht bei der AUC für eine höhere Trennschärfe des verwendeten Parameters.

Zunächst wurden GDF-15 sowie NTproBNP, MRproANP, MRproADM, CTproET1 und CTproAVP hinsichtlich ihrer Fähigkeit zur Diskrimination der Patienten mit DD von gesunden Probanden untersucht. 


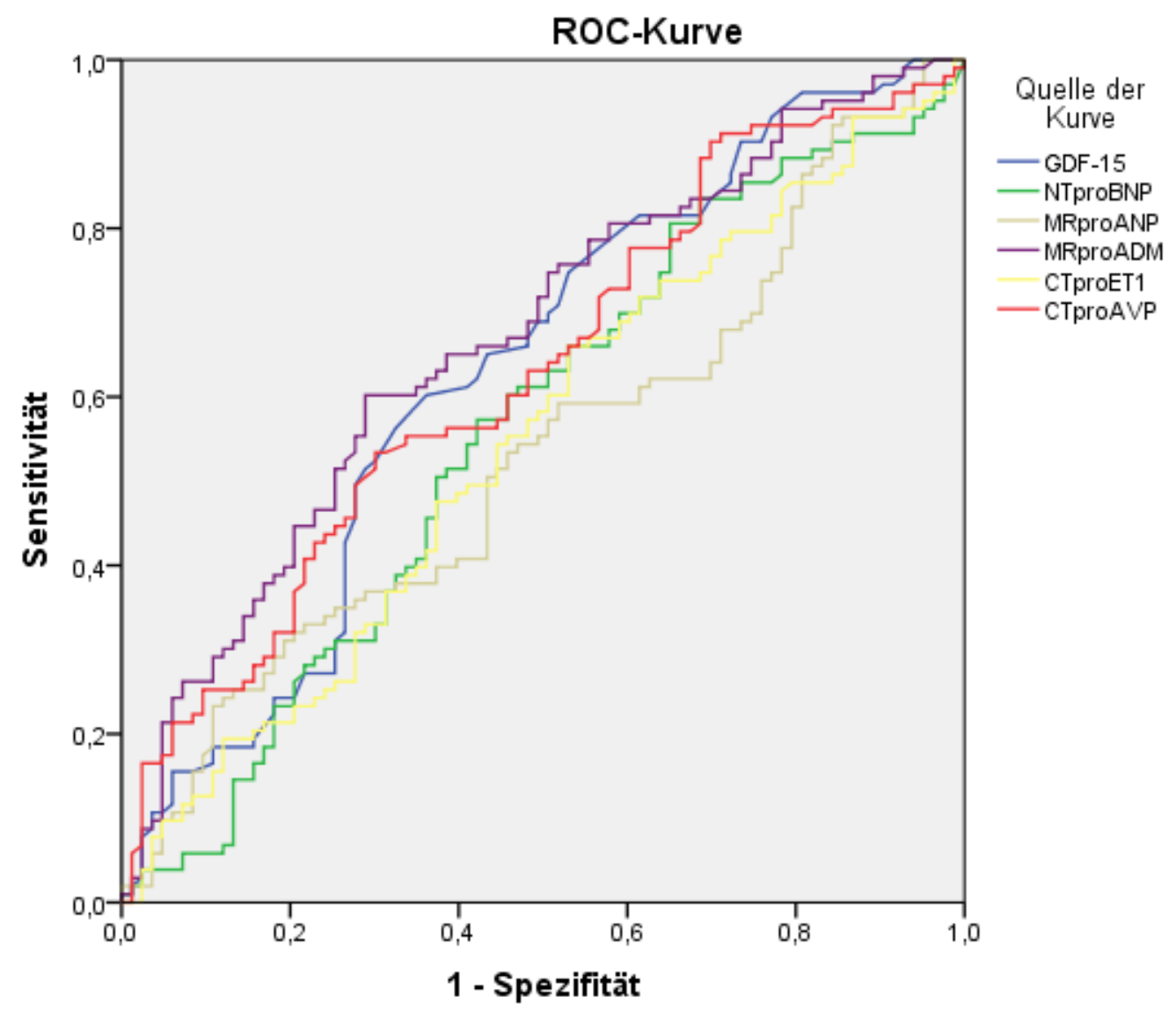

Abbildung 17: Dargestellt ist die ROC-Kurve von GDF-15, NTproBNP, MRproANP, MRproADM, CTproET1 und CTproAVP in Bezug auf die Diskrimination zwischen Patienten mit DD und gesunden Probanden der Kontrollgruppe.

Hierbei erreicht GDF-15 eine AUC von 0,631 [0,549; 0,712]. Für die übrigen Biomarker ergab sich folgende AUC: NTproBNP 0,559 [0,475; 0,643], MRproANP 0,533 [0,450; 0,617], MRproADM 0,668 [0,591; 0,746], CTproET1 0,547 [0,464; 0,631] und CTproAVP 0,630 $[0,550,0,710]$. 


\subsubsection{Vorhersage des Vorhandenseins einer HFPEF anhand des Laborparameters GDF-15}

Im Folgenden wurden GDF-15, NTproBNP, MRproANP, MRproADM, CTproET1 und CTproAVP hinsichtlich ihrer Fähigkeit zur Diskrimination der Patienten mit HFPEF von gesunden Probanden untersucht. Hierbei erreicht GDF-15 ein AUC von $0,910[0,870 ; 0,950]$.

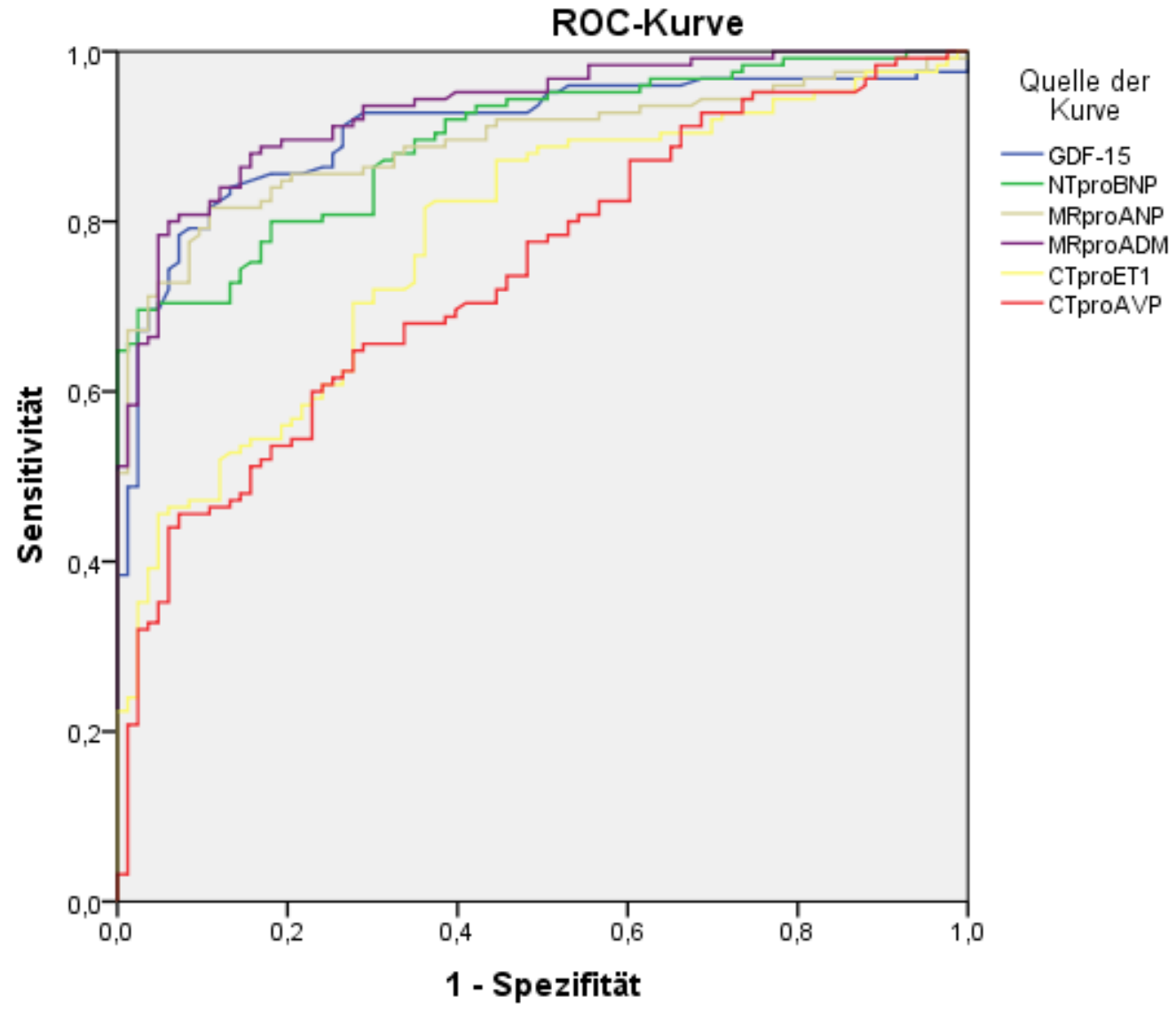

Abbildung 17: Dargestellt ist die ROC-Kurve von GDF-15, NTproBNP, MRproANP, MRproADM, CTproET1 und CTproAVP in Bezug auf die Diskrimination zwischen Patienten mit HFPEF und gesunden Probanden der Kontrollgruppe.

Hierbei erreicht GDF-15 eine AUC von 0,907 [0,866; 0,949]. Für die übrigen Biomarker ergab sich folgende AUC: NTproBNP 0,895 [0,854; 0,936], MRproANP 0,893 [0,849; 0,937], MRproADM 0,932 [0,900; 0,964], CTproET1 0,781 [0,719; 0,843] und CTproAVP 0,741 $[0,674 ; 0,807]$. 


\section{Diskussion}

Zur Diagnose einer DD gibt es keine einheitlichen Diagnosekriterien, sondern mehrere, hauptsächlich auf echokardiographischen Parametern basierende Schemata. Wünschenswert wäre daher ein Biomarker, welcher sich mit dem Auftreten einer DD reproduzierbar verändert und somit die Diagnosefindung einer DD erleichtern könnte. Idealerweise fände sich auch eine Korrelation zwischen der Konzentration des Biomarkers und dem klinischen Schweregrad der Erkrankung. Dies würde helfen, an DD oder HFPEF erkrankte Patienten von gesunden zu unterscheiden. Im Idealfall wäre dieser Biomarker zur primären Detektion einer DD oder einer HFPEF fähig und könnte somit die bisher uneinheitliche und aufwendige Diagnostik, beispielsweise durch die Echokardiographie, erleichtern.

In dieser Arbeit wurde der Zusammenhang von GDF-15 mit dem Vorliegen einer DD oder einer HFPEF untersucht. Insbesondere wurde die Fähigkeit von GDF-15 zur Diskrimination von Patienten mit DD oder HFPEF von gesunden Probanden untersucht und mit der diagnostischen Fähigkeit anderer Biomarker, im Einzelnen NTproBNP, MRproANP, MRproADM, CTproET1 und CTproAVP, verglichen.

Ebenfalls wurde der Zusammenhang von GDF-15 mit der im 6-Minuten-Gehtest zurückgelegten Gehstrecke sowie dem SF-36 untersucht als Parameter der körperlichen Leistungsfähigkeit sowie der Lebensqualität, um somit auch einen Rückschluss auf den klinischen Schweregrad der Erkrankung zu erlauben.

\subsection{Patientenkollektiv}

Grundlage dieser Arbeit ist die prospektive und multizentrische Kohortenstudie „Prävalenz und Verlauf der diastolischen Dysfunktion und der diastolischen Herzinsuffizienz" (DiastCHF) des Teilprojektes 7 (TP 7) Diastolische Dysfunktion des Kompetenznetzes Herzinsuffizienz (KNHI). Die Rekrutierung für die Diast-CHF-Studie erfolgte über den Basisdatensatz der Abteilung für Allgemeinmedizin an der Universität Göttingen sowie über die Praxis-EDV teilnehmender Hausärzte. Bedingung für den Einschluss in die Studie war das Vorliegen von mindestens einem Risikofaktor für die Entwicklung einer diastolischen Dysfunktion oder die bereits ärztlich gestellte Diagnose einer HF. Somit handelt es sich bei der Diast-CHF-Studie auch um ein nicht vorselektiertes Risikokollektiv für das Auftreten einer HF. So wird durchaus eine dem klinischen Alltag entsprechende Situation widergespiegelt, in der ein bestehender Verdacht auf eine vorliegende DD oder HF abgeklärt werden soll.

Dinh et al. (2011) untersuchten die Serumkonzentrationen von GDF-15 bei Patienten mit präklinischer DD oder HFPEF. Kempf et al. (2007b) untersuchten in einem Kollektiv von 
Patienten mit HFREF den prognostischen Nutzen von GDF-15. Anand et al. (2010) untersuchten die Aussagekraft von GDF-15 bei Patienten mit HFREF. Grundlage ihrer Arbeit war das Valsartan Heart Failure Trial (Val-HeFT). Hierbei handelte es sich um eine randomisierte, Placebo-kontrollierte, doppel-blinde, multizentrische Studie, in die Patienten mit symptomatischer HFREF eingeschlossen wurden, um die therapeutische Wirkung des AT-1 Antagonisten Valsartan zu untersuchen.

In der vorliegenden Arbeit wurden aus der Diast-CHF-Studie insgesamt 330 Patienten näher untersucht. Hierbei handelte es sich um 142 Patienten mit HFPEF, 103 Patienten mit DD und 85 Patienten als Kontrollgruppe. Dinh et al. untersuchten insgesamt 119 Patienten, davon 38 mit HFPEF, 61 mit DD sowie 20 gesunde Kontrollprobanden. Die Arbeit von Kempf et al. (2007b) umfasst 455 Patienten, welche alle an einer HFREF leiden. Anand et al. (2010) untersuchten ein insgesamt aus 1734 Patienten mit HFREF bestehendes Kollektiv.

In der vorliegenden Arbeit waren die Patienten mit HFPEF mit 64\% überwiegend weiblich, die Patienten mit DD waren zu 61\% weiblich und die Kontrollgruppe war zu 74\% weiblich. Bei Dinh et al. (2011) waren die Patienten mit HFPEF zu 73\% weiblich, die Patienten mit DD zu $67 \%$ weiblich und die Kontrollprobanden zu 51\% weiblich. Bei Kempf et al. (2007b) waren nur 9,5\% weiblich. Bei Anand et al. (2010), der ja ebenfalls nur Patienten mit HFREF einschloss, betrug der Anteil der Frauen lediglich 21\%. Somit findet sich in der vorliegenden Arbeit eine Geschlechterpräferenz bei der HFPEF. Es sind hier in der Mehrzahl Frauen betroffen, was sich auch in der Literatur widerspiegelt. Bei der HFREF sind hingegen Patienten männlichen Geschlechts stark in der Überzahl.

In der vorliegenden Arbeit betrug das Alter der Patienten im HFPEF im Mittel 73 Jahre, bei Patienten mit DD 61 Jahre und bei der Kontrollgruppe 53 Jahre. Bei Dinh et al. (2011) betrug das Alter der Patienten mit HFPEF im Mittel 73 Jahre, bei Patienten mit DD 67 Jahre und bei den Kontrollprobanden 51 Jahre. Somit ähneln sich das vorliegende Patientenkollektiv und das Patientenkollektiv von Dinh et al. (2011) bezüglich der Altersstruktur stark. Bei Kempf et al. (2007b) hingegen betrug das Alter im Mittel 64 Jahre und bei Anand et al. (2010) 63 Jahre.

Auf diese starken Altersdifferenzen dürften auch die Unterschiede im BMI zurückzuführen sein. So betrug hier der Median bei den Patienten aus Diast-CHF 29,8 kg/m² für Patienten mit HFPEF und 26,3 kg/m² für Patienten mit DD. Bei Kempf et al. (2007b) betrug er 25,9 $\mathrm{kg} / \mathrm{m}^{2}$ und bei Anand et al. (2010) 27,5 kg/m². Bei Dinh et al. (2011) hingegen lag der Median für den BMI bei Patienten mit HFPEF bei $27 \mathrm{~kg} / \mathrm{m}^{2}$ und für Patienten mit DD bei $28 \mathrm{~kg} / \mathrm{m}^{2}$.

Bezüglich des systolischen Blutdrucks bei Diast-CHF lag der Median bei Patienten mit HFPEF bei $147 \mathrm{mmHg}$ und bei Patienten mit DD bei $130 \mathrm{mmHg}$. Bei Dinh et al. (2011) 
betrug der Median für den systolischen Blutdruck für Patienten mit HFPEF $133 \mathrm{mmHg}$ und für Patienten mit DD $130 \mathrm{mmHg}$. Somit sind hier die Messergebnisse von Dinh et al. bezüglich des systolischen Blutdrucks mit der vorliegenden Arbeit vergleichbar. Bei Anand et al. (2010) lag der systolische Blutdruck im Mittel bei $121 \mathrm{mmHg}$. Der im Vergleich höhere Blutdruck im Diast-CHF-Kollektiv lässt sich zumindest teilweise durch das höhere Alter und das größere Körpergewicht erklären. Bei Kempf et al. (2007b) wird der Blutdruck nicht aufgeführt.

Der diastolische Blutdruck bei Diast-CHF lag im Mittel bei $80 \mathrm{mmHg}$ für Patienten mit DD und ebenfalls bei $80 \mathrm{mmHg}$ für Patienten mit HFPEF. Bei Dinh et al. (2011) lag der Median für den diastolischen Blutdruck bei $80 \mathrm{mmHg}$ sowohl für Patienten mit DD als auch für Patienten mit HFPEF, somit sind hier die Messergebnisse bei Diast-CHF und Dinh et al. identisch. Bei Anand et al. (2010) lag der diastolische Blutdruck im Mittel bei $73 \mathrm{mmHg}$.

Die Herzfrequenz lag im Mittel bei den Patienten aus Diast-CHF bei 66/min für Patienten mit HFPEF und bei 74/min bei Patienten mit DD. Diese Frequenzen sind mit den Ergebnissen von Dinh et al. (2011) vergleichbar. Hier lag die Herzfrequenz im Mittel bei Patienten mit HFPEF bei 69/min und bei Patienten mit DD bei 74/min. Bei Anand et al. (2010) fand sich im Mittel eine Herzfrequenz von $73 / \mathrm{min}$.

Eher geringe Unterschiede zwischen den unterschiedlichen Patientenkollektiven fanden sich bezüglich der GFR, wobei diese jedoch weder bei Kempf et al. (2007b) noch bei Dinh et. al (2011) aufgeführt wurden. So betrug der Median für die Patienten aus Diast-CHF 64 $\mathrm{ml} / \mathrm{min} / 1,73 \mathrm{~m}^{2}$ für Patienten mit HFPEF und $77 \mathrm{ml} / \mathrm{min} / 1,73 \mathrm{~m}^{2}$ für Patienten mit DD. Bei Anand et al. (2010) betrug der Median für die GFR 57,3 ml/min/1,73 m².

Die arterielle Hypertonie war bei den Patienten aus dem Diast-CHF-Kollektiv der mit Abstand häufigste Risikofaktor. So hatten von den Patienten mit HFPEF 93\% eine Hypertonie, bei den Patienten mit DD lediglich 1\%. Bei Kempf et al. (2007b) wurde die Hypertonie nicht aufgeführt und bei Anand et al. fand sich bei nur bei 7\% der Patienten eine Hypertonie. Bei Dinh et al. hatten 98\% der Patienten mit HFPEF eine Hypertonie und 92\% der Patienten mit DD.

Bei der Betrachtung von Diabetes mellitus findet sich dieser im Diast-CHF-Kollektiv bei 30\% der Patienten mit HFPEF. Bei Dinh et al. (2011) liegt bei $24 \%$ der Patienten mit HFPEF ein bekannter Diabetes mellitus vor. Bei Anand et al. (2010) findet sich bei 31\% der Patienten ein Diabetes mellitus.

Betrachtet man die Verteilung von Vorhofflimmern als weiterem Risikofaktor, so findet sich dieser bei Diast-CHF bei 25\% der Patienten mit HFPEF. Bei Anand et al. (2010) findet sich bei $11 \%$ der Patienten Vorhofflimmern und bei Kempf et al. (2007b) finden sich hierzu keine 
Angaben. Bei Dinh et al. (2011) war das Vorliegen von Vorhofflimmern ein Ausschlusskriterium.

Die KHK als weiterer Risikofaktor fand sich bei Diast-CHF bei 35\% der Patienten mit HFPEF. Bei Dinh et al. war bei $66 \%$ der Patienten eine KHK bekannt. Der große Unterschied dürfte hier darauf zurückzuführen sein, dass Dinh et al. ihr Kollektiv aus Patienten rekrutierten, bei denen eine KHK entweder bekannt oder vermutet wurde und die einer elektiven Koronarangiographie zugeführt wurden. Bei Kempf et al. (2007b) und bei Anand et al. (2010) fanden sich keine Angaben zum Vorliegen einer KHK.

Es ist auffällig, dass im Diast-CHF-Kollektiv im Vergleich mit dem Kollektiv von Anand et. al (2010) deutlich mehr Risikofaktoren vorliegen. Ein Grund dafür dürfte in der Art der Rekrutierung liegen. So war das Vorliegen von mindestens einem Risikofaktor Bedingung für den Einschluss in Diast-CHF.

Betablocker waren in Diast-CHF die am häufigsten verordnete Substanzgruppe mit kardiovaskulärer Intention. So fanden sich bei Patienten mit HFPEF bei $61 \%$ der Patienten Betablocker in der Vormedikation. Bei Kempf et al. (2007b) nahmen 58,6\% der Patienten einen Betablocker ein, bei Anand et al. (2010) nahmen 33\% der Patienten einen Betablocker ein. Bei Dinh et al. (2011) nahmen 89\% der Patienten mit HFPEF einen Betablocker ein.

Am zweithäufigsten war bei Diast-CHF die Verordnung von ACE-Hemmern. So hatten $49 \%$ der Patienten mit HFPEF einen ACE-Hemmer in der Vormedikation. Bei Anand et al. (2010) nahmen sogar 93\% der Patienten einen ACE-Hemmer ein. Bei Kempf et al. (2007b) nahmen mit 92,7\% der Patienten ebenfalls sehr viele Patienten einen ACE-Hemmer ein. Bei Dinh et al. hingegen hatten $61 \%$ der Patienten einen ACE-Hemmer in der Vormedikation.

Die Verordnungshäufigkeit von Diuretika wird bei Anand et al. (2010) pauschal mit 87\% angegeben. Bei Kempf et al. (2007b) wurde sie ebenfalls pauschal angegeben und beträgt $79,3 \%$ und bei Dinh et al. (2011), ebenfalls pauschal angegeben, beträgt sie 55\%. Bei Diast-CHF fand bezüglich Diuretika eine weitere Aufschlüsselung statt. So nahmen von den Patienten mit HFPEF 49\% Thiazide und 36\% Schleifendiuretika.

Aldosteronantagonisten wie Spironolacton werden hingegen vergleichsweise selten verordnet. So nehmen in Diast-CHF 5\% der Patienten mit HFPEF regelmäßig einen Aldosteronantagonisten ein. Bei Dinh et al. wird die Einnahme von Spironolacton nicht angegeben. Bei Anand et al. (2010) wird von 2\% der Patienten Spironolacton eingenommen. Bei Kempf et al. (2007b) wird von 23,7\% der Patienten Spironolacton eingenommen. Die Unterschiede dürften auf die unterschiedliche Verschreibungspraxis in den jeweiligen Ländern zurückzuführen sein, in welchen die Kollektive rekrutiert wurden. 
Ebenfalls häufig erfolgte die Einnahme von Statinen. So nahmen in Diast-CHF $40 \%$ der Patienten mit HFPEF Statine ein. Bei Dinh et al. nehmen 65\% der Patienten mit HFPEF Statine ein. Bei Anand et al. wird die Einnahmehäufigkeit von Statinen mit 38\% angegeben. Bei Kempf et al. (2007b) finden sich keine weiteren Angaben über die Medikation.

Auch ASS wird häufig eingenommen. So fand sich in Diast-CHF bei $41 \%$ der Patienten mit HFPEF ASS in der Vormedikation. Bei Dinh et al. wird ASS von $76 \%$ der Patienten mit HFPEF dauerhaft eingenommen. Bei Anand et al. wird ASS von insgesamt $51 \%$ der Patienten regelmäßig eingenommen.

Zusammenfassend lässt sich festhalten, dass bei den Studien unterschiedliche Fragestellungen vorlagen, die sich auch auf die Rekrutierung auswirkten. Bei Kempf et al. (2007b) wurde ein vorselektiertes und voruntersuchtes Patientenkollektiv betrachtet. Bei Anand et al. wurde mit Val-HeFT ebenfalls ein vorselektiertes Patientenkollektiv betrachtet und auf einen Zusammenhang von Mortalität und Morbidität mit den Serumkonzentrationen von GDF-15 untersucht. Bei Dinh et al. (2011) wurde ebenfalls ein vorselektiertes Kollektiv betrachtet, welches sich aus Patienten rekrutierte, bei denen eine KHK entweder bekannt war oder vermutet wurde und die einer elektiven Koronarangiographie zugeführt wurden. Bei Diast-CHF wurde ein Risikokollektiv mit Patienten ab 50 Jahren ausgewählt und es liegt somit eine epidemiologische Studie vor. Auch wurden sowohl bei Anand et al. (2010) als auch bei Kempf et al. (2007b) lediglich Patienten mit HFREF eingeschlossen, wohingegen bei Dinh et al. (2011) und Diast-CHF sowohl Patienten mit HFPEF als auch mit DD sowie gesunde Kontrollprobanden eingeschlossen wurden. Die anamnestischen und klinisch erhobenen Parameter sind somit nur bedingt vergleichbar, allerdings finden sich auch einige Parallelen.

\subsection{Echokardiografie}

In Diast-CHF wurde ein Schema verwendet, das an der der Universität Göttingen etabliert wurde (Wachter et al. 2007).

Die Einteilung der Patienten geschieht hier zunächst einmal anhand der EF. Patienten, die eine $\mathrm{EF}<50 \%$ und/oder eine anormale Wandbewegung zweier benachbarter Segmente aufweisen, wurden als Patienten mit HFREF klassifiziert. Ähnlich erfolgte die Bestimmung einer HFREF bei Anand et al. (2010). Kriterien für eine HFREF waren hier das Vorliegen einer linksventrikulären Dysfunktion mit einer $E F<40 \%$ sowie eines LVIDD von mehr als 2,9 $\mathrm{cm} / \mathrm{m}^{2}$. Bei Kempf et al. (2007b) werden als Kriterien für die Diagnose einer HFREF das Vorliegen einer Vergrößerung des linken Ventrikels und einer linksventrikulären Dysfunktion aufgeführt. Ein genauer Grenzwert für die EF wird nicht genannt, allerdings legt die Beschrei- 
bung seines Patientenkollektivs nahe, dass auch hier ein Grenzwert von < 40\% für die EF galt. Sowohl Kempf et al. (2007b) als auch Anand et al. (2010) schlossen in ihre Studie lediglich Patienten mit HFREF ein. In die vorliegende Arbeit wurden Patienten mit HFREF nicht eingeschlossen.

Die weitere Einteilung der Patienten erfolgte bei Diast-CHF anhand des E/A Verhältnisses, des Verhältnisses von $E / E^{\prime}$ und des Verhältnisses von $S / D$. Ein weiterer diagnostisch relevanter Parameter ist das Verhältnis von E/A unter dem Valsalva-Manöver. Redfield et al. (2004) verwendeten ein ähnliches Schema, welches mit dem von Diast-CHF vergleichbar ist (Redfield et al. 2003). Auch dieses Schema verwendete das E/E'-Verhältnis und auch hier fand mithilfe des Valsalva-Manövers eine Unterteilung des restriktiven Stadiums in reversibel und irreversibel statt. Bei der Beurteilung des E/A-Verhältnisses finden sich jedoch unterschiedliche Grenzwerte. So definieren Redfield et al. (2003) das Stadium der verzögerten Relaxation mit $E / A \leq 0,75$, während bei Diast-CHF hier ein $E / A<1$ als Grenzwert gilt. Diast-CHF sieht das Stadium der verzögerten Relaxation mit einem E/A $<1$ als hinreichend definiert an, während bei Redfield et al. (2003) auch S/D und E/E' zusätzlich in der Definition verwendet werden.

Für das Stadium der Pseudonormalisierung und der Restriktion gelten bezüglich des E/AVerhältnisses ebenfalls unterschiedliche Grenzwerte, die für $E / E^{\prime}$ sind hingegen gleich.

Tschöpe et al. (2005) verwenden ebenfalls einen Gewebedoppler zur Beurteilung der diastolischen Funktion, beurteilen jedoch anstatt des $E / E^{\prime}$ das $E^{\prime} / a^{\prime}$-Verhältnis. a' stellt hier die spätdiastolische Mitralanulusgeschwindigkeit dar. Zusätzlich wurde neben dem S/DVerhältnis die Dezelerationszeit zur Stadieneinteilung verwendet.

Vergleicht man nun jeweils die Patienten mit einer HFPEF aus Diast-CHF und aus dem Kollektiv von Tschöpe et al. (2005), so lag der Mittelwert der LVEF bei Diast-CHF bei 60\%, was unter den bei Tschöpe et al. (2005) ermittelten 68\% lag.

Beim LVMI zeigte sich ebenfalls ein Unterschied. Der Mittelwert lag bei den Patienten aus Diast-CHF bei $129 \mathrm{~g} / \mathrm{m}^{2}$, während er bei Tschöpe et al. (2005) bei $114 \mathrm{~g} / \mathrm{m}^{2}$ lag.

Betrachtet man den LAVI bei den Patienten mit HFPEF, so liegt dieser bei Diast-CHF bei 30,8 und bei Tschöpe et al. (2005) bei $21 \mathrm{ml} / \mathrm{m}^{2}$. Somit ist er bei Diast-CHF wiederum höher als bei Tschöpe et al. (2005).

Das mittlere E/A-Verhältnis der Patienten mit HFPEF lag bei Tschöpe et al. (2005) bei 0,9. Dies liegt nahe an dem Mittelwert in Diast-CHF für E/A, welcher bei 0,9 liegt.

Für die Dezelerationszeit liefert Diast-CHF mit 230 ms einen deutlich höheren Mittelwert als Tschöpe et al. (2005), welcher bei 198 ms liegt. 
Die Unterschiede dürften auf den großen mittleren Altersunterschied zwischen den Kollektiven zurückzuführen sein und relativieren sich daher. So waren die Patienten bei Tschöpe et al. (2005) 22 Jahre jünger als in Diast-CHF.

Bei Redfield et al. (2004) werden die erhobenen Echoparameter leider nicht einzeln aufgeführt.

Betrachtet man die echokardiographischen Kriterien in den einzelnen Studien, so finden sich bei der HFREF verhältnismäßig ähnliche Kriterien. Allerdings variiert bezüglich der LVEF der Grenzwert, ab dem man von einem Vorliegen einer HFREF spricht. Hinsichtlich der echokardiographischen Klassifikation einer HFPEF ergibt sich zumindest in groben Zügen ein einheitliches Bild.

\subsection{Biomarker}

\subsubsection{Erhöhung von GDF-15 bei Patienten mit DD und HFPEF}

In der vorliegenden Arbeit lag die mittlere Konzentration von GDF-15 bei Patienten mit DD bei $0,96 \mathrm{ng} / \mathrm{ml}$ und ist somit signifikant $(\mathrm{p}=0,002)$ erhöht im Vergleich zur Kontrollgruppe, in welcher der Median für GDF-15 bei $0,84 \mathrm{ng} / \mathrm{ml}$ lag. Bei Dinh et al. (2011) zeigt sich ein ähnliches Bild. Auch hier ist die Konzentration von GDF-15 mit einem Median von 0,78 ng/ml bei Patienten mit präklinischer DD gegenüber $0,6 \mathrm{ng} / \mathrm{ml}$ in der Kontrollgruppe signifikant $(p=0,003)$ erhöht.

Betrachtet man Diast-CHF hinsichtlich des Grades der DD, so findet sich ein signifikanter Zusammenhang zwischen höheren Serumkonzentrationen von GDF-15 und einem höheren Grad der DD. Patienten mit einem Grad 0 der DD haben im Mittel normale Konzentrationen von GDF-15. Patienten mit einem Grad 1 der DD haben im Mittel bereits eine erhöhte Serumkonzentration von GDF-15. Mit dem Grad der DD steigt die Serumkonzentration von GDF-15 dann weiter an.

Ferner wird deutlich, dass die Serumkonzentration von GDF-15 bei Patienten mit HFPEF mit $1,64 \mathrm{ng} / \mathrm{ml} \mathrm{im}$ Vergleich zur Kontrollgruppe mit $0,84 \mathrm{ng} / \mathrm{ml}$ signifikant $(\mathrm{p}<0,001)$ erhöht ist. Ebenfalls findet sich ein signifikanter $(p<0,001)$ Unterschied bei einem Vergleich von Patien-ten mit HFPEF und Patienten mit DD 0,96 ng/ml. Der obere Normbereich der Serumkonzen-tration von GDF-15 endet bei $1,20 \mathrm{ng} / \mathrm{ml}$ (Kempf et al. 2007a). $79,5 \%$ der Patienten mit HFPEF liegen über diesem Grenzwert.

Ähnlich verhält es sich bei Dinh et al. (2011). Hier war die Serumkonzentration von GDF-15 bei Patienten mit HFPEF mit $1,08 \mathrm{ng} / \mathrm{ml}$ signifikant $(p<0,001)$ erhöht gegenüber Patienten 
mit präklinischer DD mit 0,78 ng/ml und auch gegenüber der Kontrollgruppe, in welcher der Median für die Serumkonzentration von GDF-15 bei $0,6 \mathrm{ng} / \mathrm{ml} \mathrm{lag.}$

In einer multivariaten linearen Regressionsanalyse wurde das Vorliegen einer HFPEF als abhängige Variable verwendet und log GDF-15 sowie Alter, Geschlecht, BMI und das Vorliegen einer KHK als unabhängige Variablen verwendet. Es zeigte sich ein signifikanter Zusammenhang zwischen erhöhten Serumkonzentrationen von GDF-15 und dem Vorliegen einer HFPEF. Der $\mathrm{r}^{2}$-Wert dieses Modells betrug 0,702.

In einer weiteren multivariaten linearen Regressionsanalyse, in welcher das Vorliegen einer DD als abhängige Variable verwendet wurde, wurden neben log GDF-15 auch Alter, Geschlecht sowie der BMI als unabhängige Variablen integriert. Hierbei zeigte sich allerdings kein signifikanter Zusammenhang zwischen der Konzentration von GDF-15 und dem Vorliegen einer DD. Der r²-Wert dieses Modells betrug 0,243.

In der Zusammenschau lässt sich also festhalten, dass bei Patienten mit HFPEF die Serumkonzentration von GDF-15 gegenüber Kontrollprobanden erhöht ist und dass diese Erhöhung unabhängig von den Einflussfaktoren Alter, Geschlecht, BMI und dem Vorliegen einer KHK ist. Bei Patienten mit DD stellt sich dieser Zusammenhang im beschriebenen Modell im vorliegenden Kollektiv nicht dar.

\subsubsection{Zusammenhang von GD-15 mit der körperlichen Leistungs- fähigkeit und der Lebensqualität}

An dieser Stelle ist auch die nähere Betrachtung der erhobenen Parameter der körperlichen Leistungsfähigkeit sowie der Lebensqualität geboten.

Im 6-Minuten-Gehtest lag der Median der zurückgelegten Gehstrecke bei den Patienten aus Diast-CHF bei $431 \mathrm{~m}$ für Patienten mit HFPEF, bei $570 \mathrm{~m}$ für Patienten mit DD und in der Kontrollgruppe bei $598 \mathrm{~m}$.

Sowohl bei Kempf et al. (2007b) als auch bei Anand et al. (2010) und Dinh et al. (2011) wurde kein 6-Minuten-Gehtest durchgeführt. Frankenstein et al. (2007) untersuchten ein Kollektiv mit einer EF $\leq 40 \%$, hier betrug die zurückgelegte Gehstrecke im Mittel $459 \mathrm{~m}$. Da bei Frankenstein et al. jedoch ein Kollektiv aus Patienten mit HFREF untersucht wurde, ist die Vergleichbarkeit mit der vorliegenden Arbeit naturgemäß eingeschränkt. Es lässt sich aber festhalten, dass das Vorliegen einer DD mit einer geringeren körperlichen Leistungsfähigkeit einhergeht, wie bereits von Grewal et al. (2009) gezeigt.

Im Folgenden zeigte sich bei der Untersuchung des Zusammenhangs zwischen der Serumkonzentration von GDF und der im 6-Minuten-Gehtest zurückgelegten Gehstrecke ein deut- 
licher inverser Zusammenhang mit einem Korrelationskoeffizienten von -0,418 bei Betrachtung des Gesamtkollektivs. Im vorliegenden Gesamtkollektiv gehen also erhöhte Serumkonzentrationen mit einer verminderten körperlichen Leistungsfähigkeit einher. Bei einer isolierten Betrachtung der Patienten mit HFPEF, DD bzw. der Kontrollgruppe bleibt der beschriebene Zusammenhang nicht bestehen. Eine mögliche Erklärung hierfür ist, dass durch die Unterteilung die betrachteten Untergruppen zu klein werden und signifikante Zusammenhänge nicht mehr zur Darstellung kommen.

Betrachtet man nun die Ergebnisse des SF-36 näher, so ergibt sich bei dem physischen Summenscore eine Punktzahl von 36 für Patienten mit HFPEF, eine Punktzahl von 54 für Patienten mit DD und für die Kontrollgruppe ebenfalls eine Punktzahl von 54.

Der psychische Summenscore betrug für Patienten mit HFPEF 53 Punkte, gegenüber 54 Punkten für Patienten mit DD und 55 Punkten für die Kontrollprobanden.

Der SF-36 wurde von Kempf et al. (2007b), Anand et al. (2010) und Dinh et al. (2011) ebenfalls nicht durchgeführt.

Bei der Untersuchung des Zusammenhangs zwischen der Serumkonzentration von GDF-15 und dem SF-36 findet sich im Gesamtkollektiv eine deutliche inverse Korrelation zwischen GDF-15 sowie den Items im SF-36, sofern sie sich auf die rein physischen Körperfunktionen beziehen.

So ergibt sich für den physischen SF-36 Summenscore ein signifikanter inverser Korrelationskoeffizient von -0,409 mit der Serumkonzentration von GDF-15 bei Betrachtung des Gesamtkollektivs. Kein signifikanter Zusammenhang hingegen fand sich zwischen der Serumkonzentration von GDF-15 und dem psychischen Summenscore des SF-36. Im vorliegenden Patientenkollektiv korrelierten erhöhte Serumkonzentrationen von GDF-15 also invers mit dem physischen Summenscore von SF-36.

Edelmann et al. (2011) zeigten in ihrem aus Patienten mit DD und Kontrollprobanden bestehenden Kollektiv, dass NT-proBNP und MR-proADM mit den physischen Parametern des SF-36 korrelieren. Dabei fand sich bei MR-proADM ein stärkerer Zusammenhang mit den physischen Parametern des SF-36 als bei NT-proBNP. Dies ist insofern interessant, als wie im folgenden Kapitel gezeigt, in der vorliegenden Arbeit GDF-15 bei der Diskrimination der Patienten mit HFPEF von gesunden Probanden zwar NT-proBNP überlegen ist, nicht aber MR-proADM.

Bei einer weiteren Unterteilung des Kollektivs in Patienten mit HFPEF, DD und Kontrollprobanden bleibt der Zusammenhang zwischen der Serumkonzentration von GDF-15 und den physischen Parametern des SF-36 nicht bestehen. Eine mögliche Erklärung hierfür ist, 
dass durch eine Unterteilung des Gesamtkollektivs die zu betrachtenden Gruppen zu klein werden und signifikante Zusammenhänge daher nicht mehr zur Darstellung kommen.

In der Zusammenschau fällt also auf, dass in Diast-CHF ein Zusammenhang zwischen einer eingeschränkten körperlichen Leistungsfähigkeit und einer Reduktion der physischen Parameter der SF-36 als Maß für die Lebensqualität auf der einen Seite und einer erhöhten Serumkonzentration von GDF-15 auf der anderen Seite besteht. Somit scheint sich GDF-15 auch als Biomarker für den klinischen Schweregrad bei Patienten mit HFPEF und DD anzubieten.

\subsubsection{Zusammenhang von GDF-15 mit Echoparametern}

Die HFPEF und ihr Verlauf sind zum einen nach Stadien, zum anderen aber auch anhand sich kontinuierlich verändernder echokardiografischer Parameter einteilbar. Dazu gehören beispielsweise das Verhältnis von E/E' oder der LAVI, aber auch der LVMI oder E'/a' und E/A. Dabei stellt sich die Frage des Verhältnisses dieser Parameter der DD zu den im Serum vorliegenden Konzentrationen von GDF-15. Die angegebenen Korrelationen liegen dabei, so nicht anders angegeben, auf einem Signifikanzniveau von $\mathrm{p}<0,01$.

Betrachtet man nun zunächst das Gesamtkollektiv der vorliegenden Arbeit, so ergibt sich für E/A ein mittlerer negativer Korrelationskoeffizient von $-0,139$ bei einem Signifikanzniveau von $p<0,05$. Allerdings verändert sich $E / A$ im Rahmen der verschiedenen Stadien einer DD in beide Richtungen. Hierbei ist zu beachten, dass sich das E/A-Verhältnis beim Durchlaufen der Stadien einer DD definitionsgemäß in verschiedene Richtungen verändert. Bei normaler diastolischer Funktion gilt laut Schema des KNHI E/A $\geq 1$. Während der Grad I mit E/A $<1$ als hinreichend definiert gilt, sind die Schweregrade ab II unter anderem erneut durch ein erhöhtes E/A-Verhältnis definiert. Dieser Sachverhalt erschwert die Aufstellung einer Korrelationsrechnung und könnte dieses uneinheitliche Bild bewirken. Dies erschwert die Interpretation der Korrelation. Kontinuierlich ansteigende Parameter, wie etwa das E/E'Verhältnis, zeigen dagegen eindeutigere Korrelationen. Im Anschluss wurden die Patienten mit HFPEF, DD und die Kontrollgruppe isoliert hinsichtlich einer möglichen Korrelation von E/A mit der Serumkonzentration von GDF-15 untersucht. Bei einer isolierten Betrachtung fand sich jedoch keine signifikante Korrelation zwischen E/A und der Serumkonzentration von GDF-15. Eine mögliche Erklärung hierfür ist, dass bei einer Unterteilung des Gesamtkollektivs die betrachteten Gruppen zu klein werden.

Für E'/A' findet sich bei Betrachtung des Gesamtkollektivs ein negativer Korrelationskoeffizient von 0,252. Betrachtet man die Patienten mit HFPEF, DD und die Kontrollgruppe 
jedoch isoliert hinsichtlich eines möglichen Zusammenhangs von E'/A' mit der Serumkonzentration von GDF-15, so findet sich auch hier keine signifikante Korrelation.

Bezüglich des LVMI findet sich bei Betrachtung des Gesamtkollektivs ein Korrelationskoeffizient von 0,292 mit der Serumkonzentration von GDF-15. Lind et al. (2009) berichten ebenfalls von einer positiven Korrelation von GDF-15 mit dem LVMI. Sie beschreiben in ihrem Kollektiv auch einen deutlichen Zusammenhang von GDF-15 mit dem Auftreten einer $\mathrm{HI}$, jedoch wird eine weitere Unterteilung in Patienten mit HFPEF und HFREF nicht aufgeführt. Im Anschluss wurden die Patienten mit HFPEF, DD sowie die Kontrollprobanden isoliert hinsichtlich einer Korrelation des LVMI mit der Serumkonzentration von GDF-15 untersucht. Hier fand sich jedoch kein signifikanter Zusammenhang.

Ein signifikanter Zusammenhang fand sich im Gesamtkollektiv zwischen der Serumkonzentration von GDF-15 und dem LAVI bei einem Korrelationskoeffizienten von 0,323. Dinh et. al (2011) beschreiben in ihrem Kollektiv ebenfalls einen signifikanten Zusammenhang von GDF-15 mit dem LAVI, sie geben hier mit 0,354 sogar einen ähnlichen Korrelationskoeffizienten an. Betrachtet man in der vorliegenden Arbeit die Patienten mit HFPEF, DD und die Kontrollgruppe jedoch isoliert, so bleibt die Korrelation von GDF-15 mit dem LAVI nicht signifikant. Wie oben erwähnt, ist eine mögliche Erklärung hierfür, dass durch eine weitere Unterteilung die untersuchten Gruppen zu klein werden.

Für E/E' findet sich bei einer Betrachtung des Gesamtkollektivs ein Korrelationskoeffizient von 0,374 mit der Serumkonzentration von GDF-15. Dies ist insofern bedeutsam, als E/E' bei der Diagnosestellung der DD eine zentrale Rolle einnimmt. Ferner wurden die Patienten mit HFPEF, DD sowie die Kontrollprobanden isoliert hinsichtlich einer Korrelation von E/E' mit der Serumkonzentration von GDF-15 untersucht, hierbei blieben die Korrelationen jedoch nicht signifikant.

In der Zusammenschau fällt also auf, dass in Diast-CHF ein Zusammenhang zwischen echokardiografischen Parametern der diastolischen Funktion auf der einen Seite und einer erhöhten Serumkonzentration von GDF-15 auf der anderen Seite besteht. Es scheint, dass eine höhere Serumkonzentration von GDF-15 mit dem Auftreten von pathologischen Veränderungen in der Echokardiografie im Sinne einer DD einhergeht. Bei einer weiteren Unterteilung des Kollektivs in Patienten mit HFPEF, DD und Kontrollprobanden bleibt dieser Zusammenhang nicht bestehen. Eine mögliche Erklärung hierfür ist, dass durch eine Unterteilung des Gesamtkollektivs die betrachteten Gruppen zu klein werden und signifikante Zusammenhänge somit nicht mehr zur Darstellung kommen. 


\subsubsection{Fähigkeit der untersuchten Biomarker zur Detektion einer kar- dialen Dysfunktion}

Im Idealfall wäre GDF-15 zur Detektion einer kardialen Dysfunktion in der Lage. Somit hätte im klinischen Alltag der Untersucher ein vergleichsweise einfaches diagnostisches Mittel zur Verfügung und könnte echokardiografische oder invasive Untersuchungen ergänzen oder sogar ganz auf diese verzichten. Im Folgenden wurde GDF-15 zunächst auf seine Diskriminationsfähigkeit von Patienten mit DD von Kontrollprobanden hin untersucht. Im Anschluss wurde GDF-15 auf seine Diskriminationsfähigkeit von Patienten mit HFPEF von Kontrollprobanden hin untersucht. Um GDF-15 auf diese Diskriminationsfähigkeiten hin zu prüfen, wurden ROC-Kurven erstellt. Ebenfalls wurden an dieser Stelle ROC-Kurven für NTproBNP erstellt, welches bereits beim Nachweis einer HFPEF Verwendung findet (Paulus et al. 2007), sowie für die ebenfalls bestimmten Peptide MRproANP, MRproADM, CTproET1 und CTproAVP.

Bei der Diskrimination zwischen Patienten mit DD und Kontrollprobanden zeigt sich folgendes Ergebnis. Zwar liegen die AUC sowohl von GDF-15 als auch der übrigen bestimmten Biomarker fast ausnahmslos über 0,5, allerdings sind die AUC im Allgemeinen vergleichsweise klein. GDF-15 weist hier eine AUC von 0,631 auf. Interessanterweise weist MRproADM mit einer AUC von 0,668 eine geringfügig größere AUC auf als GDF-15. Die übrigen bestimmten Peptide haben eine geringere AUC als GDF-15. Die kleinste AUC fand sich für MRproANP und betrug 0,533. Aufgrund der geringen AUC scheint GDF-15 sich in der vorliegenden Arbeit nicht zur Diagnose einer DD zu eignen.

Ein anderes Bild hingegen zeigt sich bei der Diskrimination von Patienten mit HFPEF von Kontrollprobanden. Hier liegt die AUC für GDF-15 bei 0,907. MRproADM erreicht hier eine AUC von 0,932, welche lediglich geringfügig größer ist als die AUC von GDF-15. Die AUC von MRproANP, NTproBNP, CTproET1 und CTproAVP sind sämtlich kleiner als die AUC von GDF-15. Die kleinste AUC fand sich hier für CTproAVP und lag bei 0,741.

In der Zusammenschau ist GDF-15 in der vorliegenden Arbeit also gut geeignet für die Diagnose einer HFPEF und ist darin den Biomarkern MRproANP, NTproBNP, CTproET1 und CTproAVP überlegen. Lediglich MRproADM wies eine noch bessere Fähigkeit zur Diagnose einer HFPEF auf als GDF-15.

Zur Diagnose einer DD hingegen erscheint GDF-15 aufgrund der vergleichsweise niedrigen AUC nicht geeignet. 


\subsection{Limitierungen der Arbeit}

Invasive Methoden gelten als Mittel zum definitiven Nachweis einer DD (Zile et al. 2004). Daher wäre eine invasive Bestätigung und Quantifizierung der Patienten mit DD bei DiastCHF wünschenswert gewesen. Allerdings sind invasive Methoden im klinischen Alltag nicht praktikabel. Im Rahmen der Diast-CHF-Studie wäre es sowohl ethisch als auch finanziell nicht vertretbar gewesen, invasive Messungen bei allen Patienten durchzuführen.

Eine weitere Limitierung ist die eher kleine Anzahl untersuchter Patienten, was die Aussagekraft der Studie einschränkt und sich insbesondere bei einer weiteren Unterteilung des Kollektivs in Untergruppen bemerkbar macht.

Tschöpe et al. (2005) pausierten in ihrem Kollektiv sämtliche Medikation mit Einfluss auf die Hämodynamik 48 Stunden vor der Untersuchung. Dieser Schritt mag zwar konsequent erscheinen und genauere Ergebnisse liefern. Im klinischen Alltag wäre es jedoch weder ethisch vertretbar noch praktikabel, vor einer Untersuchung die Medikation abzusetzen. Genauso wenig wäre dies in einer Studie wie Diast-CHF machbar gewesen. 


\section{Zusammenfassung}

Herzinsuffizienz (HF) ist eine Erkrankung von hoher Prävalenz und Mortalität. Je nach Studie leiden über $50 \%$ der Patienten mit HF an einer Herzinsuffizienz mit normaler Ejektionsfraktion (HFPEF).

Bei Patienten mit Herzinsuffizienz bei reduzierter Ejektionsfraktion (HFREF) spielt die Verwendung von Biomarkern zur klinischen Beurteilung, Diagnose und Verlaufskontrolle eine zentrale Rolle. Die natriuretischen Peptide NTproBNP und BNP finden bereits im klinischen Alltag Verwendung und sind Teil der Richtlinien der European Society of Cardiology (ESC) zur Diagnose einer HFPEF. Eine größer werdende Anzahl von Biomarkern wird auf ihre Verwendbarkeit bei einer HFPEF hin überprüft. Der Stellenwert von GDF-15 bei Patienten mit HFPEF ist bislang nicht ausreichend untersucht. Ziel dieser Arbeit ist es daher, die klinische Relevanz und diagnostische Fähigkeit von GDF-15-Konzentrationen im Plasma von Patienten mit DD und von Patienten mit HFPEF zu untersuchen und mit anderen etablierten Biomarkern zu vergleichen.

Zu diesem Zweck wurden aus der prospektiven, multizentrischen Studie „Prävalenz und Verlauf der diastolischen Dysfunktion und der diastolischen Herzinsuffizienz" (Diast-CHF) insgesamt 330 Patienten mit bekannter HF oder positiven Framingham-Kriterien ausgewählt. Die Einteilung in Patienten mit HFPEF $(n=142)$ und in Patienten mit DD $(n=103)$ erfolgte anhand echokardiografischer Kriterien und gegebenenfalls notwendiger Zusatzkriterien. Prospektiv eingeschlossen wurde eine Gruppe gesunder Probanden (KON) ( $n=85)$ zu Vergleichszwecken. Das mediane Alter der Patienten betrug 73 Jahre für Patienten mit HFPEF, 61 Jahre für Patienten mit DD und 53 Jahre für die KON. Der Anteil weiblicher Patienten lag bei $64 \%$ für Patienten mit HFPEF, 59\% für Patienten mit DD und 74\% für die KON.

Die Bestimmung von GDF-15 erfolgte mit einem noch nicht kommerziell verfügbaren Test der Firma Roche Diagnostics. Die Serumkonzentrationen von GDF-15 waren bei Patienten mit HFPEF mit einem Median von 1,64 ng/ml im Vergleich zu den KON mit einem Median von $0,84 \mathrm{ng} / \mathrm{ml}$ signifikant höher. Bei Patienten mit DD lag der Median für die Serumkonzentration von GDF-15 bei $0,96 \mathrm{ng} / \mathrm{ml}$. Auch hier ergab sich ein signifikanter Unterschied im Vergleich mit HFPEF. Der obere Normbereich der Serumkonzentration von GDF-15 endet bei $1,20 \mathrm{ng} / \mathrm{ml}$ (Kempf et al. 2007a). Mit steigendem Grad der diastolischen Dysfunktion stieg auch die Serumkonzentration von GDF-15. Zudem korrelierte GDF-15 mit mehreren echokardiografischen Parametern, welche zur Diagnose einer HFPEF herangezogen wurden.

Im Rahmen einer ROC-Analyse erfolgte der Vergleich von GDF-15 mit den ebenfalls bestimmten Biomarkern BNP (NTproBNP), ANP (MRproANP), Adrenomedullin (MRproADM), Endothelin-1 (CTproET1) und Vasopressin (CTproAVP) bezüglich der Fähigkeit zur Detek- 
tion einer HFPEF. Hierbei lag die Fläche unter der Kurve (AUC) für GDF-15 bei 0,907. MRproADM erreichte eine AUC von 0,932, welche sogar noch geringfügig größer ist als die AUC von GDF-15. Die AUC von MRproANP, NTproBNP, CTproET1 und CTproAVP waren sämtlich kleiner als die AUC von GDF-15. Die kleinste AUC fand sich hier für CTproAVP und lag bei 0,741 .

In der Zusammenschau ist GDF-15 in der vorliegenden Arbeit also gut geeignet für die Diagnose einer HFPEF und ist darin den zum Teil etablierten Biomarkern MRproANP, NTproBNP, CTproET1 und CTproAVP überlegen. Lediglich MRproADM wies eine noch bessere Fähigkeit zur Diagnose einer HFPEF auf als GDF-15. Zur Diagnose einer DD hingegen erscheint GDF-15 aufgrund der vergleichsweise niedrigen AUC nicht geeignet.

Ferner fand sich im vorliegenden Kollektiv ein signifikanter Zusammenhang zwischen einer eingeschränkten körperlichen Leistungsfähigkeit und einer Reduktion der physischen Parameter des Short Form Health Survey (SF-36) als Maß für die Lebensqualität auf der einen Seite und einer erhöhten Serumkonzentration von GDF-15 auf der anderen Seite. Somit scheint sich GDF-15 auch als Biomarker für den klinischen Schweregrad bei Patienten mit HFPEF und DD anzubieten.

Zusammenfassend weisen die vorliegenden Daten darauf hin, dass GDF-15 einen relevanten Stellenwert bei der Diagnose und der klinischen Beurteilung von Patienten mit HFPEF hat. Diese sich somit abzeichnende klinische Relevanz sollte in künftigen Studien in größeren Patientenkollektiven untersucht werden. 


\section{English summary}

Heart failure (HF) is a disease of high prevalence and mortality. Depending on the respective study, more than $50 \%$ of patients with HF suffer from heart failure with preserved ejection fraction (HFPEF). In patients with heart failure and reduced ejection fraction (HFREF), the use of biomarkers plays a central part in medical diagnosis and monitoring of the disease course. According to the guidelines of the European Society of Cardiology (ESC), the natriuretic peptides NTproBNP and BNP should be implemented in the diagnosis of HFPEF. An increasing number of biomarkers are currently being tested with respect to their utility for the diagnosis of HEPEF. The importance of GDF-15 for patients with HFPEF has not been sufficiently examined yet. Therefore, this study investigated the clinical relevance and diagnostic utility of GDF-15 plasma concentrations in patients with diastolic dysfunction (DD) and HFPEF and, furthermore, compared these results with other established biomarkers.

For this purpose, a total of 330 patients with ascertained HF or positive Framingham criteria were selected from the prospective multicenter study "Prävalenz und Verlauf der diastolischen Dysfunction und der diastolischen Herzinsuffizienz" (Diast-CHF). Patients with HFPEF $(n=142)$ and DD $(n=103)$ were grouped predominantly according to echocardiographic criteria. In order to compare the clinical results, a group of healthy persons ( $n=85$ ) was additionally included. The median age of study participants with HFPEF was 73 years and for patients with DD 61 years, while the median age of healthy controls was 53 years. Among patients grouped as HEPEF, the percentage of female patients was $64 \%$, which was higher than for patients with DD (59\%) but less than for healthy individuals (74\%).

Serum levels of GDF-15 were measured using a kit developed by Roche Diagnostics which is not commercially available yet. In patients with HFPEF, the serum concentration of GDF15 reached a median of $1.64 \mathrm{ng} / \mathrm{ml}$ and was significantly higher than in the group of healthy controls $(0.84 \mathrm{ng} / \mathrm{ml})$. In the group of DD patients, the median concentration of GDF-15 was $0.96 \mathrm{ng} / \mathrm{ml}$, which was significantly lower as compared to patients with HFPEF. I found a significant positive association between serum-concentration of GDF-15 and the severity of diastolic dysfunction. In addition, GDF-15 correlated with several echocardiographic parameters that were used for the diagnosis of HFPEF.

Using ROC analysis, the biomarkers BNP (NTproBNP), ANP (MRproANP), adrenomedullin (MRproADM), endothelin-1(CTproET1) and vasopressin (CTproAVP) were compared for their utility to detect HFPEF. For GDF-15 the area under the curve (AUC) was 0.907, and for MRproADM this value was 0.932, while the AUCs for MRproANP, NTproBNP, CTproET1 and CTproAVP were lower than that for GDF-15. However, GDF-15 appeared less suitable 
for the diagnosis of DD. Furthermore, in controls I found a significant association between serum concentrations of GDF-15 and reduced physical capacity. Thus, GDF-15 seems to be well suited as a biomarker to classify the clinical severity grade of patients with HFPEF and DD. This clinical relevance should be investigated by research still to come in a larger group of patients. 


\section{Abkürzungsverzeichnis}

A

$A^{\prime}$

ACE

$\mathrm{ADH}$

ADM

ANP

ASS

AT1

AUC

b

BMI

BNP

${ }^{\circ} \mathrm{C}$

$\mathrm{cm}$

COPD

CTproAVP

CTproET1

D

DD

Diast-CHF

E

E'

ED

EDTA

EDV

$\mathrm{E} / \mathrm{E}^{\prime}$

EF

EKG

ESC

ET 1

EZM

GDF-15

GFR atrialer Mitralstromeinfluss

spätdiastolische Mitralringbewegung

Angiotensin-converting-Enzym

antidiuretisches Hormon

Adrenomedullin

atriales natriuretisches Peptid

Acetylsalicylsäure

Antiotensin-II-Rezeptor Typ 1

Fläche unter der Kurve

diastolische linksventrikuläre Steifigkeitskonstante

Body Mass Index

brain natriuretic peptide

Grad Celsius

Zentimeter

chronisch-obstruktive Lungenerkrankung

C-terminaler Teil des proVasopressin

C-terminales Fragment von proEndothelin 1

diastolischer pulmonalvenöser Fluss

diastolische Dysfunktion

Prävalenz und Verlauf der diastolischen Dysfunktion und der diastolischen Herzinsuffizienz

frühdiastolischer Mitralstromeinfluss

frühdiastolische Mitralringbewegung

enddiastolisch

Ethylendiamintetraessigsäure

elektronische Datenverarbeitung

linksventrikulärer Füllungsindex

Ejektionsfraktion

Elektrokardiogramm

European Society of Cardiology

Endothelin 1

extrazelluläre Matrix

growth and differentiation factor 15

glomeruläre Filtrationsrate 


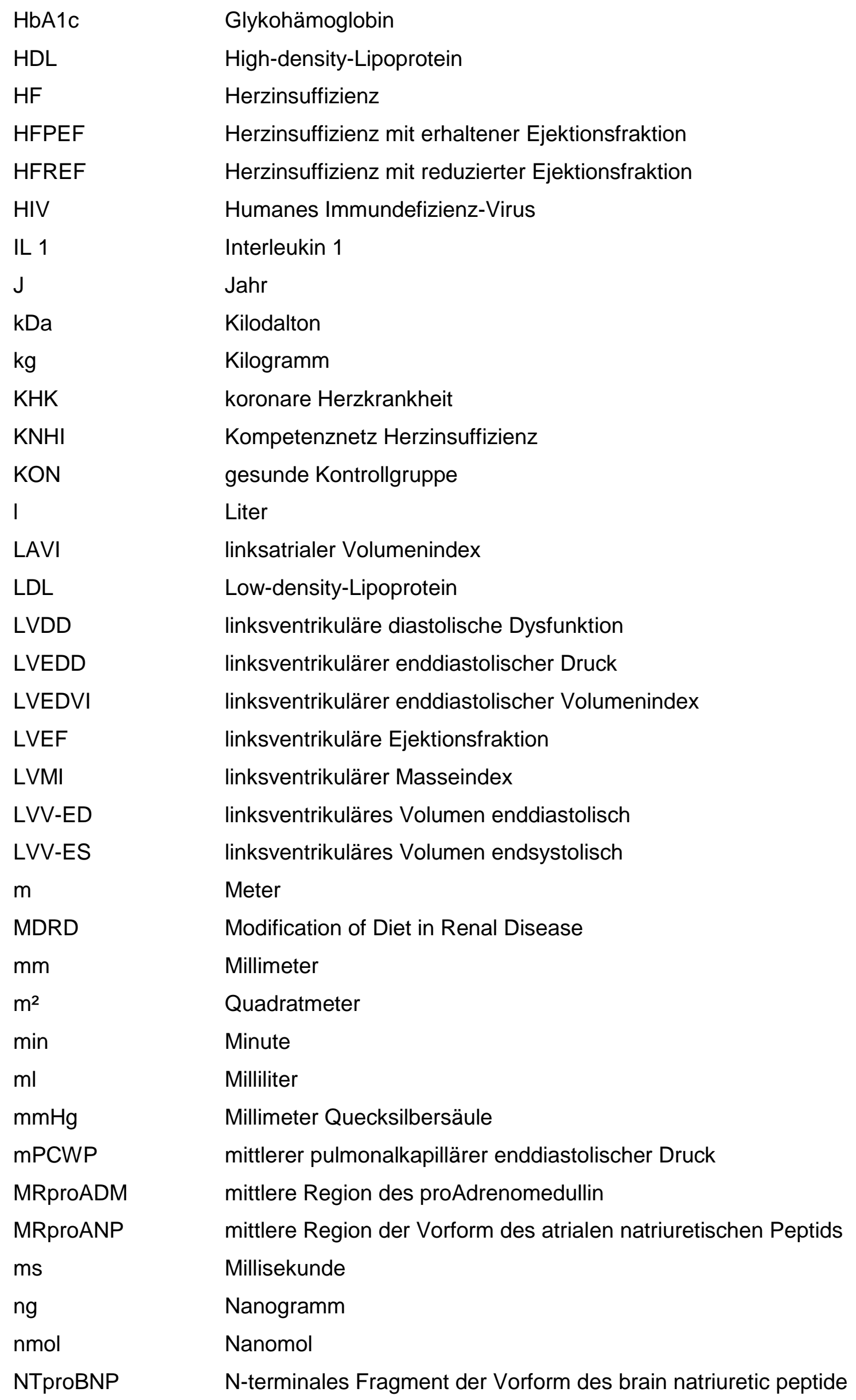




$\begin{array}{ll}\text { NYHA } & \text { New York Heart Association } \\ \text { OSAS } & \text { obstruktives Schlafapnoesyndrom } \\ \text { pAVK } & \text { periphere arterielle Verschlusskrankheit } \\ \text { pg } & \text { Picogramm } \\ \text { pmol } & \text { Picomol } \\ \text { ROC } & \text { receiver operating characteristic } \\ \text { RR } & \text { Blutdruckmessung nach Riva-Rocci } \\ \text { S } & \text { systolischer pulmonalvenöser Fluss } \\ \text { S } & \text { Sekunde } \\ \text { SF-36 } & \text { short form health survey } \\ \text { T } & \text { linksventrikuläre Relaxationszeit } \\ \text { TGF B } & \text { transforming growth factor B } \\ \text { TNF a } & \text { Tumornekrosefaktor } \alpha \\ \text { TP 7 } & \text { Teilprojekt „Diastolische Dysfunktion“ } \\ \text { TSH } & \text { Thyroidea-stimulierendes Hormon } \\ \text { Val-HeFT } & \text { Valsartan Heart Failure Trial } \\ \text { vs. } & \text { versus }\end{array}$




\section{Literaturverzeichnis}

Anand IS, Kempf T, Rector TS, Tapken H, Allhoff T, Jantzen F, Kuskowski M, Cohn JN, Drexler H, Wollert KC (2010): Serial measurement of growth-differentiation factor-15 in heart failure: relation to disease severity and prognosis in the Valsartan Heart Failure Trial. Circulation 122, 1387-95

Angermann CE, Ertl G (2004): Natriuretic peptides - new diagnostic markers in heart disease. Herz $\underline{29}, 609-17$

Bhatia RS, Tu JV, Lee DS, Austin PC, Fang J, Haouzi A, Gong Y, Liu PP (2006): Outcome of heart failure with preserved ejection fraction in a population-based study. N Engl J Med $\underline{355}$, 260-9

Bittner V, Weiner DH, Yusuf S, Rogers WJ, Mclntyre KM, Bangdiwala SI, Kronenberg MW, Kostis JB, Kohn RM, Guillotte M (1993): Prediction of mortality and morbidity with a 6-minute walk test in patients with left ventricular dysfunction. SOLVD Investigators. JAMA 270, 1702-7

Boix Martínez R, Almazá Isla J, Medrano Albero MJ (2002): Mortalidad por insuficiencia cardiac en Espana. Rev Clin Esp 프, 219-26

Bootcov MR, Bauskin AR, Valenzuela SM, Moore AG, Bansal M, He XY, Zhang HP, Donnellan M, Mahler S, Pryor K (1997): MIC-1, a novel macrophage inhibitory cytokine, is a divergent member of the TGF-beta superfamily. Proc Natl Acad Sci U S A. $\underline{94}, 11514-9$

Borlaug BA, Melenovsky V, Russell SD, Kessler K, Pacak K, Becker LC, Kass DA (2006): Impaired chronotropic and vasodilator reserves limit exercise capacity in patients with heart failure and a preserved ejection fraction. Circulation. 114, 2138-47

Brotons C, Moral I, Ribera A, Pérez G, Cascant P, Bustins M (1998): Tendencias de la morbimortalidad por insuficiencia cardiac en Cataluna. Rev Esp Cardiol 47, 633-7

Brown DA, Breit SN, Buring J, Fairlie WD, Bauskin AR, Liu T, Ridker PM (2002): Concentration in plasma of macrophage inhibitory cytokine-1 and risk of cardiovascular events in women: a nested case-control study. Lancet $\underline{359}, 2159-63$ 
Buckley MG, Marcus NJ, Yacoub MH (1999): Cardiac peptide stability, aprotinin and room temperature: importance for assessing cardiac function in clinical practice. Clin Sci (Lond) $\underline{97}$, 689-95.

Bullinger M. (1995): German translation and psychometric testing of the SF-36 Health Survey: preliminary results from the IQOLA Project. International Quality of Life Assessment. Soc Sci Med 41, 1359-66

Burkhoff D, Maurer MS, Packer M (2003): Heart failure with a normal ejection fraction: is it really a disorder of diastolic function? Circulation. $\underline{107}, 656-8$

Burnett JC Jr, Kao PC, Hu DC, Heser DW, Heublein D, Granger JP, Opgenorth TJ, Reeder GS (1986): Atrial natriuretic peptide elevation in congestive heart failure in the human. Science 231, 1145-7.

Bursi F, Weston SA, Redfield MM, Jacobsen SJ, Pakhomov S, Nkomo VT, Meverden RA, Roger VL (2006): Systolic and diastolic heart failure in the community. JAMA 296, 2209-16

Cleland JG, Khand A, Clark A (2001): The heart failure epidemic: exactly how big is it? Eur Heart J 22; 676-83

Collinson PO, Barnes SC, Gaze DC, Galasko G, Lahiri A, Senior R (2004): Analytical performance of the $\mathrm{N}$ terminal pro $\mathrm{B}$ type natriuretic peptide (NT-proBNP) assay on the Elecsys 1010 and 2010 analysers. Eur J Heart Fail 6(3):365-8.

Cortina A, Reguero J, Segovia E, Rodríguez Lambert JL, Cortina R, Arias JC, Vara J, Torre $F$ (2001): Prevalence of heart failure in Asturias (a region in the north of Spain). Am J Cardiol $\underline{87}, 1417-9$

Daniels LB, Clopton P, Bhalla V, Krishnaswamy P, Nowak RM, McCord J, Hollander JE, Duc P, Omland T, Storrow AB (2006): How obesity affects the cut-points for B-type natriuretic peptide in the diagnosis of acute heart failure. Results from the Breathing Not Properly Multinational Study. Am Heart J $\underline{151}$, 999-1005

de Bold AJ, Borenstein HB, Veress AT, Sonnenberg H (1981): A rapid and potent natriuretic response to intravenous injection of atrial myocardial extract in rats. Life Sci $\underline{28}, 89-94$ 
Dinh W, Füth R, Lankisch M, Hess G, Zdunek D, Scheffold T, Kramer F, Klein RM, Barroso MC, Nickl W (2011): Growth-differentiation factor-15: a novel biomarker in patients with diastolic dysfunction? Arq Bras Cardiol 97(1):65-75. Epub 2011 May 13.

Edelmann F, Stahrenberg R, Polzin F, Kockskämper A, Düngen HD, Duvinage A, Binder L, Kunde J, Scherer M, Gelbrich G, Hasenfuss G, Pieske B, Wachter R, Herrmann-Lingen C (2011): Impaired physical quality of life in patients with diastolic dysfunction associates more strongly with neurohumoral activation than with echocardiographic parameters: quality of life in diastolic dysfunction. Am Heart J $\underline{164}, 797-804$

Eggers KM, Kempf T, Allhoff T, Lindahl B, Wallentin L, Wollert KC (2008): Growthdifferentiation factor-15 for early risk stratification in patients with acute chest pain. Eur Heart J 29, 2327-35

Fischer M, Baessler A, Hense HW, Hengstenberg C, Muscholl M, Holmer S, Döring A, Broeckel U, Riegger G, Schunkert H. (2003): Prevalence of left ventricular diastolic dysfunction in the community. Results from a Doppler echocardiographic-based survey of a population sample. Eur Heart J $\underline{24}, 320-8$

Francis GS, Benedict C, Johnstone DE, Kirlin PC, Nicklas J, Liang CS, Kubo SH, RudinToretsky E, Yusuf S (1990): Comparison of neuroendocrine activation in patients with left ventricular dysfunction with and without congestive heart failure. A substudy of the Studies of Left Ventricular Dysfunction (SOLVD). Circulation 82, 1724-9

Frankenstein L, Remppis A, Graham J, Schellberg D, Sigg C, Nelles M, Katus HA, Zugck C (2007): Gender and age related predictive value of walk test in heart failure: Do anthropometrics matter in clinical practice? Int J Cardiol 127, 331-6

Geske JB, Sorajja P, Nishimura RA, Ommen SR (2007): Evaluation of left ventricular filling pressures by Doppler echocardiography in patients with hypertrophic cardiomyopathy: correlation with direct left atrial pressure measurement at cardiac catheterization. Circulation $\underline{116}, 2702-8$

Gottdiener JS, McClelland RL, Marshall R, Shemanski L, Furberg CD, Kitzman DW, Cushman M, Polak J, Gardin JM, Gersh BJ (2002): Outcome of congestive heart failure in elderly persons: influence of left ventricular systolic function. The Cardiovascular Health Study. Ann Intern Med 2002, 137, 631-9 
Grewal J, McCully RB, Kane GC, Lam C, Pellikka PA. (2009): Left ventricular function and exercise capacity. JAMA $\underline{301}, 286-94$

Guyatt GH, Sullivan MJ, Thompson PJ, Fallen EL, Pugsley SO, Taylor DW, Berman LB (1985): The 6-minute walk: a new measure of exercise capacity in patients with chronic heart failure. Can Med Assoc J $\underline{132}$, 919-23

Heinrich P, Haan S, Hermanns H, Löffler G, Müller-Newen G, Schaper F: Kommunikation zwischen Zellen: Extrazelluläre Signalmoleküle, Rezeptoren und Signaltransduktion; in: Biochemie \& Pathobiochemie; hrsg. v. Löffler G, Petrides P, Heinrich P; Springer Medizin Verlag, Heidelberg 2007, 755-808

Ho KK, Pinsky JL, Kannel WB, Levy D (1993): The epidemiology of heart failure: the Framingham Study. J Am Coll Cardiol 22, 6-13

Hogg K, Swedberg K, McMurray J (2004): Heart failure with preserved left ventricular systolic function; epidemiology, clinical characteristics, and prognosis. J Am Coll Cardiol $\underline{43}$, 317-27

Jones AE, Kline JA (2003): Elevated brain natriuretic peptide in septic patients without heart failure. Ann Emerg Med 42, 714-5

Kawaguchi M, Hay I, Fetics B, Kass DA (2003): Combined ventricular systolic and arterial stiffening in patients with heart failure and preserved ejection fraction: implications for systolic and diastolic reserve limitations. Circulation 107, 714-20

Kempf T, Eden M, Strelau J, Naguib M, Willenbockel C, Tongers J, Heineke J, Kotlarz D, Xu J, Molkentin JD (2006): The transforming growth factor-beta superfamily member growthdifferentiation factor-15 protects the heart from ischemia/reperfusion injury. Circ Res $\underline{98}, 351$ 60

Kempf T, Horn-Wichmann R, Brabant G, Peter T, Allhoff T, Klein G, Drexler H, Johnston N, Wallentin L, Wollert KC (2007a): Circulating concentrations of growth-differentiation factor 15 in apparently healthy elderly individuals and patients with chronic heart failure as assessed by a new immunoradiometric sandwich assay. Clin Chem $\underline{53}, 284-91$

Kempf T, von Haehling S, Peter T, Allhoff T, Cicoira M, Doehner W, Ponikowski P, Filippatos GS, Rozentryt P, Drexler H (2007b): Prognostic utility of growth differentiation factor-15 in patients with chronic heart failure. J Am Coll Cardiol $\underline{50}$, 1054-60 
Kitamura K, Kangawa K, Kawamoto M, Ichiki Y, Nakamura S, Matsuo H, Eto T (1993): Adrenomedullin: a novel hypotensive peptide isolated from human pheochromocytoma. Biochem Biophys Res Commun 192, 553-60

Kitzman DW, Gardin JM, Gottdiener JS, Arnold A, Boineau R, Aurigemma G, Marino EK, Lyles M, Cushman M, Enright PL (2001): Importance of heart failure with preserved systolic function in patients $>$ or $=65$ years of age. Am J Cardiol $\underline{87}, 413-9$

Kitzman DW (2008): Diastolic dysfunction: one piece of the heart failure with normal ejection fraction puzzle. Circulation $\underline{117}, 2044-6$

Kobayashi K, Kitamura K, Etoh T, Nagatomo Y, Takenaga M, Ishikawa T, Imamura T, Koiwaya Y, Eto T (1996): Increased plasma adrenomedullin levels in chronic congestive heart failure. Am Heart J $\underline{131}, 994-8$

Lankeit M, Kempf T, Dellas C, Cuny M, Tapken H, Peter T, Olschewski M, Konstantinides S, Wollert KC (2008): Growth differentiation factor-15 for prognostic assessment of patients with acute pulmonary embolism. Am J Respir Crit Care Med $\underline{177}, 1018-25$

La Villa G, Romanelli RG, Casini Raggi V, Tosti-Guerra C, De Feo ML, Marra F, Laffi G, Gentilini P (1992): Plasma levels of brain natriuretic peptide in patients with cirrhosis. Hepatology $\underline{16}, 156-61$

Lerman A, Gibbons RJ, Rodeheffer RJ, Bailey KR, McKinley LJ, Heublein DM, Burnett JC Jr (1993): Circulating N-terminal atrial natriuretic peptide as a marker for symptomless leftventricular dysfunction. Lancet. $\underline{341} 1105-9$

Levey AS, Greene T, Kusek JW, Beck GJ, MDRD Study Group (2000): A simplified equation to predict glomerular filtration rate from serum creatinine. J Am Soc Nephrol 11, A0828

Lind L, Wallentin L, Kempf T, Tapken H, Quint A, Lindahl B, Olofsson S, Venge P, Larsson A, Hulthe J, Elmgren A, Wollert KC (2009): Growth-differentiation factor-15 is an independent marker of cardiovascular dysfunction and disease in the elderly: results from the Prospective Investigation of the Vasculature in Uppsala Seniors (PIVUS) Study. Eur Heart J $\underline{30}, 2346-53$

Liu Y, Haddad T, Dwivedi G (2013): Heart failure with preserved ejection fraction: current understanding and emerging concepts. Curr Opin Cardiol 28(2):187-96. 
Lubien E, DeMaria A, Krishnaswamy P, Clopton P, Koon J, Kazanegra R, Gardetto N, Wanner E, Maisel AS (2002): Utility of B-natriuretic peptide in detecting diastolic dysfunction: comparison with Doppler velocity recordings. Circulation $\underline{105}, 595-601$

McDonagh TA, Holmer S, Raymond I, Luchner A, Hildebrant P, Dargie HJ (2004): NTproBNP and the diagnosis of heart failure: a pooled analysis of three European epidemiological studies. Eur J Heart Fail $\underline{6}$, 269-73

McMurray JJ, Stewart S (2000): Epidemiology, aetiology, and prognosis of heart failure. Heart $\underline{83}, 596-602$

McMurray JJ, Ray SG, Abdullah I, Dargie HJ, Morton JJ (1992): Plasma endothelin in chronic heart failure. Circulation $\underline{85}, 1374-9$

McMurray JJ, Carson PE, Komajda M, McKelvie R, Zile MR, Ptaszynska A, Staiger C, Donovan JM, Massie BM (2008): Heart failure with preserved ejection fraction: clinical characteristics of 4133 patients enrolled in the I-PRESERVE trial. Eur J Heart Fail $\underline{10}$, 149-56

Meeran K, O'Shea D, Upton PD, Small CJ, Ghatei MA, Byfield PH, Bloom SR (1997): Circulating adrenomedullin does not regulate systemic blood pressure but increases plasma prolactin after intravenous infusion in humans: a pharmacokinetic study. J Clin Endocrinol Metab $\underline{\text { 82, }}$ 95-100

Morgenthaler NG, Struck J, Thomas B, Bergmann A (2004): Immunoluminometric assay for the midregion of pro-atrial natriuretic peptide in human plasma. Clin Chem $\underline{50}, 234-6$

Morgenthaler NG, Struck J, Alonso C, Bergmann A (2005): Measurement of midregional proadrenomedullin in plasma with an immunoluminometric assay. Clin Chem $\underline{51}, 1823-9$

Morgenthaler NG, Struck J, Alonso C, Bergmann A (2006): Assay for the measurement of copeptin, a stable peptide derived from the precursor of vasopressin. Clin Chem $\underline{52}, 112-9$

Mosteller RD (1987): Simplified calculation of body-surface area. N Engl J Med 317, 1098

Mottram PM, Leano R, Marwick TH (2003): Usefulness of B-type natriuretic peptide in hypertensive patients with exertional dyspnea and normal left ventricular ejection fraction and correlation with new echocardiographic indexes of systolic and diastolic function. Am J Cardiol $\underline{92}, 1434-8$ 
Mueller T, Gegenhuber A, Poelz W, Haltmayer M (2003): Comparison of the Biomedica NTproBNP enzyme immunoassay and the Roche NT-proBNP chemiluminescence immunoassay: implications for the prediction of symptomatic and asymptomatic structural heart disease. Clin Chem $\underline{49}$, 976-9

Naughton MT (2003) Sleep disorders in patients with congestive heart failure. Curr Opin Pulm Med $\underline{9}$, 453-8

Nowatzke WL, Cole TG (2003): Stability of N-terminal pro-brain natriuretic peptide after storage frozen for one year and after multiple freeze-thaw cycles. Clin Chem $\underline{49}, 1560-2$

Owan TE, Hodge DO, Herges RM, Jacobsen SJ, Roger VL, Redfield MM (2006): Trends in prevalence and outcome of heart failure with preserved ejection fraction. N Engl J $\underline{355}$, $251-9$

Papassotiriou J, Morgenthaler NG, Struck J, Alonso C, Bergmann A (2006): Immunoluminometric assay for measurement of the C-terminal endothelin-1 precursor fragment in human plasma. Clin Chem $\underline{52}, 1144-51$

Paulus WJ, Tschöpe C, Sanderson JE, Rusconi C, Flachskampf FA, Rademakers FE, Marino P, Smiseth OA, De Keulenaer G, Leite-Moreira AF (2007): How to diagnose diastolic heart failure: a consensus statement on the diagnosis of heart failure with normal left ventricular ejection fraction by the Heart Failure and Echocardiography Associations of the European Society of Cardiology. Eur Heart J $\underline{28}, 2539-50$

Piechota M, Banach M, Jacoń A, Rysz J (2008): Natriuretic peptides in cardiovascular diseases. Cell Mol Biol Lett $\underline{13}, 155-81$

Preibisz JJ, Sealey JE, Laragh JH, Cody RJ, Weksler BB (1983): Plasma and platelet vasopressin in essential hypertension and congestive heart failure. Hypertension $\underline{5}$, I129-38

Querejeta R, López B, González A, Sánchez E, Larman M, Martínez Ubago JL, Díez J (2004): Increased collagen type I synthesis in patients with heart failure of hypertensive origin: relation to myocardial fibrosis. Circulation $\underline{110}, 1263-8$

Redfield MM, Jacobsen SJ, Burnett JC Jr, Mahoney DW, Bailey KR, Rodeheffer RJ (2003): Burden of systolic and diastolic ventricular dysfunction in the community: appreciating the scope of the heart failure epidemic. JAMA $\underline{289}, 194-202$ 
Redfield MM, Rodeheffer RJ, Jacobsen SJ, Mahoney DW, Bailey KR, Burnett JC Jr (2004): Plasma brain natriuretic peptide to detect preclinical ventricular systolic or diastolic dysfunction: a community-based study. Circulation $\underline{109}$, 3176-81

Rodríguez-Artalejo F, Guallar-Castillón P, Banegas Banegas JR, del Rey Calero J (1997): Trends in hospitalization and mortality for heart failure in Spain, 1980-1993. Eur Heart J $\underline{18}$, $1771-9$

Sanderson JE, Tse TF (2003): Heart failure: a global disease requiring a global response. Heart $\underline{89}, 585-6$

Shah R (2007): Endothelins in health and disease. Eur J Intern Med 18, 272-82

Singh Ranger G (2002): The physiology and emerging roles of antidiuretic hormone. Int J Clin Pract $\underline{56}, 777-82$

Sokoll LJ, Baum H, Collinson PO, Gurr E, Haass M, Luthe H, Morton JJ, Nowatzke W, Zingler C (2004): Multicenter analytical performance evaluation of the Elecsys ${ }^{\circledR}$ proBNP assay. Clin Chem Lab Med $\underline{42}, 965-972$

Stahrenberg R, Edelmann F, Mende $M$, Kockskämper A, Düngen HD, Lüers C, Binder L, Herrmann-Lingen C, Gelbrich G, Hasenfuss G, Pieske B, Wachter R (2010): The novel biomarker growth differentiation factor 15 in heart failure with normal ejection fraction. Eur J Heart Fail 12, 1309-16

Struck J, Morgenthaler NG, Bergmann A (2005): Proteolytic processing pattern of the endothelin-1 precursor in vivo. Peptides $\underline{26}$, 2482-6

Sudoh T, Kangawa K, Minamino N, Matsuo H (1988): A new natriuretic peptide in porcine brain. Nature $\underline{332}, 78-81$

Sugo S, Minamino N, Kangawa K, Miyamoto K, Kitamura K, Sakata J, Eto T, Matsuo H (1994): Endothelial cells actively synthesize and secrete adrenomedullin. Biochem Biophys Res Commun 201, 1160-6

Tahara A, Tomura Y, Wada K, Kusayama T, Tsukada J, Ishii N, Yatsu T, Uchida W, Tanaka A (1998): Effect of YM087, a potent nonpeptide vasopressin antagonist, on vasopressininduced protein synthesis in neonatal rat cardiomyocyte. Cardiovasc Res $\underline{38}, 198-205$ 
Tan M, Wang Y, Guan K, Sun Y (2000): PTGF-beta, a type beta transforming growth factor (TGF-beta) superfamily member, is a p53 target gene that inhibits tumor cell growth via TGFbeta signaling pathway. Proc Natl Acad Sci U S A $\underline{97}$, 109-14

Thune JJ, Solomon SD (2006): Left ventricular diastolic function following myocardial infarction. Curr Heart Fail Rep $\underline{3}, 170-4$

Tschöpe C, Kasner M, Westermann D, Gaub R, Poller WC, Schultheiss HP (2005): The role of NT-proBNP in the diagnostics of isolated diastolic dysfunction: correlation with echocardiographic and invasive measurements. Eur Heart J 26, $2277-84$

Tsutamoto T, Wada A, Sakai H, Ishikawa C, Tanaka T, Hayashi M, Fujii M, Yamamoto T, Dohke T, Ohnishi M (2006): Relationship between renal function and plasma brain natriuretic peptide in patients with heart failure. J Am Coll Cardiol $\underline{47}, 582-6$

van Beneden R, Gurné O, Selvais PL, Ahn SA, Robert AR, Ketelslegers JM, Pouleur HG, Rousseau MF (2004): Superiority of big endothelin-1 and endothelin-1 over natriuretic peptides in predicting survival in severe congestive heart failure: a 7-year follow-up study. J Card Fail 10, 490-5

van Heerebeek L, Borbély A, Niessen HW, Bronzwaer JG, van der Velden J, Stienen GJ, Linke WA, Laarman GJ, Paulus WJ (2006): Myocardial structure and function differ in systolic and diastolic heart failure. Circulation $\underline{113}, 1966-73$

van Heerebeek L, Hamdani N, Handoko ML, Falcao-Pires I, Musters RJ, Kupreishvili K, Ijsselmuiden AJ, Schalkwijk CG, Bronzwaer JG, Diamant M (2007): Diastolic stiffness of the failing diabetic heart: importance of fibrosis, advanced glycation end products, and myocyte resting tension. Circulation $\underline{117}, 43-51$

Vasan RS, Larson MG, Benjamin EJ, Evans JC, Reiss CK, Levy D (1999): Congestive heart failure in subjects with normal versus reduced left ventricular ejection fraction: prevalence and mortality in a population-based cohort. J Am Coll Cardiol $\underline{33}, 1948-55$

Vasan RS, Levy D (2000) Defining diastolic heart failure: a call for standardized diagnostic criteria. Circulation $101,2118-21$

Wachter R, Lüers C, Kleta S, Griebel K, Herrmann-Lingen C, Binder L, Janicke N, Wetzel D, Kochen MM, Pieske B (2007): Impact of diabetes on left ventricular diastolic function in patients with arterial hypertension. Eur J Heart Fail $\underline{9}, 469-76$. 
Wang J, Kurrelmeyer KM, Torre-Amione G, Nagueh SF (2007): Systolic and diastolic dyssynchrony in patients with diastolic heart failure and the effect of medical therapy. J Am Coll Cardiol $\underline{49}, 88-96$

Weitzberg E, Ahlborg G, Lundberg JM (1991): Long-lasting vasoconstriction and efficient regional extraction of endothelin-1 in human splanchnic and renal tissues. Biochem Biophys Res Commun 180, 1298-303

Wenger NK, Mattson ME, Furberg CD, Elinson J (1984): Assessment of quality of life in clinical trials of cardiovascular therapies. Am J Cardiol $\underline{54}, 908-13$

Wollert KC, Kempf T, Peter T, Olofsson S, James S, Johnston N, Lindahl B, Horn-Wichmann R, Brabant G, Simoons ML (2007a): Prognostic value of growth-differentiation factor-15 in patients with non-ST-elevation acute coronary syndrome. Circulation $\underline{115}, 962-71$

Wollert KC, Kempf T, Lagerqvist B, Lindahl B, Olofsson S, Allhoff T, Peter T, Siegbahn A, Venge P, Drexler H, Wallentin L (2007b): Growth differentiation factor 15 for risk stratification and selection of an invasive treatment strategy in non ST-elevation acute coronary syndrome. Circulation $\underline{116}, 1540-8$

Xu D, Emoto N, Giaid A, Slaughter C, Kaw S, deWit D, Yanagisawa M (1994): ECE-1: a membrane-bound metalloprotease that catalyzes the proteolytic activation of big endothelin1. Cell $\underline{78}, 473-85$

Xu J, Kimball TR, Lorenz JN, Brown DA, Bauskin AR, Klevitsky R, Hewett TE, Breit SN, Molkentin JD (2006): GDF15/MIC-1 functions as a protective and antihypertrophic factor released from the myocardium in association with SMAD protein activation. Circ Res $\underline{98}$, $342-50$

Yip GW, Ho PP, Woo KS, Sanderson JE (1999): Comparison of frequencies of left ventricular systolic and diastolic heart failure in Chinese living in Hong Kong. Am J Cardiol $\underline{84}$, 563-7

Yu CM, Cheung BM, Leung R, Wang Q, Lai WH, Lau CP (2001): Increase in plasma adrenomedullin in patients with heart failure characterised by diastolic dysfunction. Heart $\underline{6}$, $155-60$

Zile MR, Brutsaert DL (2002): New concepts in diastolic dysfunction and diastolic heart failure: Part II: causal mechanisms and treatment. Circulation $\underline{105}, 1503-8$ 
Zile MR, Lewinter MM (2007): Left ventricular end-diastolic volume is normal in patients with heart failure and a normal ejection fraction: a renewed consensus in diastolic heart failure. $J$ Am Coll Cardiol 49, 982-5

Zile MR, Baicu CF, Gaasch WH (2004): Diastolic heart failure--abnormalities in active relaxation and passive stiffness of the left ventricle. N Engl J Med $\underline{350}, 1953-9$ 


\section{Danksagung}

Mein Dank gilt zunächst und in besonderer Weise meinem Doktorvater PD Dr. med. Frank Edelmann. Seine geduldige und ausdauernde Unterstützung ermöglichte das Gelingen dieser Dissertation. Durch seine unkomplizierte und entgegenkommende Art sorgte er dafür, dass auch in frustranen Situationen die nötige Motivation erhalten blieb, um die Arbeit erfolgreich abzuschließen.

Außerdem bedanke ich mich bei allen Mitarbeitern und Doktoranden des KNHI.

Mein besonderer Dank gilt hier meinen beiden Mitdoktoranden Dr. med. Ingmar Rahn und Herrn André Duvinage für die freundschaftliche und verlässliche Zusammenarbeit.

Weiterhin bedanke ich mich bei den zahlreichen Patienten, die an der Diast-CHF-Studie teilgenommen haben.

An dieser Stelle danke ich auch meinen Eltern Ursula und Ulrich Gabriel für die orthografischen Korrekturen. 


\section{Lebenslauf}

Am 26. Juli 1981 wurde ich, Fabian Gabriel, als erstes von drei Kindern in Stuttgart Bad Cannstatt geboren. Meine Mutter ist Ursula Gabriel (geb. Cremer), mein Vater Ulrich Gabriel. Meine ersten Lebensjahre verbrachte ich in Madrid. Nach der Einschulung im Jahre 1988 besuchte ich die Blankenstein-Grundschule in Steinheim an der Murr. Im Anschluss wechselte ich auf das Friedrich-Schiller-Gymnasium in Marbach am Neckar, wo ich im Jahre 2001 die Allgemeine Hochschulreife erwarb.

Nach der Erfüllung meines Wehrdienstes begann ich das Studium der Humanmedizin und konnte im Herbst 2005 mein Physikum an der Eberhard Karls Universität Tübingen erfolgreich ablegen. Während des klinischen Studienabschnitts famulierte ich in den Fächern Innere Medizin, Chirurgie und Radiologie. Das praktische Jahr mit den Tertialen Innere Medizin, Chirurgie und Neurologie leistete ich an verschiedenen akademischen Lehrkrankenhäusern in Niedersachsen und Nordrhein-Westfalen. Im Herbst 2010 schloss ich mein Studium der Humanmedizin mit dem Bestehen des Zweiten Abschnitts der Ärztlichen Prüfung an der Georg-August-Universität Göttingen ab.

Seit Anfang 2011 befinde ich mich in der Weiterbildung zum Facharzt für Radiologie am Brüderkrankenhaus St. Josef in Paderborn.

Die vorliegende Dissertation begann ich bereits Anfang 2007 in der Klinik für Kardiologie und Pneumologie am Universitätsklinikum Göttingen. 